\title{
Canadian clinical practice guidelines for invasive candidiasis in adults
}

\author{
Co-Chairs (listed alphabetically): Eric J Bow MD MSC D Bacteriol FRCPC ${ }^{1}$, Gerald Evans MD FRCPC ${ }^{2}$, \\ Jeff Fuller PhD FCCM D(ABMM) ${ }^{3}$, Michel Laverdière $M^{4}$, Coleman Rotstein MD FRCPC FACP5; \\ Principal Authors (listed alphabetically): Robert Rennie PhD FCCM D (ABMM) ${ }^{3}$, \\ Stephen D Shafran MD FRCPC FACP 6 , Don Sheppard MD FRCPC ${ }^{7}$; \\ Co-Authors (listed alphabetically): Sylvie Carle BPharm $\mathrm{MSC}^{8}$, Peter Phillips MD FRCPC ${ }^{9}$, \\ Donald C Vinh MD FRCPC FACP10
}

EJ Bow, G Evans, J Fuller, et al. Canadian clinical practice guidelines for invasive candidiasis in adults. Can J Infect Dis Med Microbiol 2010;21(4):e122-e150.

Candidemia and invasive candidiasis (C/IC) are life-threatening opportunistic infections that add excess morbidity, mortality and cost to the management of patients with a range of potentially curable underlying conditions. The Association of Medical Microbiology and Infectious Disease Canada developed evidence-based guidelines for the approach to the diagnosis and management of these infections in the ever-increasing population of at-risk adult patients in the health care system. Over the past few years, a new and broader understanding of the epidemiology and pathogenesis of $\mathrm{C} / \mathrm{IC}$ has emerged and has been coupled with the availability of new antifungal agents and defined strategies for targeting groups at risk including, but not limited to, acute leukemia patients, hematopoietic stem cell transplants and solid organ transplants, and critical care unit patients. Accordingly, these guidelines have focused on patients at risk for $\mathrm{C} / \mathrm{IC}$, and on approaches of prevention, early therapy for suspected but unproven infection, and targeted therapy for probable and proven infection.

\section{Des directives cliniques canadiennes sur la candidose envahissante chez les adultes}

La septicémie à Candida et la candidose envahissante (SC/CE) sont des infections opportunistes au potentiel fatal qui ajoutent une morbidité, une mortalité et des coûts excessifs à la prise en charge des patients atteints d'une série de troubles sous-jacents pouvant être guéris. L'Association pour la microbiologie médicale et l'infectiologie Canada a préparé des directives probantes sur les méthodes diagnostiques et thérapeutiques de ces infections dans la population toujours croissante de patients adultes vulnérables au sein du système de santé. Depuis quelques années, on constate de nouvelles connaissances et une meilleure compréhension de l'épidémiologie et de la pathogenèse de la SC/CE, couplées à la mise en marché de nouveaux antifongiques et de stratégies définies pour cibler les groupes vulnérables, y compris, sans s'y limiter, les patients atteints d'une leucémie aiguë, les greffés de cellules souches hématopoiétiques et d'organes pleins et les patients aux soins intensifs. Par conséquent, ces directives portent sur les patients vulnérables à la SC/CE et sur les démarches de prévention, le traitement précoce d'une infection présumée mais non démontrée et une thérapie ciblée en vue de soigner une infection probable et prouvée.

Key Words: Adults; Candidiasis; Epidemiology; Guidelines; Prophylaxis; Therapy

\section{EXECUTIVE SUMMARY}

Candidemia and invasive candidiasis (C/IC) are infections affecting an ever-increasing number of hospitalized patients. $\mathrm{C} / \mathrm{IC}$ causes considerable morbidity and mortality in patients with medical comorbidities who possess risk factors for these infections such as broad-spectrum antibacterial therapy, intense myelosuppression and cytotoxic therapies, recent gastrointestinal surgery and the presence of central venous access devices. A variety of Candida species may produce
$\mathrm{C} / \mathrm{IC}$, but Candida albicans continues to be the most common inciting pathogen. The present document, prepared by the Association of Medical Microbiology and Infectious Disease (AMMI) Canada with the assistance of practitioners from Pharmacy and Hematology-Oncology, attempts to provide an evidence-based guideline for the diagnosis and management of $\mathrm{C} / \mathrm{IC}$ in adult patients. The guidelines were prepared with other similar endeavours in mind (1-13), and are for consideration by critical care physicians, internal medicine specialists,

${ }^{1}$ Department of Medical Microbiology and Infectious Diseases, University of Manitoba; Clinical and Academic Services, and Infection Control Services, Cancer Care Manitoba; Oncology Program, Winnipeg Regional Health Authority, Winnipeg, Manitoba; ${ }^{2}$ Division of Infectious Diseases, Department of Medicine, Queen's University, Kingston General Hospital, Kingston, Ontario; ${ }^{3}$ Department of Laboratory Medicine and Pathology, University of Alberta, University of Alberta Hospital, Edmonton, Alberta; ${ }^{4}$ Department of Microbiology-Infectious Diseases, University of Montreal, Laboratory Program, Hôpital Maisonneuve-Rosemont, Montreal, Quebec; ${ }^{5}$ Division of Infectious Disease, Department of Medicine, University of Toronto and Transplant Infectious Diseases, Oncologic Infectious Diseases, University Health Network, Toronto, Ontario; ${ }^{6}$ Division of Infectious Diseases, Department of Medicine, University of Alberta, Capital Health Authority, Edmonton, Alberta; ${ }^{7}$ Departments of Medicine, and Microbiology and Immunology, McGill University, Montreal, Quebec; ${ }^{8}$ Department of Pharmacy, University of Montreal, McGill University Health Centre, Montreal, Quebec; ${ }^{9}$ Division of Infectious Diseases, Department of Medicine, University of British Columbia, St Paul's Hospital, Vancouver, British Columbia; ${ }^{10}$ Division of Infectious Diseases, Department of Medicine, Department of Medical Microbiology, McGill University, Montreal, Quebec and Laboratory of Clinical Infectious Diseases

Correspondence: Dr Eric J Bow, Department of Medical Microbiology and Infectious Diseases, c/o Cancer Care Manitoba, 675 McDermot

Avenue, Winnipeg, Manitoba R3E 0V9. Telephone 204-787-3964, fax 2054-796-0196, e-mail ejbow@cancercare.mb.ca 
pharmacists, infectious diseases physicians, clinical and medical microbiologists, surgical specialists, hematologists and medical oncologists.

These guidelines cover the epidemiology, pathogenesis and immunobiology, microbiology and resistance issues, diagnosis, infection prevention and control concepts, and therapy of C/IC. Recommendations based on existing evidence and expert opinion for the risk stratification of the severity of illness are provided to guide diagnosis and therapy of $\mathrm{C} / \mathrm{IC}$ in both non-neutropenic and neutropenic hosts. Furthermore, the principles of therapeutic approaches to $\mathrm{C} / \mathrm{IC}$ involving prophylaxis, pre-emptive, empirical and specific therapy for documented infection are reviewed in the present guidelines. A grading system was used to rate recommendations according to strength (A to C) and the quality of evidence (I to III). The following is a summary of the recommendations:

\section{Prevention of $\mathrm{C} / \mathrm{IC}$ in leukemic and hematopoietic stem cell transplant recipients}

1. For acute leukemia patients undergoing primary or secondary remission induction therapy, in which the duration of severe neutropenia is expected to be longer than 10 days, oral fluconazole $400 \mathrm{mg}$ daily may be administered from the time of initiation of induction chemotherapy until myeloid reconstitution (A-I). The intravenous (IV) formulation may be substituted during periods of intolerance due to oral mucositis (B-I). Alternatively, oral itraconazole $200 \mathrm{mg}$ twice daily (B-I) or posaconazole $200 \mathrm{mg}$ three times daily initiated $24 \mathrm{~h}$ after completion of chemotherapy (such as vinca alkaloids, taxanes or anthracyclines) (A-I), or IV caspofungin $50 \mathrm{mg}$ daily may be considered (B-III).

2. For allogeneic hematopoietic stem cell transplant (HSCT) recipients, oral fluconazole $400 \mathrm{mg}$ daily is recommended for use from the beginning of conditioning until at least 75 days post-transplant (A-I). The IV formulation may be substituted during periods of intolerance due to oral mucositis (B-I). Alternatively, itraconazole oral solution $200 \mathrm{mg}$ twice daily (B-I), posaconazole $200 \mathrm{mg}$ three times daily initiated $24 \mathrm{~h}$ after completion of chemotherapy (A-I), or IV micafungin $50 \mathrm{mg}$ daily may be considered, commencing at the time of transplant (B-I).

3. Antifungal prophylaxis with fluconazole among postremission consolidation patients is not recommended (B-II).

4. Antifungal prophylaxis with fluconazole for autologous HSCT recipients, particularly those receiving concomitant hematopoietic growth factor support, is not recommended (B-II).

\section{Prevention of $\mathrm{C} / \mathrm{IC}$ in solid organ transplant recipients}

\section{Hepatic transplantation}

i. Routine use of antifungal prophylaxis is not recommended (C-III);

ii. For transplant recipients at high risk, as described in the text below, fluconazole $400 \mathrm{mg} /$ day for four weeks posttransplantation may be recommended (A-I); and

iii. Data are insufficient to support a recommendation for extended-spectrum azoles (posaconazole or voriconazole) or echinocandins for this indication (C-III).

\section{Pancreatic transplantation}

i. Data are insufficient to support routine fungal cultures of the donor duodenal fluid (C-III); and

ii. To support anastomotic healing, fluconazole $400 \mathrm{mg} /$ day for four weeks post-transplant may be recommended (B-III). Alternative antifungal agents for this purpose may include lipid formulations of amphotericin B, extended-spectrum azoles or echinocandins (B-III).

7. Small bowel transplantation

i. In centres where $\mathrm{C}$ albicans is prevalent, fluconazole $400 \mathrm{mg} /$ day for four weeks post-transplant may be recommended (B-III). In centres where Candida glabrata and Candida krusei are potentially more prevalent, a lipid formulation of amphotericin B $3 \mathrm{mg} / \mathrm{kg} /$ day to $5 \mathrm{mg} / \mathrm{kg} /$ day may be substituted (B-III).

8. Renal transplantation

i. Data are insufficient to support a recommendation for routine antifungal prophylaxis (C-III).

9. Lung and heart/lung transplantation

i. Specific recommendations for anti-Candida prophylaxis cannot be made in isolation. The risks for invasive aspergillosis must be considered when deciding on prophylaxis.

10. Cardiac transplantation

i. Specific recommendations for anti-Candida prophylaxis cannot be made in isolation. The risks for invasive aspergillosis must be considered.

\section{Prevention of $\mathrm{C} / \mathrm{IC}$ in intensive care unit patients}

11. Routine antifungal prophylaxis of all intensive care unit (ICU) patients is not recommended (B-III). However, antifungal prophylaxis aimed at Candida species using fluconazole in selected high-risk subgroups of ICU patients may significantly decrease the likelihood of developing proven $\mathrm{C} / \mathrm{IC}$ and reduce all-cause mortality (A-I).

12. High-risk subgroups of patients who may be candidates for prophylaxis include the following:

i. ICU patients with recurrent gastrointestinal perforation or anastomotic leakage. In this selected high-risk group, IV fluconazole 400 once daily may be administered until either complete resolution of intra-abdominal disease, development of proven Candida species infection requiring directed antifungal therapy or development of a severe drug-related adverse event (A-I);

ii. Patients admitted to a tertiary referral centre ICU (surgical or medical) with a baseline risk for $\mathrm{C} / \mathrm{IC}$ of $10 \%$ or greater if there is an anticipated stay of more than three days. In such cases, oral fluconazole $400 \mathrm{mg}$ daily may be administered until ICU discharge, until initiation of directed antifungal therapy for suspected/confirmed disease or development of a severe drug-related adverse event (A-I); and

iii. There are insufficient data to support specific recommendations for antifungal prophylaxis in severe acute pancreatitis (SAP) (C-III).

\section{Treatment of $\mathrm{C} / \mathrm{IC}$ in neutropenic patients and $\mathrm{HSCT}$ recipients}

13. Pre-emptive use of antifungal agents for $\mathrm{C} / \mathrm{IC}$ in neutropenic patients, based on the presence of colonization and/or 
surrogate serological markers for $\mathrm{C} / \mathrm{IC}$, is impractical and not recommended (C-III).

14. Empirical antifungal therapy is recommended for patients with a persistent or recrudescent neutropenic fever syndrome after four to seven days of broad-spectrum antibacterial therapy without a focus of infection for suspected $\mathrm{C} / \mathrm{IC}$ or other possible invasive fungal infections (IFI) (B-I).

15. Therapeutic choices for empirical antifungal therapy in febrile neutropenic cancer patients and HSCT recipients with a persistent neutropenic fever syndrome or recrudescent neutropenic fever syndrome include the following: a lipid formulation of IV amphotericin B at a dose of $3 \mathrm{mg} / \mathrm{kg} /$ day (A-I), IV caspofungin $70 \mathrm{mg}$ as a loading dose and then IV $50 \mathrm{mg}$ daily (A-I), IV amphotericin B deoxycholate $0.6 \mathrm{mg} / \mathrm{kg} /$ day to $1.0 \mathrm{mg} / \mathrm{kg} /$ day (B-II in the absence of risk factors for nephrotoxicity, otherwise the deoxycholate formulation of amphotericin B is not recommended), fluconazole for those less critically ill patients with neutropenia of short duration (seven days or fewer) and in the absence of azole prophylaxis with IV fluconazole $800 \mathrm{mg}$ as a loading dose and then IV $400 \mathrm{mg}$ daily with the option of proceeding to oral doses of $400 \mathrm{mg}$ daily (B-II), and IV voriconazole $6 \mathrm{mg} / \mathrm{kg}$ every $12 \mathrm{~h}$ for $24 \mathrm{~h}$ and then IV $4 \mathrm{mg} / \mathrm{kg}$ every $12 \mathrm{~h}$ or oral doses of $200 \mathrm{mg}$ twice daily (based on the risk of mould infection in these patients) (B-I).

16. The duration of empirical antifungal therapy is until resolution of symptoms and signs of infection, including fever, in conjunction with the recovery of the absolute neutrophil count (ANC) to $0.5 \times 10^{9} / \mathrm{L}$ or greater for at least $48 \mathrm{~h}(\mathrm{~A}-\mathrm{I})$.

17. For microbiologically or histologically documented (proven) $\mathrm{C} / \mathrm{IC}$ in neutropenic patients and HSCT recipients, IV amphotericin B deoxycholate $0.6 \mathrm{mg} / \mathrm{kg} /$ day to $1.0 \mathrm{mg} / \mathrm{kg} /$ day (in the absence of risk factors for nephrotoxicity), a lipid formulation of IV amphotericin B $3 \mathrm{mg} / \mathrm{kg} /$ day, and IV caspofungin $70 \mathrm{mg}$ as a loading dose and then IV $50 \mathrm{mg}$ daily are all recommended (A-I). IV anidulafungin $200 \mathrm{mg}$ initially followed by IV $100 \mathrm{mg}$ daily or IV micafungin $100 \mathrm{mg}$ daily may also be effective (B-III). Fluconazole $800 \mathrm{mg}$ followed by IV/oral doses of $400 \mathrm{mg}$ doses may be used in hemodynamically stable, less severely ill patients with neutropenia of shorter duration (seven days or fewer) (A-II). The choice of agent will depend on local epidemiology, use of azole antifungal prophylaxis and concerns regarding coexistent mould infection.

18. If Candida parapsilosis $\mathrm{C} / \mathrm{IC}$ is present and caspofungin, anidulafungin or micafungin have been used, another agent of a different class (amphotericin B deoxycholate, lipid formulation of amphotericin B or fluconazole for less critically ill patients with a shorter duration of neutropenia) may be considered, if the patient is not responding or improving. However, if the patient has improved on echinocandin therapy, then it may be continued (B-III). For hemodynamically unstable neutropenic patients and HSCT recipients with proven $\mathrm{C}$ parapsilosis $\mathrm{C} / \mathrm{IC}$, amphotericin $\mathrm{B}$ deoxycholate or a lipid formulation of amphotericin $\mathrm{B}$ is preferred (B-III).

19. Removal of venous access devices is recommended for candidemia in neutropenic cancer patients and HSCT recipients (whether catheter related or not) provided that this procedure is feasible (B-II).
20. The duration of therapy for microbiologically documented $\mathrm{C} / \mathrm{IC}$ in neutropenic patients is at least two weeks after the clearance of organisms from the bloodstream and/or the infected body site, with resolution of all signs and symptoms at the infected site and recovery of the ANC to greater than $0.5 \times 10^{9} / \mathrm{L}$ for at least $48 \mathrm{~h}(\mathrm{~A}-\mathrm{I})$.

\section{Treatment of C/IC in non-neutropenic patients}

21. Pre-emptive antifungal therapy in non-neutropenic patients with the presence of colonization is currently not recommended (C-III).

22. Empirical antifungal therapy may be beneficial in critically ill patients who meet specific criteria based on clinical prediction rules for C/IC (B-II). Fluconazole remains efficacious in reducing $\mathrm{C} / \mathrm{IC}$ and is cost effective at a loading dose of $800 \mathrm{mg}$ followed by IV $400 \mathrm{mg}$ daily for hemodynamically stable patients (B-II). However, empirical antifungal therapy may not produce resolution of fevers of unknown origin in non-neutropenic ICU patients and is weakly endorsed (C-II). In hemodynamically unstable patients, an echinocandin (anidulafungin $200 \mathrm{mg}$ initially followed by IV $100 \mathrm{mg}$ daily, caspofungin $70 \mathrm{mg}$ initially followed by IV $50 \mathrm{mg}$ daily or IV micafungin $100 \mathrm{mg}$ daily) may be preferred for empirical therapy (C-III).

23. The duration of empirical therapy in non-neutropenic patients should be 14 days (B-II).

24. For microbiologically or histologically documented (proven) $\mathrm{C} / \mathrm{IC}$ in hemodynamically stable patients with no previous azole exposure in the past 30 days, fluconazole $800 \mathrm{mg}$ initially followed by IV $400 \mathrm{mg}$ daily, or an echinocandin (anidulafungin $200 \mathrm{mg}$ as a loading dose followed by IV $100 \mathrm{mg}$ daily, caspofungin $70 \mathrm{mg}$ as a loading dose followed by IV $50 \mathrm{mg}$ daily or IV micafungin $100 \mathrm{mg}$ daily) are recommended (A-I).

25. IV amphotericin B deoxycholate at a dose of $0.5 \mathrm{mg} / \mathrm{kg} /$ day to $1 \mathrm{mg} / \mathrm{kg} /$ day (in the absence of risk factors for nephrotoxicity) or lipid formulations of IV amphotericin B at a dose of $3 \mathrm{mg} / \mathrm{kg} /$ day are alternatives (B-I).

26. For proven $\mathrm{C} / \mathrm{IC}$ caused by $\mathrm{C}$ glabrata in hemodynamically stable patients, in centres where susceptibility testing is available, fluconazole should only be used if the isolate is susceptible. However, if fluconazole is initiated at the outset but susceptibilities are not available and the patient is clinically improved, it may be continued (B-III).

27. For hemodynamically stable or unstable patients with proven $\mathrm{C} / \mathrm{IC}$ caused by $\mathrm{C}$ parapsilosis, fluconazole is preferred (B-II). In hemodynamically unstable patients, lipid formulations of amphotericin B or amphotericin B deoxycholate are alternatives for therapy for C/IC (C-II).

28. In hemodynamically unstable patients with proven $\mathrm{C} / \mathrm{IC}$ due to Candida species other than $\mathrm{C}$ parapsilosis with or without azole exposure, an echinocandin (anidulafungin $200 \mathrm{mg}$ followed by IV $100 \mathrm{mg}$ daily, caspofungin $70 \mathrm{mg}$ initially followed by IV $50 \mathrm{mg}$ daily or IV micafungin $100 \mathrm{mg}$ daily) is preferred (B-III).

\section{METHOD}

The authors' working group was comprised of specialists with expertise in hematology, infectious diseases, clinical and medical 


\begin{tabular}{|c|c|}
\hline $\begin{array}{l}\text { Category, } \\
\text { grade }\end{array}$ & Definition \\
\hline \multicolumn{2}{|l|}{ Strength } \\
\hline $\bar{A}$ & Good evidence to support a recommendation for or against use \\
\hline B & Moderate evidence to support a recommendation for or against use \\
\hline C & Poor evidence to support a recommendation \\
\hline \multicolumn{2}{|c|}{ Quality of evidence } \\
\hline 1 & Evidence from $\geq 1$ properly randomized, controlled trial \\
\hline II & $\begin{array}{l}\text { Evidence from } \geq 1 \text { well-designed clinical trial, without } \\
\text { randomization; from cohort or case-controlled analytic studies } \\
\text { (preferably from }>1 \text { centre); from multiple time-series or from } \\
\text { dramatic results from uncontrolled experiments }\end{array}$ \\
\hline III & $\begin{array}{l}\text { Evidence from opinions of respected authorities, based on clinical } \\
\text { experience, descriptive studies, or reports of expert committees }\end{array}$ \\
\hline
\end{tabular}

Adapted from reference 14

microbiology, oncology, pharmacy and transplant medicine and were selected based on member expertise by the co-chairs of the AMMI Canada Guidelines Committee. A Medline literature review of more than 600 articles, published between 2000 and 2009 in the English language literature, was accomplished using a combination of more than 40 key words pertaining to invasive candidiasis. Sections of the document were assigned to individual primary and co-author pairs, with sections being merged into a single draft document that was circulated twice to all authors for initial and final review. A grading system for rating clinical practice guidelines was used to categorize the recommendations according to strength (A to $\mathrm{C}$ ) and quality of evidence (I to III) (Table 1) (14). Consensus on the recommendations contained in the document was obtained using the Delphi process (15).

All members of the working group complied with the AMMI policy on conflicts of interest that require disclosure of any financial or other interests that might be construed as constituting an actual, potential or apparent conflict. Members of the working group were provided a conflicts of interest disclosure statement and were asked to identify any affiliations or financial interests with pharmaceutical companies that might potentially affect the guideline. Information was requested regarding ownership of stock or stock options, employment or paid consultancy within the past two years, honoraria, speaker fees, educational grants and travel assistance to attend meetings. Potential conflicts are identified at the end of the present document.

\section{EPIDEMIOLOGY AND RISK FACTORS}

Candida species cause a wide spectrum of diseases. These range from the frequent superficial infections of mucosal surfaces, skin or nail infections, to the less-common life-threatening invasive infections. By definition, invasive candidiasis refers to infection in deep-seated tissue or other normally sterile sites, excluding the urine, documented by histopathology and/or microbiological culture. The current epidemiology of invasive candidiasis is almost exclusively based on Candida bloodstream infection (BSI) studies (16-25). Surveillance studies (26-30) have shown that Candida species are responsible for up to
TABLE 2

Incidence of candidemia in various populations

\begin{tabular}{llcc}
\hline $\begin{array}{l}\text { Years of } \\
\text { observation }\end{array}$ & Country & $\begin{array}{c}\text { Rate } \\
\text { (per 100,000 population) }\end{array}$ & Reference \\
\hline 1999-2004 & Canada & 2.9 & 21 \\
$1998-2001$ & USA & 6.0 & 36 \\
$1998-2000$ & USA & 10.0 & 53 \\
$2003-2004$ & Denmark & 11.0 & 24 \\
$1995-1999$ & Iceland & 4.9 & 27 \\
$1995-1999$ & Finland & 1.9 & 37 \\
$2002-2003$ & Spain & 4.3 & 22 \\
$1991-2003$ & Norway & 2.4 & 38 \\
$2001-2004$ & Australia & 1.8 & 51 \\
\hline
\end{tabular}

$10 \%$ of all documented BSIs. Large variations exist among countries, as shown in Table 2, which illustrates the incidence of candidemia identified from surveillance studies conducted in general populations. Reviews (19) have reported similar incidences in hospital populations. Variations reflect the differences in the populations surveyed including their geographical situation and the nature of their illnesses. The highest rates are observed in the very young and elderly patient populations (31).

A large database of nosocomial BSIs in the United States has ranked Candida species fourth overall among nosocomial BSIs, and the third most common cause of such infections in the ICU (32). Similar findings were reported in a survey (33) of ICUs in the Calgary Health Region, Alberta. Between May 2000 and April 2003, Candida species accounted for $10 \%$ of BSIs, equivalent to Enterococcus faecium as the fifth most common pathogen. However, reports $(26,34,35)$ from European hospitals have shown lower rates of Candida species BSI (sixth to eighth most common cause of nosocomial infections). It is generally perceived that the incidence of $\mathrm{C} / \mathrm{IC}$ continues to rise; data from several surveillance studies $(24,32,36-39)$ have shown a continued rise into the 21 st century. By contrast, other studies (26,40-43) have reported either stability or a reduction in their observed incidence of $\mathrm{C} / \mathrm{IC}$. The use of different denominators and results derived from specific critically ill populations may explain those discrepant observations. The repeated use of the same statistics to support the rising incidence of invasive Candida species infections has likely masked the true regional and global incidences. Only comparisons of carefully collected standardized data at discrete time points will establish the true variations between centres, regions and countries.

There are clear geographical differences in the distribution of Candida species causing BSIs. C albicans is the most commonly reported species (Table 3 ). In most countries, it is followed by C glabrata except in Latin America and Australia, where $C$ parapsilosis is more prevalent. The emergence of C glabrata and C parapsilosis as the second/third most common Candida species causing BSIs was mainly recognized during the past 20 years and is strongly associated with patient comorbid state and patient type. C glabrata tends to affect patients with hematological malignancies and solid tumours or older patients, while $\mathrm{C}$ parapsilosis is more likely to be associated with intravascular catheter-related BSIs and is more predominant in neonatal units $(36,44-46)$. It has been suggested by some 
TABLE 3

Candida bloodstream infections: Distribution of species reported in publications from 2000 to 2006

\begin{tabular}{|c|c|c|c|c|c|c|c|c|}
\hline \multirow[b]{2}{*}{ Location } & \multirow{2}{*}{$\begin{array}{c}\text { Studies, } \\
\text { n }\end{array}$} & \multirow{2}{*}{$\begin{array}{l}\text { Isolates, } \\
\text { n (range) }\end{array}$} & \multicolumn{6}{|c|}{ Median percentage (range) } \\
\hline & & & C albicans & C glabrata & C tropicalis & C parapsilosis & C krusei & Reference \\
\hline \multirow[t]{2}{*}{ USA } & 5 & 6130 & 55 & 20 & 11 & 11 & 2 & $36,43,53,380,381$ \\
\hline & & (254-2759) & $(45-59)$ & $(12-24)$ & $(9-12)$ & $(7-14)$ & $(1-2)$ & \\
\hline & & (302-2089) & $(51-65)$ & $(9-15)$ & $(7-11)$ & $(3-23)$ & $(1-4)$ & \\
\hline \multirow[t]{2}{*}{ Scandinavia } & 3 & 2201 & 70 & 13 & 4 & 5 & 3 & $37,38,383$ \\
\hline & & $(307-1415)$ & $(63-70)$ & $(9-20)$ & $(3-7)$ & $(4-6)$ & $(2-8)$ & \\
\hline Canada & & $(208-464)$ & $(54-64)$ & $(11-17)$ & $(4-9)$ & $(9-12)$ & (3) & \\
\hline \multirow[t]{2}{*}{ Latin America } & 2 & 967 & 40 & 8 & 22 & 23 & 1 & 20,383 \\
\hline & & $(255-712)$ & $(40-41)$ & $(5-12)$ & $(21-23)$ & $(21-25)$ & (1) & \\
\hline Australia & 1 & 1068 & 47 & 15 & 5 & 20 & 4 & 51 \\
\hline
\end{tabular}

TABLE 4

Common conditions and interventions at risk for candidemia/invasive candidiasis

\begin{tabular}{ll}
\hline Factors & References \\
\hline Age & 386,387 \\
Broad-spectrum antibiotic therapy & $186,203,386,388-390$ \\
Candida colonization & $113,132,134,252,339$ \\
Central vascular venous and arterial catheters & $218,273,388,391$ \\
Diabetes & 176 \\
Extensive surgery or burns & 388,392 \\
Immunosuppressed status & 393,394 \\
Intensive cancer ablative chemotherapy & 17,119 \\
Organ transplantation & 99,111 \\
Prolonged intensive care unit stay & $71,380,395,396$ \\
Prolonged neutropenia & $109,252,397$ \\
Parenteral nutrition & 398 \\
Renal disease and hemodialysis & $70,380,399$ \\
\hline
\end{tabular}

authors that the increased use of fluconazole for antifungal prophylaxis and treatment may have favoured the emergence of C glabrata, while other studies failed to establish a similar relationship (47-49).

The common underlying medical conditions and risk factors predisposing patients to invasive Candida infections are indicated in Table 4. An important continuum exists between the conditions and the risk factors. To predisposed medical conditions, such as cancer, prematurity, advanced age and acute renal failure, added risk factors such as broad-spectrum antibacterial therapy, intense myelosuppressive and cytotoxic therapies for hematological malignancies or solid tumours, recent gastrointestinal surgery, treatments in ICUs and use of central venous catheterization are among the factors that increase the risk and incidence of $\mathrm{C} / \mathrm{IC}(25,30,43,45,46,50-53)$. Some factors may, however, be surrogate markers of the burden of the underlying illness and in-hospital treatment conditions, rather than specific factors for infection. Many of these factors are less likely to be involved in the emerging observation of patients who develop candidemia infections outside of the hospital. In a recent, large, populationbased surveillance study (54), $28 \%$ of patients with candidemia had disease onset outside of the hospital. These infections occur in patients with extensive contact with the health care system, and likely reflect the increasing number of patients with complex

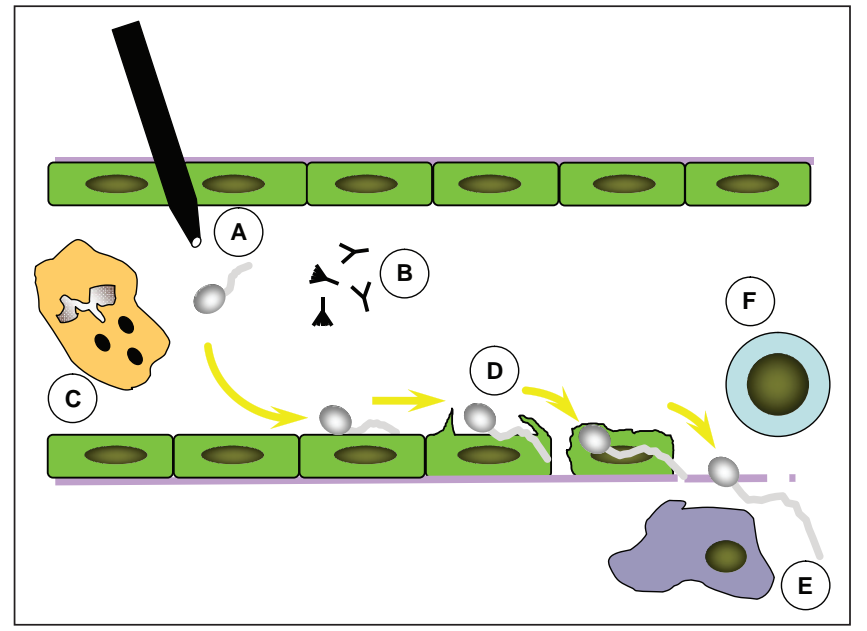

Figure 1) Pathogenesis of candidemia/invasive candidiasis. Blastospores of Candida gain access to the endovascular compartment via gut translocation or endovascular catheter colonization (A). Candida blastospores germinate within the bloodstream and interact with soluble serum components (B) and circulating neutrophils (C). Organisms then adhere to and penetrate vascular endothelial cells (D) to gain access to the deep organs, where they interact with dendritic cells and monocyte macrophages (E) that activate adaptive immune responses $(\mathrm{F})$

medical conditions that are treated on an outpatient basis. A high index of suspicion is necessary to reduce the morbidity and mortality in these patients.

The burden of Candida BSIs has been recently examined. Candidemia is still associated with high crude (35\% to 61\%) and attributable (24\% to $49 \%$ ) mortality rates, and significant economic burden (55-59). Different studies have attributed most of the economic burden to either an increase in hospitalization or to the cost of the antifungal treatments and their associated toxicities. In a recent analysis (60) of the economic impact of candidemia in Canada, the total average hospital and treatment charges were approximately $\$ 70,000$.

\section{PATHOGENESIS AND IMMUNOBIOLOGY}

Intact skin and mucosal epithelial cell surfaces provide the initial line of defense against invasion by Candida species (Figure 1). The first step in the pathogenesis of disseminated 
candidiasis occurs when the organism breaches these barriers and gains access to the endovascular compartment. This invasion may result from colonization and growth on an intravascular catheter, or by translocation across gut mucosa. Translocation across the intestinal mucosa can be enhanced by intestinal fungal overgrowth induced by broad-spectrum antibiotics and the presence of epithelial injury induced by surgery or cytotoxic chemotherapy. However, such injury is not absolutely required, as demonstrated by Krause et al (61) when both candiduria and candidemia resulted from the ingestion of a massive quantity of $\mathrm{C}$ albicans ( $10^{12}$ organisms) by a healthy individual. Thus, the density of organisms facilitates translocation.

After breaching the first line of defense and entering the endovascular compartment, Candida species interact with multiple arms of the host defense system including both immune cells and soluble factors. The innate immune response comprises the majority of these responses and a clearer picture of the various interactions involved in this response is emerging. The majority of these studies have been performed using C albicans, which will, therefore, be the focus of the discussion. It is important to note, however, that it is clear that not all Candida species have the same virulence factors, and further studies with non-albicans species are required.

On entry into the bloodstream, blastospores of $\mathrm{C}$ albicans interact with a number of soluble factors (Figure 1). Mannose-binding lectin avidly binds cell wall mannose ligands and activates the lectin-dependent pathway of complement, although no clear role for protection against infection has been identified for this molecule $(62,63)$. Both the classical and alternative complement pathways are also activated by Candida blastospores, and C3b fragments have been found to bind directly to the cell wall of $\mathrm{C}$ albicans $(64,65)$. This activation of the complement cascade results in opsonization and improves phagocytosis of Candida blastospores in vitro. Also, the alternative complement pathway is important for the host defense against disseminated candidiasis in experimental animal models of infection (66). While anti-Candida antibodies are often present in serum, their protective role during natural infection remains unclear (67).

Candida also interacts with multiple cellular elements of the innate immune system. Recognition of Candida by host cells is a critical element of this response and is transduced by multiple pattern recognition receptors (PRRs) that recognize candidal pathogen-associated molecular patterns (PAMPs) such as chitin, mannan and glucan. Stimulation of these receptors stimulates dendritic cells and macrophages to produce inflammatory cytokines with multiple effects including the recruitment and activation of neutrophils as well as polarization of $\mathrm{T}$ cell regulatory responses. Toll-like receptors (TLRs) - TLR-2 and TLR-4 - expressed on the surface of monocyte/macrophages and dendritic cells are the best studied of these PRRs in disseminated candidiasis. TLR-4 recognizes Candida mannan, and mediates the production of a variety of proinflammatory cytokines and chemokines including interleukin (IL)-8 and macrophageinflammatory protein 2 , which are associated with protection against Candida infection (68). Candida phospholipomannan and $\beta$-glucan are recognized by TLR-2, resulting in the production of prostaglandin E2 and the cytokine IL-10, which suppresses effective immune responses and is associated with poor prognosis during experimental infection $(69,70)$. Manipulation of this balance of immune responses by changes in morphology and cell wall content is one of the key mechanisms whereby $\mathrm{C}$ albicans evades immune responses. While blastospores of C albicans activate both TLR -2 and TLR -4 responses to induce a protective type 1 response, hyphae of $\mathrm{C}$ albicans are poorly recognized by TLR-4, leading to an increase in IL-10 production and a type 2 immune response, both of which are associated with poor survival $(70,71)$.

In addition to TLRs, other host cell PRRs have been described including the lectins dectin- 1 and -2 , and dendritic cell-specific intracellular adhesion molecule grabbing nonintegrin (DC-sign) (72-74). These receptors are thought to play an important role in the phagocytosis of nonopsonized $\mathrm{C}$ albicans, and mediation of innate immune responses. Interestingly, while dectin- 1 recognizes (1,3)- $\beta$-D-glucan in C albicans blastospores, this recognition is masked in hyphae and may, therefore, also contribute to the impaired type 1 response during disseminated infection and hyphal invasion (74).

Neutrophils provide a key line of defense against disseminated candidiasis (Figure 1). They avidly phagocytose and kill Candida blastospores, and can damage C albicans hyphae (75). This intracellular killing is dependent on the ability to generate an intact oxidative burst, explaining why patients with chronic granulomatous disease are susceptible to recurrent Candida infections (76-78). Intracellular killing and recruitment are enhanced by the cytokine milieu elaborated by dendritic cells, macrophages and $\mathrm{T}$ cells. Other professional phagocytic cells, including eosinophils, monocytes and dendritic cells, are also able to ingest and kill Candida, although to a lesser degree. To combat these host defenses, $\mathrm{C}$ albicans has evolved several virulence strategies. Hyphae of $\mathrm{C}$ albicans elaborate catalase to protect against oxidative killing $(79,80)$. Indeed, genetically engineered strains that are deficient in catalase are hypovirulent in animal models of infection (79). To enhance survival in the nutrient-poor phagolysosome of the macrophage, $\mathrm{C}$ albicans uses the glyoxylate cycle to use fatty acids and their breakdown products (81).

In addition to professional immune cells, Candida species also interact with another important cell type, the vascular endothelial cells. To develop deep-seated organ infection, organisms must adhere to and transgress the endothelial cell lining of blood vessels (82-84). Endothelial cells are more than a passive bystander in the pathogenesis of invasive candidiasis. Endothelial cells actively endocytose germinating $\mathrm{C}$ albicans, and respond to infection by releasing a variety of proinflammatory mediators including tumour necrosis factor-alpha, monocyte chemoattractant protein 1 and IL-8 $(85,86)$. They also respond to $\mathrm{C}$ albicans by increased surface expression of leukocyte adhesion molecules such as E-selectin, intercellular adhesion molecule 1 and vascular cell adhesion molecule 1 $(85,86)$. These interactions are mediated, at least in part, by the agglutinin-like sequence family of $\mathrm{C}$ albicans proteins. These immunoglobulin-like cell wall proteins mediate adherence to a variety of host substrates including endothelial and epithelial cells. In addition, one member of the agglutin family, Als3, functions as a fungal invasion by binding to endothelial cell N-cadherin (87).

In addition to the virulence mechanisms already outlined, C albicans produces a number of extracellular hydrolytic 
enzymes thought to play a role in mediating damage to host tissues. A family of secreted aspartyl proteases encompassing 10 members is expressed during infection, and confers increased virulence (82). In addition, secreted phospholipase (88) and lipase (89) have been described and may also play a role in disseminating infection. Finally, the capability to form a biofilm may also adversely affect the clinical outcome of candidemic patients $(90)$.

Mechanisms of action

\section{ANTIFUNGAL AGENTS}

Polyenes: Amphotericin B is a large molecular weight polyene agent. It interacts with sterols in the membrane of yeasts and moulds producing aqueous pores and altered membrane permeability, thereby killing the cell (91-94). Amphotericin B is fungicidal and, in some strains of yeast, fungicidal activity occurs at the minimal inhibitory concentration; in others, there is delayed killing of the cell $(95,96)$. The significance of prolonged or delayed killing is not understood clinically, but may result in either treatment failure or the necessity of prolonged treatment. The deoxycholate formulation of amphotericin B is associated with nephrotoxicity and infusion-related patient reactions (ie, fever, chills and rigors), and while newer lipidbased formulations exhibit equivalent efficacy, they are also associated with variable toxicity (97).

Azoles: Fluconazole, itraconazole, posaconazole and voriconazole are all triazole agents that are used frequently in antifungal treatment. Ketoconazole is a diazole that is used for the treatment of mycetomas, but is no longer available in the oral form in Canada. In general, azoles act by inhibiting cytochrome P-450-dependent 14-alpha-demethylation of lanosterol (in the cytoplasm), a fungal sterol that is not present in mammalian cells (98-101). Other more complex interactions may occur (99,101-104), but the result is a depletion of ergosterol, the major membrane sterol that confers cell membrane stability in yeasts and many fungi. Azole antifungals can also inhibit many mammalian cytochrome P450-dependent enzymes involved in hormone synthesis or drug metabolism. Therefore, azole antifungals are particularly susceptible to clinically significant drug interactions with other medications metabolized through the P450 pathway. Each azole offers a specific antifungal spectrum. Earlier agents in the class demonstrated potent activity against some yeasts, and itraconazole had some activity against moulds including Aspergillus species. The newer, extended-spectrum triazoles, such as voriconazole and posaconazole, have been shown to have fungicidal activity against moulds, as well as enhanced activity against Candida species and other yeasts $(105,106)$.

Echinocandins: These agents include anidulafungin, caspofungin and micafungin. All are lipopeptides that interfere with $(1,3)$ - $\beta$-D-glucan synthase activity - the major enzyme that catalyzes the linkage of glucose molecules in the cell wall to form structurally stable cells. The resulting interaction leads to an unstable fungal cell wall, leakage of cellular contents and eventual disruption of the cell $(107,109)$. The spectrum of activity is, therefore, limited to pathogens that rely on these glucan polymers and is less broad than the spectrum of the polyene or azole agents. As such, the echinocandins primarily have potent activity against species of Candida including C krusei and Aspergillus but not Cryptococcus (110). Because mammalian cells have no cell wall, the echinocandins have very few toxic adverse effects in humans.

5-Fluorocytosine (5-FC or flucytosine): The mechanism of action of this agent is to interfere with pyrimidine metabolism, causing inhibition of both DNA synthesis and protein synthesis in the fungal cell. 5-FC is transported into the fungal cell by a specific permease, converted to the active moiety 5 -fluorouracil by a specific enzyme, and is then incorporated into replicating DNA to interfere with cell division $(111,112)$. In the laboratory, 5-FC appears to have reasonable activity against many yeast species including Candida and Cryptococcus. However, in vivo, combination therapy is required with membrane active agents, such as amphotericin B, that may enhance 5-FC diffusion into the cell. The reason for this dichotomy between in vitro and in vivo activity is not well understood. 5-FC is also not recommended for monotherapy due to the high likelihood of inducing de novo resistance during therapy.

\section{Mechanisms of resistance}

Microbiological resistance to the polyenes is rare. Although the exact mechanisms are not clear, the outcome at the cellular level is either reorientation of existing ergosterol, or decreased ergosterol content $(113,114)$, ultimately creating a cell that is less responsive to the action of amphotericin B.

Resistance to azoles may result from the modification of the target heme proteins, either by a change or reduction in the affinity of the drug for the target or by changes in the concentration of the target enzymes (115-117). Alternatively, similar to many bacterial species, yeast and moulds are capable of pumping drugs back out of the cell by active efflux. Two groups of proteins have been described that can effect azole efflux. These are called major facilitator superfamily proteins and ATP-binding cassette superfamily proteins (118-120). The presence of the drug may also result in the overexpression of ergosterol synthesis and overwhelm the antifungal activity of the drug (116).

For the echinocandins, documented resistance occurs infrequently. Resistance arises from genetic mutations in the FKS genes (121). In limited publications, the minimum inhibitory concentrations (MICs) to caspofungin have been shown to rise from $0.25 \mathrm{mg} / \mathrm{L}$ to $16 \mathrm{mg} / \mathrm{L}(122,123)$, and there are few documented failures to establish the clinical significance of these mutations $(124,125)$. Some cross-resistance has been documented with the other echinocandins, micafungin and anidulafungin (126).

Resistance to 5-FC is more readily observed. It results either from loss of uptake of the agent due to decreased permease activity (required to take the agent into the cell), or loss of the enzymes cytosine deaminase or uracil phosphoribosyltransferase required to convert 5 -FC to 5 -fluorouracil and transport it to its target site $(127,128)$.

\section{Relevance of resistance}

Ideally, susceptibility interpretations for antimicrobial testing are formulated based not only on the MIC distribution within a pathogen population, but also on relevant pharmacokinetic/ pharmacodynamic $(\mathrm{PK} / \mathrm{PD})$ and clinical outcome evidence for specific disease manifestations. In this fashion, the MIC can reliably predict the likelihood of antimicrobial treatment failure. However, as with antibacterial susceptibility testing, 
there is a paucity of $\mathrm{PK} / \mathrm{PD}$ and clinical outcome data for available antifungal agents that limits the utility of $\mathrm{MIC}$ as a clinical correlate, particularly in the context of microbiological resistance.

Azole interpretive breakpoints relevant to $\mathrm{C} / \mathrm{IC}$ have been established for fluconazole, itraconazole and voriconazole by the Clinical and Laboratory Standards Institute (CLSI) (129-131). In addition to susceptible $(\mathrm{S})$ and resistant $(\mathrm{R})$ categories, there is also a susceptible dose-dependent (S-DD) category designed to indicate the need for increased serum or tissue levels of azole for Candida isolates with increased MIC values. Fluconazole breakpoints, established in 1997 (130), have been well validated and correlate with clinical outcome, especially for failure with resistant isolates (132). Cross-resistance to fluconazole and voriconazole has been reported in vitro as well as in the clinical setting, notably following prolonged azole exposure (fluconazole, then voriconazole), with $\mathrm{C}$ glabrata as the predominant isolate (133-141). This clinical resistance is captured by the new voriconazole breakpoints, in which resistance to fluconazole confers the same interpretation for voriconazole. However, for Candida isolates with a reduced fluconazole MIC (S-DD), voriconazole remains susceptible and a viable treatment option, likely due to voriconazole's increased activity (131). Interpretive breakpoints for intraconazole are not well validated, particularly for the IV (not available in Canada) and oral suspension formulations, which exhibit more reliable serum concentrations. In time, the accumulation of clinical data may improve the utility of itraconazole and facilitate the validation of relevant interpretive breakpoints.

Although C glabrata and C krusei are typically less susceptible to azoles than $\mathrm{C}$ albicans, surveillance data indicates that resistance rates have remained relatively unchanged for more than a decade. Global surveillance of Candida bloodstream and sterile site isolates from 1992 to 2004 indicates that fluconazole resistance $(13,338$ isolates) is still uncommon for most species (3\% or lower), particularly for C albicans (0.06\%) (132). $\mathrm{C}$ glabrata and $\mathrm{C}$ krusei resistance rates were considerably higher (9\% and 40\%, respectively) (132). This was not unexpected for C krusei (intrinsic fluconazole resistance), but there is growing concern that both the prevalence and fluconazole resistance of C glabrata in C/IC may be increasing $(132,140,142,143)$. Overall resistance to voriconazole (13,338 isolates) and itraconazole (7299 isolates, assumed breakpoint of $1 \mathrm{mg} / \mathrm{L}$ or less) was $0.9 \%$ and 4\%, respectively; C glabrata resistance was 3.7\% and 23\%, and $\mathrm{C}$ krusei resistance was less than $1 \%$ and $6 \%$ for voriconazole and itraconazole, respectively $(131,144,145)$.

In vitro susceptibility testing of Candida species against amphotericin B produces a very narrow range of MIC values that precludes the assignment of interpretive breakpoints with any relevance to clinical outcome $(146,147)$. This also prevents accurate surveillance of changes in the MIC distribution profile of Candida species over time. However, isolates with an MIC greater than $1 \mathrm{mg} / \mathrm{L}$ are unusual and elevated amphotericin B dosing may be required for therapy, most notably for C glabrata and C krusei (147-152).

Although the CLSI breakpoints for 5-FC have been accepted, they have not been as rigorously validated with PK/PD and clinical outcome data as other agents (ie, azoles), and it is unlikely that they will ever be used due to the contraindication of 5-FC for monotherapy. However, global surveillance of 8803 invasive Candida isolates (1992 to 2001) found that 5-FC remained highly active (3\% resistance or lower) over time, with the exception of $\mathrm{C}$ krusei (28\% resistance) (137).

An interpretive breakpoint for echinocandin-susceptible Candida has been recently proposed (153), but the clinical correlation of echinocandin in vitro activity for $\mathrm{C} / \mathrm{IC}$, particularly for elevated MIC values, remains unclear. Analysis of more than 100 invasive isolates recovered from patients receiving caspofungin therapy provided no correlation between the caspofungin MIC and clinical outcome (154). This is likely due, in part, to an absence of supporting PK/PD data and isolates with documented echinocandin resistance included in the study. Caspofungin has maintained excellent in vitro activity against Candida species, according to a fouryear (2001 to 2004) global surveillance study (155). More than $99 \%$ of 8197 invasive isolates had an MIC of $1 \mathrm{mg} / \mathrm{L}$ or less, which can be readily achieved in serum from a $1 \mathrm{mg} / \mathrm{kg}$ daily dose $(155,156)$. Isolates that had increased MIC values $(0.3 \%)$ were primarily less-frequent species causing invasive disease including $\mathrm{C}$ parapsilosis, Candida guilliermondii, C krusei and Candida lusitaniae (155). In fact, the MIC distributions of these species tend to be 10 -fold greater than more clinically prevalent species (ie, C albicans and C glabrata), but still remain $1 \mathrm{mg} / \mathrm{L}$ or less, more than $99 \%$ of the time $(155,157)$, and seem to respond well to caspofungin therapy (158). Similarly, isolates with known FKS genetic mutations (conferring caspofungin microbiological resistance) may be distinguished from wild type species by MIC values greater than $2 \mathrm{mg} / \mathrm{L}(157,159)$.

\section{Pharmacodynamic and pharmacokinetic considerations}

The selection of an appropriate agent depends on multiple factors in addition to the spectrum of activity. The routes of administration and elimination are important considerations when selecting the optimal therapy for a patient with an invasive fungal infection. Alterations in gastrointestinal tract integrity, impaired renal or hepatic function, and limited IV access are frequent issues for these patients. Some antifungals are available only as IV preparations (amphotericin B and echinocandins) or only as oral preparations (5-FC, itraconazole and posaconazole). Many antifungals are associated with host toxicities, wide intrapatient and interpatient variability in serum concentrations (voriconazole) and drug interactions (including chemotherapeutic agents) (Table 5). Therefore, it is important to have an appreciation of the differences among these drugs with regard to their pharmacokinetic properties, including absorption (may require a fatty meal or acidification for agents such as intraconazole, posaconazole and voriconazole), distribution (echinocandins do not penetrate the cerebrospinal fluid and should not be used for meningitis therapy), metabolism and excretion. Understanding the relationship among the PK/PD properties of antifungals is essential to optimize the potential for favourable clinical and microbiological outcomes, while minimizing risks of treatment-related toxicity (for further reading, refer to references 110,160-164).

\section{DIAGNOSIS OF C/IC}

The early descriptions of $\mathrm{C} / \mathrm{IC}$ highlighted the difficulty in establishing a timely diagnosis given the significant proportion 
TABLE 5

\begin{tabular}{|c|c|c|}
\hline Azole & Drug action or serum concentration is increased by azole coadministration & $\begin{array}{l}\text { Azole action or serum concentration is } \\
\text { decreased by drug coadministration }\end{array}$ \\
\hline Fluconazole & $\begin{array}{l}\text { Astemizole }{ }^{*} \text {, benzodiazepine (eg, midazolam), cisapride }{ }^{\star \dagger} \text {, cyclosporine, glyburide, glipizide, } \\
\text { phenytoin, tacrolimus, terfenadine }{ }^{\star \dagger} \text {, theophylline, warfarin }\end{array}$ & Rifabutin $^{\dagger}$, rifampin $^{\dagger}$ \\
\hline Itraconazole & $\begin{array}{l}\text { Benzodiazepine (eg, midazolam })^{\dagger} \text {, carbamazepine }{ }^{\dagger} \text {, cisapride }{ }^{\star \dagger} \text {, cyclosporine, digoxin, ergot } \\
\text { alkaloids }^{\dagger} \text {, fentanyl }{ }^{\dagger}, 3-\text { hydroxy-3-methylglutaryl-coenzyme A (eg, lovastatin) }{ }^{\dagger} \text {, barbiturates, } \\
\text { pimozide }^{\dagger} \text {, quinidine }{ }^{\dagger} \text {, rifabutin, sirolimus, tacrolimus }\end{array}$ & $\begin{array}{l}\text { Carbamazepine }{ }^{\dagger}, \text { phenytoin, rifabutin }{ }^{\dagger} \\
\text { rifampin }^{\dagger}\end{array}$ \\
\hline Voriconazole & 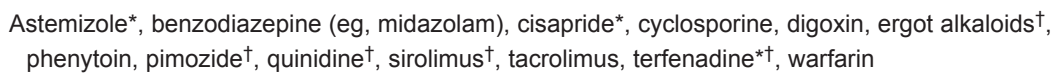 & $\begin{array}{l}\text { Carbamazepine }{ }^{\dagger}, \text { barbiturates }^{\dagger}, \text { phenytoin, }^{-} \\
\text {rifabutin }^{\dagger}, \text { rifampin }^{\dagger}\end{array}$ \\
\hline Posaconazole & $\begin{array}{l}\text { Astemizole }{ }^{\star \dagger}, \text { benzodiazepine (eg, midazolam), cisapride }{ }^{* \dagger}, \text { cyclosporine, ergot alkaloids }^{\dagger} \text {, } \\
\text { pimozide }^{\dagger}, \text { quinidine }^{\dagger}, \text { sirolimus, terfenadine }{ }^{\star \dagger}\end{array}$ & $\begin{array}{l}\text { Cimetidine, efavirenz, phenytoin, rifabutin }{ }^{\dagger}, \\
\text { rifampin }^{\dagger}\end{array}$ \\
\hline
\end{tabular}

*Not available in Canada; ${ }^{\dagger}$ Contraindicated

of cases only diagnosed postmortem $(165,166)$. In a series of 40 surgical patients with disseminated candidiasis published 37 years previously, premortem cultures established the diagnosis in $24(60 \%)$ cases including positive blood cultures in $17(43 \%)$ cases (166). Clinical signs and symptoms are usually nonspecific and cultures may be negative or only positive in advanced disease. Despite efforts to develop a variety of noninvasive assays during the past few decades, there is no widely available, reliable diagnostic technique that represents an improvement over routine culture of sterile body fluids or biopsy specimens in most cases.

\section{Microbiology}

Recovery of Candida species from a single specimen of a normally sterile body fluid (except urine) establishes a diagnosis of C/IC (167). Improved blood culture methodology has increased the sensitivity from approximately $50 \%$ to possibly $70 \%$ for candidemia or disseminated candidiasis. Improved recovery of Candida from blood cultures has been demonstrated with the lysis-centrifugation technique (168), but is labour intensive, not widely available and newer automated blood culture systems may at least be equivalent. Early identification of $\mathrm{C}$ albicans versus non-albicans Candida species may be possible by germ tube formation or rapid screening techniques such as the use of selective and chromogenic media $(169,170)$ or immunofluorescent in situ hybridization techniques (171). Recently, the germ tube test has been performed successfully on samples collected directly from positive blood cultures, rather than waiting for Candida colonies to grow on agar plates $(172,173)$.

\section{Predictive value of colonization}

Among surgical patients, Solomkin et al (174) demonstrated colonization at two or more sites in $31(50 \%)$ of 63 patients before the development of candidemia. Leukemic patients with multiple site colonization, single site colonization and no Candida colonization developed candidemia in 22\%, 5\% and $0 \%$ of cases, respectively (175). Due to the difficulty in establishing a diagnosis of invasive candidiasis, clinicians have adopted empirical antifungal therapy (176) in selected patients, particularly those at high risk, with a compatible clinical picture of sepsis and multiple sites of Candida colonization, as well as other risk factors for $\mathrm{C} / \mathrm{IC}$ as outlined below.

\section{Other laboratory investigations}

Peripheral blood leukocytosis is present in up to $50 \%$ of patients with $\mathrm{C} / \mathrm{IC}$ (177). Patients with chronic disseminated candidiasis (hepatosplenic candidiasis) usually have an elevated serum alkaline phosphatase level $(167,178,179)$.

\section{Imaging}

Various imaging studies may be helpful in establishing a diagnosis of focal invasive candidiasis. Examples include the urinary tract (eg, ultrasound for 'fungus balls'), spine (eg, bone scan, computed tomography or magnetic resonance imaging) and heart valves (echocardiogram). Patients with hematological malignancy may develop typical small, peripheral, target-like abscesses (bull's-eye lesions) in the liver and/or spleen in chronic disseminated candidiasis demonstrated by computed tomography, magnetic resonance imaging or ultrasound $(167,178,179)$.

\section{Investigational methods}

Various noninvasive assays have included detection methods for Candida antibodies, antigens, metabolites and nucleic acids $(180,181)$. Detection of antibodies directed against Candida species has not been useful in identifying patients with invasive candidiasis (182). The Candida metabolite D-arabinitol has also proven to be unreliable for this purpose (180). Although polymerase chain reaction assays have the promise of providing sensitivity beyond traditional blood culture methods $(180,183)$, further work will be needed to adapt the methodology to the clinical laboratory and provide adequate validation in at-risk patient populations (184). The detection of Candida antigens - including enolase (a glycolytic enzyme) $(185,186)$, mannan (186), a heat labile antigen (Cand-Tec assay) (186) and (1,3)- $\beta$-D-glucan (186-191) - has held the greatest potential. However, such assays have generally demonstrated variable diagnostic utility and/or limited availability. The most promising of these is the $(1,3)-\beta-D$-glucan test methodology, which detects a panfungal cell wall antigen and is now available in Canada.

\section{INFECTION PREVENTION AND CONTROL OF C/IC}

Hospital-based infection control practices should focus on prevention methods to reduce identified risk factors for nosocomial invasive Candida infections. Effective interventions that are evidence based and designed to prevent these infections require an understanding of the epidemiology including reservoirs of the pathogen, modes of transmission, evidence for clonal spread and the pathophysiology of nosocomial C/IC. Moreover, the morbidity, mortality and costs related to nosocomial C/IC are 
intimately linked to the severity of the underlying illness and the associated treatments for that illness (192).

\section{Epidemiology of nosocomial C/IC}

Successful preventive strategies are based on identification of the potential reservoir. Different reservoirs require different methods for prevention of transmission and disease. Based on molecular typing, invasive Candida species may be classified as being derived from either the patient's endogenous microflora or exogenous from another patient by direct or indirect contact $(193,194)$.

The majority of cases of $\mathrm{C} / \mathrm{IC}$ appear to be endogenous in origin based on experimental murine models (195); the identification of the same Candida genotype from multiple anatomical sites on an individual patient over time, with the density of colonization predictive of subsequent C/IC (196-199); the identical (or very closely related) genotype profile between colonizing and infecting strains and molecular typing studies demonstrating that the colonizing isolate typically precedes the infecting isolate $(25,193,194,199-202)$. This relationship has been demonstrated in neutropenic (200), non-neutropenic (193), critically ill $(199,202)$ and neonatal patients (203). The two major endogenous reservoirs are the gastrointestinal tract and the skin (195), with carriage rates of $40 \%$ to $50 \%$ reported in healthy persons (19). Alternatively, gastrointestinal candidiasis may be acquired de novo while in hospital, with colonization rates as high as $40 \%$ being reported (204). Infection occurs with translocation of Candida species from the gastrointestinal tract into the submucosal tissue and the circulation.

Numerous exogenously acquired nosocomial clusters of C/ IC have been reported. Based on molecular typing, the most commonly implicated vehicles of transmission have been from the hands of health care workers (HCWs) (205-213). In addition to the hands of HCWs (214-216), environmental surfaces (217,218), contaminated IV infusates (219-221), medications (222), the hospital environment (223-225), fomites such as blankets and mattresses (226) and hands of family members (227) have also been reported as reservoirs. In some cases, patients may act as the initial nosocomial source, bringing their strain into the hospital, with subsequent transmission to HCWs and to other patients (228-230). Direct patient-to-patient transmission of Candida species has also been described unmediated by HCWs (231).

\section{Preventive measures}

Colonization is the essential first step in the pathogenesis of C/IC; accordingly, effective infection control measures should focus on reducing or preventing such exposures.

Endogenous acquisition: It is not clear whether oral ingestion of Candida species in foods or liquids contributes significantly to the risk for C/IC. Only one cluster of invasive $\mathrm{C}$ krusei infections in association with a foodborne source, bottled lemon juice, has been reported in the literature (232). Otherwise, there is a paucity of evidence linking health care facility-derived food sources to outbreaks of $\mathrm{C} / \mathrm{IC}$. The prolonged use of broad-spectrum antibacterial agents has been repeatedly identified as a significant risk factor for C/IC $(25,194,228,233-237)$. While direct empirical evidence is lacking, it may be reasonable to expect that rational antimicrobial usage policies, extrapolated from strategies designed to limit nosocomial bacterial resistance
(238), may affect the rates of Candida species colonization and infection. The risk for endogenously acquired $\mathrm{C} / \mathrm{IC}$ can be estimated by examining the degree of colonization of body sites by Candida species. Pittet et al (199) described the colonization index as the ratio between the number of different body sites (other than blood) colonized by Candida and the total number of anatomical sites cultured. The corrected colonization index is estimated from the ratio between the number of different body sites showing heavy growth and the total number of different body sites from which Candida species were isolated, then multiplying this ratio by the colonization index. The derived thresholds to predict risk of $\mathrm{C} / \mathrm{IC}$ were colonization index greater than 0.5 (positive predictive value $66 \%$; negative predictive value $100 \%$ ) and corrected colonization index greater than 0.4 (positive predictive value $100 \%$; negative predictive value $100 \%$ ) (199). The use of surrogate prediction rules based on colonization profiles, as a strategy to trigger or prevent the pre-emptive administration of antifungal agents, is an attractive possibility (239-243), but not routinely practiced (57).

Exogenous acquisition: The high prevalence of hand carriage of Candida species by HCWs and the isolation of identical (or highly related) genotypes among nosocomial clusters provide indirect evidence for HCWs as a significant reservoir for transmission within the hospital $(209,212,244,245)$. Hand hygiene is, therefore, recommended using an antimicrobial soap and water; however, alcohol-based hygienic hand rubs are acceptable alternatives (246). Hand jewellery and inadequate nail hygiene may compromise the efficacy of such techniques $(216,247,249)$. Some investigators have implemented additional aggressive infection prevention measures successfully - including cohorting of patients and personnel, barrier precautions (including wearing gowns and gloves on entering patient rooms), minimizing patient transfers to and from their rooms and enforcing hand hygiene among colonized patients - either alone (250) or in conjunction with selected chemoprophylaxis (251).

Central venous catheters may serve as a portal of entry for Candida either by extraluminal skin contamination, by contaminated catheter hubs or by contaminated infusates. Candida species infection accounts for approximately $10 \%$ of all vascular catheter-related infections (252). This topic has been recently reviewed (253) and guidelines regarding the prevention (254) and management $(255,256)$ of central venous catheter-related infections have been published.

\section{ANTIFUNGAL MANAGEMENT OF C/IC}

$\mathrm{C} / \mathrm{IC}$ affects disparate patient populations depending on the underlying immune deficiency and extrinsic predisposing risk factors. The populations affected range from neutropenic cancer patients and HSCT recipients to non-neutropenic patients $(52,257)$. As a result, the approach to the treatment of $\mathrm{C} / \mathrm{IC}$ can be subdivided into two groups of patients: those who are neutropenic versus those who are non-neutropenic. There are four strategies that have evolved for the prevention and treatment of C/IC: prophylactic antifungal therapy to prevent Candida infection in those at high risk; pre-emptive antifungal therapy for patients without evidence of clinical candidiasis, but who are at risk and who may have additional surrogate markers of early infection such as mucosal colonization, circulating antigens, serological markers or circulating genomic material; 


\section{TABLE 6}

Recommendations for the prophylaxis and treatment of candidemia/invasive candidiasis (C/IC) in neutropenic patients

\begin{tabular}{|c|c|c|}
\hline \multirow[b]{2}{*}{ Therapeutic strategy } & \multicolumn{2}{|c|}{ Antifungal therapeutic options } \\
\hline & Preferred & Second line \\
\hline \multicolumn{3}{|l|}{ Prophylactic therapy } \\
\hline Low-risk patients (neutropenia <7 days) & Not recommended (A-III) & NA \\
\hline $\begin{array}{l}\text { Acute leukemia (remission induction) and } \\
\text { allogeneic HSCT }\end{array}$ & Intravenous (IV)/oral fluconazole 400 mg/day (A-I) & $\begin{array}{l}\text { Oral itraconazole } 200 \mathrm{mg} / \text { twice a day (B-I); or oral } \\
\text { posaconazole } 200 \mathrm{mg} / \text { three times a day (A-I); or } \\
\text { IV caspofungin } 50 \mathrm{mg} / \text { day (acute leukemia [B-III]); or } \\
\text { IV micafungin } 50 \mathrm{mg} / \text { day (allogeneic HSCT [B-I]) }\end{array}$ \\
\hline $\begin{array}{l}\text { Acute leukemia (postremission } \\
\text { consolidation) or HGF-supported } \\
\text { autologous HSCT }\end{array}$ & Not recommended (B-II) & NA \\
\hline Pre-emptive therapy & Not recommended - insufficient data (C-III) & NA \\
\hline Empirical therapy & $\begin{array}{l}\text { IV LFAmB } 3 \mathrm{mg} / \mathrm{kg} / \text { day }(\mathrm{A}-\mathrm{I}) \text {; or caspofungin } 70 \mathrm{mg} \text { on } \\
\text { day } 1 \text {, then IV } 50 \mathrm{mg} \text { daily (A-I); or IV AmB-d } 0.6 \mathrm{mg} / \mathrm{kg} / \text { day } \\
\text { to } 1.0 \mathrm{mg} / \mathrm{kg} / \text { day (B-II in the absence of risk factors for } \\
\text { nephrotoxicity) }\end{array}$ & $\begin{array}{l}\text { Fluconazole } 800 \mathrm{mg} \text { or IV/oral } 400 \mathrm{mg} / \mathrm{day} \text { (for less } \\
\text { severely ill patients [B-II]); or voriconazole } 6 \mathrm{mg} / \mathrm{kg} \\
\text { every } 12 \mathrm{~h} \text { for } 24 \mathrm{~h} \text {, then IV doses of } 4 \mathrm{mg} / \mathrm{kg} \text { every } \\
12 \mathrm{~h} \text { or oral doses of } 200 \mathrm{mg} \text { twice daily (if risk of } \\
\text { mould infection present) (B-I) }\end{array}$ \\
\hline $\begin{array}{l}\text { Therapy for microbiologically } \\
\text { or histologically documented C/IC }\end{array}$ & $\begin{array}{l}\text { IV AmB-d } 0.6 \mathrm{mg} / \mathrm{kg} / \text { day to } 1.0 \mathrm{mg} / \mathrm{kg} / \mathrm{day}(\mathrm{A}-\mathrm{I}) \text {; or IV } \\
\text { LFAmB } 3 \mathrm{mg} / \mathrm{kg} / \mathrm{day}(\mathrm{A}-\mathrm{I}) \text {; or IV ECH (IV anidulafungin } \\
200 \mathrm{mg} \rightarrow 100 \mathrm{mg} \text { daily [B-III]; or IV caspofungin } \\
70 \mathrm{mg} \rightarrow 50 \mathrm{mg} \text { daily [A-I]; or IV micafungin } 100 \mathrm{mg} \\
\text { daily [B-III]) }\end{array}$ & $\begin{array}{l}\text { Fluconazole } 800 \mathrm{mg} \text { or IV/oral } 400 \mathrm{mg} / \text { day daily (for } \\
\text { less severely ill patients [A-II]); or IV voriconazole } \\
6 \mathrm{mg} / \mathrm{kg} \text { every } 12 \mathrm{~h} \text { for } 24 \mathrm{~h} \text { then } 4 \mathrm{mg} / \mathrm{kg} \text { every } 12 \mathrm{~h} \\
\text { or oral doses of } 200 \mathrm{mg} \text { twice daily (if risk of mould } \\
\text { infection is present) (B-I) }\end{array}$ \\
\hline
\end{tabular}

AmB-d Amphotericin B deoxycholate; LFAmB Lipid formulation amphotericin B; ECH Echinocandin; HGF Hematopoietic growth factor; HSCT Hematopoietic stem cell transplant; NA Not applicable

empirical antifungal therapy for suspected but unproven $\mathrm{C} / \mathrm{IC}$ based on the symptom of fever unresponsive to broad-spectrum antibacterial therapy with no other obvious source of infection (258,259); and directed antifungal therapy for the treatment of proven or probable (microbiologically or histologically documented) $\mathrm{C} / \mathrm{IC}$ infection.

\section{Prevention of $\mathrm{C} / \mathrm{IC}$ in leukemic and HSCT recipients Recommendations (Table 6)}

1. For acute leukemia patients undergoing primary or secondary remission-induction therapy in which the duration of severe neutropenia is expected to be longer than 10 days, oral fluconazole at $400 \mathrm{mg}$ daily may be administered from the time of initiation of induction chemotherapy until myeloid reconstitution (A-I). The IV formulation may be substituted during periods of intolerance due to oral mucositis (B-I). Alternatively, itraconazole oral solution $200 \mathrm{mg}$ twice daily (B-I) or posaconazole $200 \mathrm{mg}$ three times daily initiated $24 \mathrm{~h}$ after completion of chemotherapy (such as vinca alkaloids, taxanes or anthracyclines) (A-I) or IV caspofungin $50 \mathrm{mg}$ daily may be considered (B-III).

2. For allogeneic HSCT recipients, oral fluconazole $400 \mathrm{mg}$ daily is recommended for use from the beginning of conditioning until at least day 75 post-transplant (A-I). The IV formulation may be substituted during periods of intolerance due to oral mucositis (B-I). Alternatively, itraconazole oral solution $200 \mathrm{mg}$ twice daily (B-I), posaconazole $200 \mathrm{mg}$ three times daily initiated $24 \mathrm{~h}$ after completion of chemotherapy (A-I), or IV micafungin $50 \mathrm{mg}$ daily commencing at the time of transplant (B-I) may be considered.

3. Antifungal prophylaxis with fluconazole among postremission consolidation patients is not recommended (B-II).

4. Antifungal prophylaxis with fluconazole for autologous HSCT recipients, particularly those receiving concomitant hematopoietic growth factor support, is not recommended (B-II).

\section{Summary of evidence}

Effective infection prevention strategies for leukemic and HSCT patients should exert their effects during periods of greatest patient vulnerability (260). Host defense deficits that place patients at risk for IFIs are not constant over time and the pathogeneses of IFIs vary with the pathogens involved. For example, the pathogenesis of $\mathrm{C} / \mathrm{IC}$ is, for the most part, related to translocation of opportunistic yeasts across cytotoxic therapydamaged mucosal surfaces colonized by these microorganisms (Figure 1) (261,262). In contrast, opportunistic moulds are transmitted by inhalation of airborne conidia into the upper and lower airways of susceptible hosts. An understanding of these two pathogenic mechanisms is important to the selection of effective strategies for the prevention of pathogen acquisition.

Most HSCT transplant centres in the United States, Japan and Europe report using antifungal chemoprophylaxis (fluconazole 67\%; itraconazole 13\%; IV amphotericin B $13 \%)(263-266)$. The proportional average increase in use of extended-spectrum mould-active azoles between 2001 and 2005 was $192 \%$, suggesting that physicians' concerns for mould infections increased significantly over this time period.

Fluconazole has been administered in oral doses ranging from $50 \mathrm{mg}$ to $400 \mathrm{mg}$ once daily; however, the weight of evidence suggests that among highest risk patients, the higher dose is more effective (267). A similar observation for the oral solution of itraconazole has been reported (268). The ability to switch from the oral formulation to an IV formulation for the same antifungal product in the setting of severe oral mucositis has been seen as an advantage. The prophylactic use of voriconazole in allogeneic HSCT recipients at oral doses of $200 \mathrm{mg}$ twice daily or IV doses of $200 \mathrm{mg}$ every $12 \mathrm{~h}$ has also been considered. In one recently completed but unpublished 
trial (269), voriconazole was associated with a significant reduction in the likelihood of invasive aspergillosis compared with fluconazole, yet the fungal infection-free survival was not different. A small, double-blind, placebo-controlled trial (270) of prophylactic voriconazole in acute leukemia patients demonstrated a marked reduction in the incidence of pulmonary infiltrates and hepatosplenic candidiasis. Two large randomized fluconazole- or itraconazole-based controlled clinical trials in acute leukemia patients (271) and in HSCT recipients with acute or chronic graft-versus-host disease (272) have demonstrated the efficacy of oral posaconazole at doses of $200 \mathrm{mg}$ three times daily for reducing invasive mould infections. Prophylactic micafungin (273) and caspofungin (274) at daily IV doses of $50 \mathrm{mg}$ have been shown to have similar anti-Candida treatment effects as fluconazole and itraconazole, respectively.

\section{Start and stop dates for antifungal prophylaxis for invasive candidiasis}

Prophylaxis should be initiated in parallel with the administration of cytotoxic therapy $(263,267)$ to ensure a protective effect at the time of maximal neutropenia and intestinal epithelial damage. Triazole-related drug interactions with anthracyclines (QT interval prolongation), vincristine (enhanced peripheral neurotoxicity) and alkylating agents (enhanced hepatotoxicity) have compelled some investigators to modify the application of triazole-based prophylaxis until after the administration of cytotoxic therapy $(271,272,275)$.

The duration of antifungal prophylaxis should be based on the duration of the host defense defect. Prevention of $\mathrm{C} / \mathrm{IC}$ during the period of severe neutropenia for recipients of remission induction or reinduction therapy for acute leukemia or preengraftment period for HSCT recipients begins in parallel with the administration of the cytotoxic regimen and ends with sustained recovery of the ANC to at least $0.5 \times 10^{9} / \mathrm{L}$ (266). HSCT recipients often begin prophylaxis with conditioning therapy and end with recovery of the ANC to at least $0.5 \times 10^{9} / \mathrm{L}$ $(263,264)$, despite the dearth of evidence supporting this practice $(264,276)$. There has been no consensus regarding the duration of antifungal prophylaxis in allogeneic HSCT recipients. The start date has varied from the beginning of conditioning therapy $(263,275)$ to the day of $(277)$ or day after $(278)$ transplant. The reported stop dates have also varied significantly and include the time of recovery of the ANC to at least $0.5 \times 10^{9} / \mathrm{L}(263)$, a finite protocol-driven post-transplant day (day 75 [277], day 100 [278], day 120 [275] or day 180 [275]), or until cessation of immunosuppressive therapy (263). Based on the observed overall survival advantage for the administration of anticandidal prophylaxis beyond engraftment (279), it seems prudent to recommend the duration of prophylaxis until at least day 75 post-transplant. The anticandidal effects of mould-active agents such as itraconazole (275), posaconazole $(271,272)$, voriconazole (269) and micafungin (273) are very similar to fluconazole.

Several systematic reviews (267,268,280-284) evaluating the published clinical trials of antifungal prophylaxis efficacy are available for review. These studies have demonstrated clinically important reductions by approximately $50 \%$ in a variety of outcomes including the use of empirical antifungal therapy for persistent neutropenic fever (OR 0.52, 95\% CI 0.42 to 0.67 for fluconazole compared with placebo or no treatment [267]; RR $0.83,95 \%$ CI 0.73 to 0.88 for systemic antifungals including fluconazole, itraconazole, ketoconazole or parenteral amphotericin B compared with placebo, no treatment or oral polyenes [284]), mucosal colonization, superficial fungal infection (OR $0.54 ; 95 \% \mathrm{CI} 0.44$ to 0.74), proven IFI (RR 0.50, 95\% CI 0.41 to 0.61 [284]), IFI-related mortality (OR 0.48, 95\% CI 0.28 to 0.81 [267]; RR 0.49, 95\% CI 0.23 to 0.75 [284]), and all-cause mortality (OR 0.76, 95\% CI 0.62 to 0.95 [267]; RR 0.49, 95\% CI 0.32 to 0.75 [284]). Prophylaxisrelated reduction of all-cause mortality is demonstrable in subsets of patients with prolonged severe neutropenia (ANC less than $0.5 \times 10^{9} / \mathrm{L}$ for more than 15 days) such as acute leukemia patients undergoing intensive induction therapy or those undergoing allogeneic HSCT $(267,284)$. Moreover, the protective effects against $\mathrm{C} / \mathrm{IC}$ are more apparent when event rates are greater than $15 \%$ (280) (RR 0.31 , 95\% CI 0.23 to 0.41 [284]). Similar effects are also noted for patients with non-albicans Candida infection (RR 0.46, 95\% CI 0.31 to 0.47) (284). Event rates for proven C/IC among neutropenic patients not receiving systemic antifungal prophylaxis have ranged from $3 \%$ to $15 \%(267,280)$. Fluconazole, itraconazole, posaconazole and caspofungin or micafungin have reduced the reported event rates to ranges of $0.4 \%$ to $12 \%(267,268,271,272), 0.5 \%$ to $7 \%(267,268,271,272), 0.7 \%$ to $2.3 \%(271,272)$ and $0.2 \%$ to $2 \%(273,274)$, respectively. Fluconazole chemoprophylaxis has been associated with reductions in all-cause mortality among allogeneic HSCT recipients $(267,279,285)$, but not autologous HSCT $(276,286)$ or acute leukemia patients unless the neutropenic period lasted longer than 14 days (267).

\section{Prevention of $\mathrm{C} / \mathrm{IC}$ in solid organ transplant recipients Recommendations (Table 7)}

5. Hepatic transplantation

i. Routine use of antifungal prophylaxis is not recommended (C-III);

ii. For transplant recipients at high risk, as described in the text below, fluconazole $400 \mathrm{mg} /$ day for four weeks posttransplant may be recommended (A-I); and

iii. Data are insufficient to support a recommendation for extended-spectrum azoles (posaconazole or voriconazole) or the echinocandins for this indication (C-III).

6. Pancreatic transplantation

i. Data are insufficient to support routine fungal cultures of the donor duodenal fluid (C-III); and

ii. To support anastomotic healing, fluconazole $400 \mathrm{mg} / \mathrm{day}$ for four weeks post-transplant may be recommended (B-III). Alternative antifungal agents for this purpose may include lipid formulations of amphotericin B, extended-spectrum azoles or echinocandins (B-III).

7. Small bowel transplantation

i. For centres where $\mathrm{C}$ albicans is prevalent, fluconazole $400 \mathrm{mg} /$ day for four weeks post-transplant may be recommended (B-III). In centres where C glabrata and C krusei are potentially more prevalent, a lipid formulation of amphotericin B $3 \mathrm{mg} / \mathrm{kg} /$ day to $5 \mathrm{mg} / \mathrm{kg} /$ day may be substituted (B-III).

8. Renal transplantation:

i. Data are insufficient to support a recommendation for routine antifungal prophylaxis (C-III). 
TABLE 7

Recommendations for the prophylaxis and treatment of candidemia/invasive candidiasis (C/IC) in non-neutropenic patients

\begin{tabular}{llc}
\hline & & Antifungal therapeutic options \\
\cline { 2 - 3 } Therapeutic strategy & Preferred & Second line \\
\hline Prophylactic therapy
\end{tabular}

Not routinely recommended. High-risk groups: Fluconazole $400 \mathrm{mg} / \mathrm{day}$ Insufficient data to recommend ESA or ECH (C-III) for 4 weeks post-transplant (A-I)

Fluconazole $400 \mathrm{mg} /$ day for 4 weeks post-transplant (B-III)

IV LFAmB 3 mg/kg/day, or ESA (oral itraconazole
Prophylactic therapy

Hepatic transplantation

Small bowel transplantation

Fluconazole $400 \mathrm{mg} /$ day for 4 weeks post-transplant where Candida albicans is prevalent (B-III)

Renal transplantation

Heart/lung transplantation

Intensive care unit

Severe acute pancreatitis

\section{Pre-emptive therapy}

Empirical therapy in intensive care unit patients based on prediction rules

Hemodynamically stable

Treatment of documented C/IC Hemodynamically stable and no previous azole exposure

Hemodynamically unstable and/or previous azole exposure

Urinary tract infection $(400,401)$

Cystitis

Pyelonephritis

Urinary fungus ball

Central nervous system candidiasis (402-404)

Endophthalmitis $(405,406)$

Septic arthritis $(407,408)$

Osteomyelitis (409)

Endocarditis (410) prophylaxis (C-III) IV/oral fluconazole $400 \mathrm{mg}$ daily (A-I) prophylaxis (C-III)

(C-III)

$50 \mathrm{mg}$ daily; or IV micafungin $100 \mathrm{mg}$ daily) (A-I)

used daily (B-II)

IV/oral fluconazole $200 \mathrm{mg}$ daily for 2 weeks (A-II)

to $1.0 \mathrm{mg} / \mathrm{kg} /$ day for at least 2 weeks (C-III) $5 \mathrm{mg} / \mathrm{kg} /$ day (B-II) to $800 \mathrm{mg}$ daily (C-III) daily for 6 weeks (C-III) (C-III) $50 \mathrm{mg} /$ day) (B-III)
Pancreas transplantation

Septic thrombophlebitis (411) IV/oral fluconazole $400 \mathrm{mg}$ daily or IV ECH daily (anidulafungin $200 \mathrm{mg}$ twice a day, oral posaconzole $200 \mathrm{mg}$ three times a day, or oral voriconazole $200 \mathrm{mg}$ twice a day) or ECH (IV micafungin $50 \mathrm{mg} /$ day or IV caspofungin $50 \mathrm{mg} /$ day) (B-III)

LFAmB $3 \mathrm{mg} / \mathrm{kg} /$ day where Candida glabrata and Candida krusei are potentially more prevalent (B-III)

NA

Specific recommendation for anti-Candida prophylaxis cannot be made NA

Anti-Candida prophylaxis is not recommended (B-III). Higher-risk NA patients (see text) may benefit from anti-Candida prophylaxis with

Insufficient data to support a recommendation for anti-Candida NA

Not recommended - insufficient data (C-III) NA

IV fluconazole $800 \mathrm{mg} \rightarrow$ IV/oral $400 \mathrm{mg}$ daily (B-II) NA

IV ECH (IV anidulafungin $200 \mathrm{mg} \rightarrow 100 \mathrm{mg}$ daily; or NA

IV caspofungin $70 \mathrm{mg} \rightarrow 50 \mathrm{mg}$ daily; or IV micafungin $100 \mathrm{mg}$ daily)

Fluconazole $800 \mathrm{mg} \rightarrow$ IV/oral $400 \mathrm{mg}$ daily (A-I); or IV ECH

IV AmB-d $0.5 \mathrm{mg} / \mathrm{kg} /$ day to $1.0 \mathrm{mg} / \mathrm{kg} /$ day (B-I); or

(IV anidulafungin $200 \mathrm{mg} \rightarrow 100 \mathrm{mg}$ daily; or IV caspofungin $70 \mathrm{mg} \rightarrow \quad$ IV LFAmB $3 \mathrm{mg} / \mathrm{kg} /$ day (B-I)

IV ECH (IV anidulafungin $200 \mathrm{mg} \rightarrow 100 \mathrm{mg}$ daily; or IV caspofungin

$70 \mathrm{mg} \rightarrow 50 \mathrm{mg}$ daily; or IV micafungin $100 \mathrm{mg}$ daily) (B-III), except

Candida parapsilosis where fluconazole $800 \mathrm{mg} \rightarrow \mathrm{IV} /$ oral $400 \mathrm{mg}$ is

IV LFAmB $3 \mathrm{mg} / \mathrm{kg} /$ day (C-II) or IV AmB-d

$0.5 \mathrm{mg} / \mathrm{kg} /$ day to $1.0 \mathrm{mg} / \mathrm{kg} /$ day $(\mathrm{C}-\mathrm{II})$

IV AmB-d $0.3 \mathrm{mg} / \mathrm{kg} /$ day to $0.6 \mathrm{mg} / \mathrm{kg} /$ day for $7-10$ days (B-II)

IV/oral fluconazole $200 \mathrm{mg}$ to $400 \mathrm{mg}$ daily for 2 weeks (B-II)

IV AmB-d $0.5 \mathrm{mg} / \mathrm{kg} /$ day to $1.0 \mathrm{mg} / \mathrm{kg} /$ day for 2 weeks (C-III)

IV/oral fluconazole $200 \mathrm{mg}$ to $400 \mathrm{mg}$ daily or IV AmB-d $0.5 \mathrm{mg} / \mathrm{kg} / \mathrm{day} \quad$ AmB-d local irrigation (C-II)

IV AmB-d $0.5 \mathrm{mg} / \mathrm{kg} /$ day to $1.0 \mathrm{mg} / \mathrm{kg} /$ day or IV LFAmB $3 \mathrm{mg} / \mathrm{kg} /$ day to Fluconazole $400 \mathrm{mg}$ to $800 \mathrm{mg}$ (IV/oral) daily (C-III)

IV AmB-d $0.6 \mathrm{mg} / \mathrm{kg} /$ day to $1.0 \mathrm{mg} / \mathrm{kg} /$ day or IV/oral fluconazole $400 \mathrm{mg}$ IV LFAmB $3 \mathrm{mg} / \mathrm{kg} /$ day to $5 \mathrm{mg} / \mathrm{kg} / \mathrm{day}$, intravitreal injection of AmB-d (C-III)

IV AmB-d $0.6 \mathrm{mg} / \mathrm{kg} /$ day to $1.0 \mathrm{mg} / \mathrm{kg} /$ day or IV/oral fluconazole $400 \mathrm{mg}$ IV LFAmB $3 \mathrm{mg} / \mathrm{kg} / \mathrm{day}$ to $5 \mathrm{mg} / \mathrm{kg} / \mathrm{day}$ (C-III)

IV AmB-d $0.6 \mathrm{mg} / \mathrm{kg} /$ day to $1.0 \mathrm{mg} / \mathrm{kg} /$ day, or IV LFAmB $3 \mathrm{mg} / \mathrm{kg} /$ day to $5 \mathrm{mg} / \mathrm{kg} /$ day initially then fluconazole $400 \mathrm{mg}$ daily for 6-12 months

IV AmB-d $0.6 \mathrm{mg} / \mathrm{kg} /$ day to $1.0 \mathrm{mg} / \mathrm{kg} /$ day, or IV LFAmB $3 \mathrm{mg} / \mathrm{kg} / \mathrm{day}$ to $5 \mathrm{mg} / \mathrm{kg} /$ day or $\mathrm{ECH}$ (IV micafungin $50 \mathrm{mg} /$ day or IV caspofungin $200 \mathrm{mg} \rightarrow 100 \mathrm{mg}$, or caspofungin $70 \mathrm{mg} \rightarrow 50 \mathrm{mg}$, or micafungin $100 \mathrm{mg}$ ) with surgical excision of vein for 2 weeks after negative blood cultures (C-III)
$\mathrm{ECH}$ (IV micafungin $50 \mathrm{mg} /$ day or IV caspofungin $50 \mathrm{mg} /$ day) then fluconazole for 6-12 months (C-III)

Fluconazole $400 \mathrm{mg}$ to $800 \mathrm{mg}$ daily after stabilization and surgical intervention (C-III)

IV AmB-d $0.5 \mathrm{mg} / \mathrm{kg} /$ day to $1.0 \mathrm{mg} / \mathrm{kg} /$ day or IV LFAmB $3 \mathrm{mg} / \mathrm{kg} /$ day to $5 \mathrm{mg} / \mathrm{kg} / \mathrm{d}$ (C-III)

AmB-d Amphotericin B deoxycholate; ECH Echinocandins; ESA Extended-spectrum azoles; IV Intravenous; LFAmB Lipid formulation amphotericin B; NA Not applicable 
9. Lung and heart/lung transplantation

i. Specific recommendations for anti-Candida prophylaxis cannot be made in isolation. The risks for invasive aspergillosis must be considered when deciding on prophylaxis.

10. Cardiac transplantation

i. Specific recommendations for anti-Candida prophylaxis cannot be made in isolation. The risks for invasive aspergillosis must be considered.

\section{Summary of evidence}

IFI in solid organ transplantation (SOT) remains a significant problem and the three major determinants of these infections are the complexity of the transplant surgery, environmental exposures and net state of immunosuppression (287). This interplay results in three definable risk periods for disease: early (first month after transplantation), intermediate (one to six months post-transplant), and late (beyond six months) (288). Candida species are the most common pathogens associated with IFI in SOT (289) and occur predominantly during the early period and during the early portion of the intermediate period (288). The risk for C/IC may be influenced by several factors including gastrointestinal colonization from the environment, the intensity of immunosuppressive therapy and the type of transplant. $\mathrm{C} / \mathrm{IC}$ is more common among liver, pancreas and bowel allografts ostensibly attributable to the technical complexities and complications of the surgical procedures involving transection of the gastrointestinal mucosa with the potential of subsequent dissemination of endoluminal Candida species. Because the incidence and outcomes vary with the organ transplanted, the need for, as well as the impact of, antifungal chemoprophylaxis in SOT patients varies widely.

The overall baseline event rate for IFI in hepatic transplantation has been reported to be $14.1 \%$ (95\% CI $10.7 \%$ to $18.2 \%)$. Two systematic reviews $(290,291)$ of the prophylaxis efficacy of fluconazole, itraconazole and liposomal amphotericin $\mathrm{B}$ have demonstrated that antifungal prophylaxis does reduce the rates of proven IFI (RR 0.33 to 0.39 , 95\% CI 0.18 to 0.59 to 0.85 ; number needed to treat [NNT] is between 12 and 14), the majority of which are C/IC, among liver transplant recipients. The effects were most pronounced for patients receiving fluconazole in doses of at least $400 \mathrm{mg}$ daily (RR 0.24, 95\% CI 0.10 to 0.57) for more than four weeks (RR $0.25,95 \%$ CI 0.11 to 0.56$)$ (291). Despite a $70 \%$ reduction in fungal infection-related mortality (RR 0.30, 95\% CI 0.12 to $0.75)$ (290), prophylaxis had no impact on all-cause mortality compared with controls (RR 0.84, 95\% CI 0.54 to 1.30 ) (291). However, prophylaxis is associated with almost a $40 \%$ increased risk for drug-related adverse effects (RR 1.38, 95\% CI 1.04 to 1.83 ) (290). Moreover, the administration of empirical antifungal therapy for suspected IFI was not reduced by prophylaxis (RR 0.80, 95\% CI 0.39 to 1.67 ) (290). Given these observations, routine administration of antifungal prophylaxis to all liver transplant recipients does not seem warranted. Prophylaxis should be considered for patients at high risk (25\%) for C/IC, defined by two or more of the following: fulminant hepatitis, preoperative administration of corticosteroids, dialysis or renal failure, or postoperative bacterial or cytomegalovirus infection. Under such conditions, the NNT to prevent one case of IC is 6, which is low (292). It may be recommended that such patients receive prophylaxis with a daily dose of $400 \mathrm{mg}$ of fluconazole for at least four weeks from the time of transplant. Under circumstances in which invasive aspergillosis is a risk, oral itraconazole in a daily dose of greater than $200 \mathrm{mg}$ may be an alternative (268). Other extended-spectrum azoles (voriconazole or posaconazole) or the echinocandins (micafungin or anidulafungin) have not been studied under these circumstances, and cannot be recommended for routine prophylaxis in liver tranplantation. Caspofungin prophylaxis for high-risk liver transplant recipients has been demonstrated to be effective in an open-label noncomparative trial (293).

The reported incidence of IFI in pancreatic transplantation, almost all due to Candida species $(294,295)$, ranges from 6\% to $38 \%(289,296)$. Pancreatic transplantation is performed as a single procedure (pancreas transplant alone) or as a combined procedure concurrently with (simultaneous pancreas kidney) or after (pancreas after renal) renal transplantation. The risk for $\mathrm{C} / \mathrm{IC}$ during the post-transplantation period is linked to the pancreatic allograft procedure, wherein a segment of the donor duodenum containing the pancreatic duct is involved in the transplant. Donor duodenal fungal cultures were predictive of subsequent intra-abdominal infection in one study (297), but not in others $(298,299)$. Accordingly, such cultures are not recommended. The risks for post-transplant IFI include enteric drainage, vascular graft thrombosis and postperfusion pancreatitis. Until anastomotic healing can occur, antifungal prophylaxis with fluconazole (400 mg/day) given over at least a four-week period has been recommended (289) based on retrospective observational evidence (295). Other observational studies (297,300-302) using fluconazole prophylaxis regimens have been inconsistent in reporting outcome data. The American Society of Transplantation recommends that fluconazole prophylaxis (400 mg daily) be administered for at least four weeks after transplant, with duration dependent on control of other risk factors for infection. Alternatively, lipid formulation amphotericin B, caspofungin or newer extended-spectrum azoles may be used (288).

Transplantation of the small bowel may be performed as a single procedure or as a combined multivisceral procedure with the liver or in combination with the liver and other organs including stomach, pancreas, duodenum or kidney. The reported IFI rates after this type of transplant have been high, ranging from $28 \%$ to $59 \%$, approximately $90 \%$ of which are due to Candida species $(289,296)$. Risk factors for IFI in this group of patients include graft rejection or dysfunction, augmented immunosuppression, anastomotic disruption and multivisceral transplantation (289). Although there are no randomized controlled trials or even case-control studies of antifungal prophylaxis in intestinal transplant, it seems prudent, in the presence of the risk factors cited above, to recommend prophylaxis (fluconazole $400 \mathrm{mg}$ daily or where non-albicans Candida species are prevalent, a lipid formulation of amphotericin B $3 \mathrm{mg} / \mathrm{kg} /$ day to $5 \mathrm{mg} / \mathrm{kg} /$ day) for a period of at least four weeks to allow anastomotic healing in the absence of graft rejection (289).

Renal transplantation is infrequently associated with fungal infection $(289,296)$. IFI rates of $1 \%$ to $14 \%$ have been reported $(296,303,304)$. Candida species are isolated in most cases $(70 \%$ to $80 \%$ ) within the first three to six months post-transplant (304-307). The majority of Candida species infections that 
TABLE 8

Prediction rules for the diagnosis of candidemia/invasive candidiasis in the intensive care unit (ICU)

\begin{tabular}{|c|c|c|c|c|}
\hline Reference & Study population & Risk factors for candidemia/invasive candidiasis & Risk score & Comment \\
\hline 412 & $\begin{array}{l}1107 \text { non-neutropenic adult } \\
\text { patients in } 36 \text { ICUs }>7 \text { days in } \\
\text { Spain, Argentina and France. } \\
(1-3)-\beta-D-g l u c a n \text { and } \\
\text { anti-Candida antibodies once } \\
\text { weekly for } 4 \text { weeks }\end{array}$ & $\begin{array}{l}\text { Candida score } \\
\text { Surgery } \\
\text { Multifocal colonization } \\
\text { Total parenteral nutrition } \\
\text { Severe sepsis } \\
\text { (1-3)- } \beta \text {-D-glucan } \\
\text { Anti-Candida antibodies once weekly for } 4 \text { weeks }\end{array}$ & $\begin{array}{l}1 \\
1 \\
1 \\
2 \\
\geq 75 \mathrm{pg} / \mathrm{mL}\end{array}$ & $\begin{array}{l}\text { Invasive candidiasis } \\
\text { improbable with score }<3 \text {. } \\
\text { (1-3)- } \beta \text {-D-glucan } \geq 75 \mathrm{pg} / \mathrm{mL} \\
\text { independent predictor of } \\
\text { invasive candidiasis and } \\
\text { higher response to } \\
\text { empirical antifungal therapy }\end{array}$ \\
\hline 242 & $\begin{array}{l}221 \text { surgical ICU patients with } \\
\text { peritonitis }\end{array}$ & $\begin{array}{l}\text { Female sex } \\
\text { Upper gastrointestinal origin of peritonitis } \\
\text { Intraoperative cardiovascular failure } \\
\text { Previous antimicrobial therapy } \geq 48 \mathrm{~h} \text { before onset of peritonitis }\end{array}$ & $\mathrm{N} / \mathrm{A}$ & $\begin{array}{l}\text { Presence of } 3 \text { risk factors } \\
\text { related to Candida } \\
\text { peritonitis; accuracy } 71 \%\end{array}$ \\
\hline 243 & $\begin{array}{l}2890 \text { medical-surgical ICU } \\
\text { patients admitted }>4 \text { days in } \\
\text { USA and } \geq 4 \text { days in USA and } \\
\text { Brazil }\end{array}$ & $\begin{array}{l}\text { Patients in ICU }>4 \text { days, any systemic antibiotic (days } 1 \text { to } 3 \text { ) or central } \\
\text { venous catheter (days } 1 \text { to } 3 \text { ) and at least } 2 \text { of the following: } \\
\text { Total parenteral nutrition (days } 1 \text { to } 3 \text { ) } \\
\text { Any dialysis (days } 1 \text { to } 3 \text { ) } \\
\text { Any major surgery (days }-7 \text { to } 0 \text { ) } \\
\text { Pancreatitis (days }-7 \text { to } 0 \text { ) } \\
\text { Any use of steroids (days }-7 \text { to } 3 \text { ) } \\
\text { Use of immunosuppressive agents (days }-7 \text { to } 0 \text { ) }\end{array}$ & $\mathrm{N} / \mathrm{A}$ & $\begin{array}{l}\text { RR } 4.36 \text {, sensitivity } 34 \% \text {, } \\
\text { specificity } 90 \%\end{array}$ \\
\hline
\end{tabular}

N/A Not applicable

occur involve superficial mucosal surfaces of the oropharynx, esophagus or urogenital tissues. Given the low incidence of invasive Candida species infection in renal allograft recipients, routine antifungal prophylaxis is not recommended (308).

The reported incidence of IFI among lung and lung-heart transplant recipients is in the range of $15 \%$ to $44 \%$, of which $4 \%$ to $72 \%$ and $25 \%$ to $50 \%$ may be due to Candida species and Aspergillus species, respectively (296). As for nontransplant patients (1), the simple isolation of Candida species from respiratory secretions of lung transplant recipients is not considered to be an indication for treatment $(309,310)$. While Candida species may, on occasion, be responsible for lower respiratory tract infection post-transplant (311), studies have focused on chemoprophylaxis strategies for preventing invasive aspergillosis, which in parallel reduce the incidence of $\mathrm{C} / \mathrm{IC}$. Accordingly, there are no specific recommendations for antifungal prophylaxis against Candida species in lung transplant recipients independent of those targeting Aspergillus species (refer to upcoming AMMI Canada Clinical Practice Guidelines on Aspergillus species).

The reported incidence of IFI among cardiac transplants is in the range of $5 \%$ to $21 \%$, with the majority ( $70 \%$ to $90 \%$ ) being due to Aspergillus species (296). The incidence of C/IC in cardiac transplantation without simultaneous lung allograft is very low - less than 1\% (308). That no studies on antifungal prophylaxis targeting Candida species could be identified is consistent with this observation. Accordingly, there are no specific recommendations for routine anti-Candida prophylaxis in this patient population.

\section{Prevention of $\mathrm{C} / \mathrm{IC}$ in ICU patients \\ Recommendations (Table 7)}

11. Routine antifungal prophylaxis of all ICU patients is not recommended (B-III). However, antifungal prophylaxis aimed at Candida species using fluconazole in selected highrisk subgroups of ICU patients may significantly decrease the likelihood of developing proven $\mathrm{C} / \mathrm{IC}$ and reduce allcause mortality (A-I).

12. High-risk subgroups of patients who may be candidates for prophylaxis include the following:

i. ICU patients with recurrent gastrointestinal perforation or anastomotic leakage. In this selected high-risk group, IV fluconazole $400 \mathrm{mg}$ once daily may be administered until either complete resolution of intra-abdominal disease, development of proven Candida species infection requiring directed antifungal therapy, or development of a severe drug-related adverse event (A-I);

ii. Patients admitted to a tertiary referral centre ICU (surgical or medical) with a baseline risk for $\mathrm{C} / \mathrm{IC}$ of $10 \%$ or greater if there is an anticipated stay of more than three days (Table 8). In such cases, oral fluconazole $400 \mathrm{mg}$ daily may be administered until ICU discharge, until initiation of directed antifungal therapy for suspected/confirmed disease or development of a severe drug-related adverse event (A-I); and

iii. There are insufficient data to support specific recommendations for antifungal prophylaxis in SAP (C-III).

\section{Summary of evidence}

Patients admitted to the ICU represent another population at risk for C/IC. Among those ICU patients without neutropenia, Candida species represent the overwhelming majority (greater than $80 \%$ ) of such infections (312,313), with attributable mortality rates of $24 \%$ to $49 \%$ and excess ICU stays of 12.7 days (55,314-316). While most of the experience has emerged from observations in surgical ICU patients, data suggest that medical ICU patients are also significantly affected by invasive Candida species infection $(233,317)$. Hence, there is a need for preventive measures for both types of ICU patients.

The overall incidence of $\mathrm{C} / \mathrm{IC}$ in the critical care setting is relatively low ( $0.5 \%$ to $2 \%$ ), yet the crude mortality often ranges from one in four patients to more than one in two patients 
depending on species and time to treatment $(32,318)$. Moreover, the presence of certain risk factors, such as multifocal Candida species colonization; use of broad-spectrum antibiotics; severe sepsis syndrome; presence of a central venous access catheter; administration of total parenteral nutrition; having surgery; having diabetes; and receiving hemodialysis or receipt of immunosuppressive therapy in various combinations, have identified patients at greatest risk (greater than 10\%) for IFI and all-cause mortality rates of greater than 50\% $(199,240,243)$. Such patients may be candidates for prophylactic antifungal therapy to prevent evolution to IFI and death.

The ability to detect a prophylactic treatment effect is dependent on having a baseline event rate of $\mathrm{C} / \mathrm{IC}$ of at least $10 \%$ (312). It is not surprising that prophylaxis studies that include ICU patients with a heterogeneous spectrum of risk for C/IC have been unable to show a treatment benefit $(319,320)$. A systematic review $(321,322)$ of 11 trials $(1500$ randomized subjects) examining the efficacy and safety of fluconazole and ketoconazole compared with placebo, no treatment or oral polyenes in critically ill patients has summarized the experience in this area. Among 1260 randomized subjects in 10 trials, the event rate for IFI ranged from 3\% to $40.9 \%$ (mean $11 \%$ ). Azole-based prophylaxis reduced IFI by approximately $50 \%$ (RR 0.46, 95\% CI 0.31 to 0.68; NNT 20). Across 11 trials, azole-based prophylaxis reduced the all-cause mortality compared with the controls (mean 25\%) by approximately threequarters (RR 0.24, 95\% CI 0.59 to 0.97; NNT 30). In contrast to these encouraging results, prophylaxis failed to have any impact on the use of empirical antifungal therapy for suspected but unproven IFI (RR 1.14, 95\% CI 0.25 to 5.13), superficial fungal infection (RR $0.29,95 \% \mathrm{CI} 0.27$ to 1.29 ) or the need to terminate therapy due to intolerance (RR $0.85,95 \%$ CI 0.37 to 1.94). While azole-based prophylaxis reduced mucosal fungal colonization by approximately one-third (RR 0.60, 95\% CI 0.50 to 0.73 ; NNT 13), there was no selection for colonization or infection by azole-resistant fungi such as C glabrata or C krusei.

The most important observations from these trials lie in the pooled effects for all-cause mortality and proven IFI that were not appreciated in the analyses of individual trials. The efficacy of fluconazole, for example, was consistent across studies despite variances in design suggesting applicability of these results to a variety of clinical circumstances wherein the event rates justify the use of prophylaxis (321). Among higher-risk patients for IFI (defined by one or more of the following: diabetes mellitus, new onset of hemodialysis, parenteral nutrition at the time of ICU admission and broad-spectrum antibacterial therapy [241,312]) where the IFI event rates range from $11 \%$ to $20 \%$, the number of patients requiring treatment to prevent one IFI would range from 17 to 9 (321).

Patients with SAP represent a specific subgroup of highrisk ICU patients for $\mathrm{C} / \mathrm{IC}$ for several reasons: the presence of necrosis in the pancreas that serves as a nidus for infection; the administration of prophylactic broad-spectrum antibacterial agents may predispose to Candida species superinfection $(323-328)$ by eradicating resident flora; the frequent association of infection with pancreatic necrosis $(325,326)$ that requires broad-spectrum antibiotic therapy and debridement of infected pancreatic necrosis (324-326,329); and the frequent concurrence of other established risk factors for C/IC including prolonged use of indwelling catheters and administration of total parenteral nutrition (330). Candida species may be recovered from patients with SAP either as a single isolate or with other enteric bacteria at the time of the primary or subsequent debridement and is often associated with excess mortality (327,331-336). It is estimated from retrospective series that the incidence of $\mathrm{C} / \mathrm{IC}$ in SAP may be $5 \%$ to $15 \%$ (327). However, there is no consensus case definition for C/IC in SAP. While early antifungal therapy may affect mortality (328), the role of antifungal prophylaxis in SAP has been inadequately studied $(336,337)$.

\section{Treatment of $\mathrm{C} / \mathrm{IC}$ in neutropenic patients and HSCT recipients}

Recommendations (Table 6)

13. Pre-emptive use of antifungal agents for $\mathrm{C} / \mathrm{IC}$ in neutropenic patients based on the presence of colonization and/or surrogate serological markers for $\mathrm{C} / \mathrm{IC}$ is impractical and not recommended (C-III).

14. Empirical antifungal therapy is recommended for patients with a persistent or recrudescent neutropenic fever syndrome after four to seven days of broad-spectrum antibacterial therapy without a focus of infection for suspected $\mathrm{C} / \mathrm{IC}$ or other possible IFI (B-I).

15. Therapeutic choices for empirical antifungal therapy in febrile neutropenic cancer patients and HSCT recipients with a persistent or recrudescent neutropenic fever syndrome include a lipid formulation of IV amphotericin B at a dose of $3 \mathrm{mg} / \mathrm{kg} /$ day (A-I), IV caspofungin $70 \mathrm{mg}$ as a loading dose and then IV $50 \mathrm{mg}$ daily (A-I), IV amphotericin B deoxycholate $0.6 \mathrm{mg} / \mathrm{kg} /$ day to $1.0 \mathrm{mg} / \mathrm{kg} /$ day (B-II in the absence of risk factors for nephrotoxicity, otherwise the deoxycholate formulation of amphotericin $\mathrm{B}$ is not recommended), fluconazole for those less critically ill patients with neutropenia of short duration (seven days or fewer) and in the absence of azole prophylaxis with IV $800 \mathrm{mg}$ as a loading dose and then IV $400 \mathrm{mg}$ daily with the option of proceeding to oal doses of $400 \mathrm{mg}$ daily (B-II), and IV voriconazole $6 \mathrm{mg} / \mathrm{kg}$ every $12 \mathrm{~h}$ for $24 \mathrm{~h}$ and then IV $4 \mathrm{mg} / \mathrm{kg}$ every $12 \mathrm{~h}$ or oral doses of $200 \mathrm{mg}$ twice daily (based on the risk of mould infection in these patients) (B-I).

16. The duration of empirical antifungal therapy is until resolution of symptoms and signs of infection, including fever, in conjunction with the recovery of the ANC to greater than $0.5 \times 10^{9} / \mathrm{L}$ for at least $48 \mathrm{~h}(\mathrm{~A}-\mathrm{I})$.

17. For microbiologically or histologically documented (proven) $\mathrm{C} / \mathrm{IC}$ in neutropenic patients and HSCT recipients, IV amphotericin B deoxycholate $0.6 \mathrm{mg} / \mathrm{kg} /$ day to $1.0 \mathrm{mg} / \mathrm{kg} /$ day (in the absence of risk factors for nephrotoxicity), a lipid formulation of IV amphotericin B $3 \mathrm{mg} / \mathrm{kg} /$ day, and IV caspofungin $70 \mathrm{mg}$ as a loading dose and then IV $50 \mathrm{mg}$ daily are all recommended (A-I). IV anidulafungin $200 \mathrm{mg}$ initially followed by IV $100 \mathrm{mg}$ daily or IV micafungin $100 \mathrm{mg}$ daily may also be effective (B-III). Fluconazole $800 \mathrm{mg}$ followed by IV/oral doses of $400 \mathrm{mg}$ may be used in hemodynamically stable, less severely ill patients with neutropenia of shorter duration (seven days or fewer) (A-II). Choice of agent will depend on local 
epidemiology, use of azole antifungal prophylaxis and concerns about coexistent mould infection.

18. If $\mathrm{C}$ parapsilosis $\mathrm{C} / \mathrm{IC}$ is present and caspofungin, anidulafungin or micafungin has been used, another agent of a different class (amphotericin B deoxycholate, lipid formulation of amphotericin B or fluconazole for less critically ill patients with a shorter duration of neutropenia) may be considered if the patient is not responding or improving. However, if the patient has improved on echinocandin therapy, then it may be continued (B-III). For hemodynamically unstable neutropenic patients and HSCT recipients with proven $\mathrm{C}$ parapsilosis $\mathrm{C} / \mathrm{IC}$, amphotericin $\mathrm{B}$ deoxycholate or a lipid formulation of amphotericin B is preferred (B-III).

19. Removal of venous access devices is recommended for candidemia in neutropenic cancer patients and HSCT recipients (whether catheter related or not), provided that this procedure is feasible (B-II).

20. The duration of therapy for microbiologically documented $\mathrm{C} / \mathrm{IC}$ in neutropenic patients is at least two weeks after the clearance of organisms from the bloodstream and/or the infected body site with resolution of all signs and symptoms at the infected site and recovery of the ANC to greater than $0.5 \times 10^{9} / \mathrm{L}$ for at least $48 \mathrm{~h}(\mathrm{~A}-\mathrm{I})$.

\section{Summary of evidence}

The risk of invasive Candida infections is highest in patients with hematological malignancy, particularly acute leukemia and HSCT recipients who are rendered neutropenic by antineoplastic chemotherapy $(47,338)$. Prevention of $\mathrm{C} / \mathrm{IC}$ in neutropenic patients and HSCT by means of antifungal prophylaxis has been described above. The pre-emptive antifungal strategy in neutropenic patients is still in the process of development. The precise definition remains controversial. It has been explored in presumed invasive aspergillosis with the use of galactomannan and computed tomography scanning of the chest, acting as surrogate markers indicative of the IFI (339). Moreover, a recent randomized clinical trial (340), comparing a pre-emptive strategy based on the presence of fever and positive galactomannan versus empirical antifungal therapy for fever with negative surrogate markers and using polyenes, found a reduction in antifungal drug costs for pre-emptive therapy but lower survival rates for patients receiving induction chemotherapy. However, evidence for the use of surrogate serological markers for Candida as a guide to the initiation of pre-emptive antifungal therapy in neutropenic patients has been less forthcoming (refer to the section on Diagnosis of $\mathrm{C} / \mathrm{IC}$ ). Thus, pre-emptive therapy for $\mathrm{C} / \mathrm{IC}$ in neutropenic patients may be premature in Canada due to the lack of availability and limitations for (1,3)- $\beta$-D-glucan serological testing.

Empirical antifungal therapy for suspected Candida infection in patients with persistent or recrudescent neutropenic fevers of unknown origin despite four to seven days of broadspectrum antibacterial therapy is a well-established practice (341). Pioneering work by Pizzo et al (258) with corroboration by the European Organization for Research and Treatment of Cancer (EORTC) (342) have provided evidence for this approach. This practice reduces morbidity associated with documented IFIs (fewer IFIs) and febrile morbidity, but has not had a major impact on survival $(343,344)$. Agents used for this purpose have included amphotericin B deoxycholate $(258,259,345)$, liposomal amphotericin B (345), amphotericin B lipid complex (342), fluconazole (346,347), itraconazole (348) and caspofungin (349). The panel, similar to other guideline panels $(7,9,341)$, recognizes the use of voriconazole for this indication, despite the statistical controversies surrounding the original trial $(350,351)$. Guidelines describing the time of initiation and duration for empirical antifungal therapy have been produced by the Infectious Diseases Society of America (IDSA) (344) and the National Comprehensive Cancer Network (NCCN) (11). However, the agent of choice for empirical antifungal therapy has not been resolved and depends on the following: local epidemiology of IFIs in a particular institution; patient factors such as renal function, concomitant drugs, patient tolerance of medications and allergies; cost of the antifungal medication; and the need to provide adequate coverage for mould pathogens.

Therapy for microbiologically or histologically documented (proven) $\mathrm{C} / \mathrm{IC}$ in neutropenic hematological cancer patients and HSCT recipients has only been partially addressed in the randomized empirical antifungal therapy clinical trials of amphotericin B deoxycholate versus liposomal amphotericin B (345), and caspofungin versus liposomal amphotericin B (349). Response rates for neutropenic candidemic patients are lower than their non-neutropenic counterparts (352). Based on these clinical trials, it appears that liposomal amphotericin B achieved a slightly better success rate against infections (that included candidiasis) diagnosed at the initiation of therapy compared with amphotericin B deoxycholate (81.8\% versus $72.7 \%$ ) (345). Similarly, caspofungin achieved slightly better responses in the treatment of baseline Candida infections compared with liposomal amphotericin B (66.7\% versus 41.7\%) (349). Moreover, MoraDuarte et al (158) demonstrated that there was a nonsignificant difference between caspofungin and amphotericin B deoxycholate (50\% versus $40 \%$ ) for the treatment of $\mathrm{C} / \mathrm{IC}$ in their neutropenic patients. Furthermore, other investigators have corroborated the success rate of caspofungin for candidemia (68\%) in neutropenic patients (353). However, any echinocandin-related treatment advantage in candidemic patients may be offset by the confounding effect of severe neutropenia. A systematic review (352) noted that the apparent advantage of echinocandin therapy over amphotericin B may be confined to those patients who were not neutropenic at baseline compared with those who were indeed neutropenic at the onset of candidemia. In addition, it would appear that $\mathrm{C}$ parapsilosis may be less responsive to the echinocandins (158).

Fluconazole has also been effective $(346,347,354)$. There does not appear to be any decisive advantage of one agent over another for $\mathrm{C} / \mathrm{IC}$ in neutropenic patients, but the numbers are limited. Rather, the selection of the antifungal agent is predicated on the local epidemiology of the fungal isolates, the susceptibility of the isolates, the degree of immunosuppression and the possibility of the presence of coexistent mould infection that may necessitate the use of specific therapies. Thus, fluconazole is deemed inappropriate in a neutropenic patient if antifungal therapy is also directed against possible coexistent mould infection. Moreover, fluconazole would also be inappropriate for neutropenic patients receiving this agent as antifungal chemoprophylaxis (6). It should also be underscored that although the efficacy of anidulafungin and micafungin for 
the treatment of C/IC has been evaluated in large randomized clinical trials, there were too few neutropenic patients in both clinical trials (anidulafungin 2\% [355] and micafungin 10\% [356]) to come to any firm conclusions about their use in neutropenic patients. One has to consider their use in neutropenic patients based on data extrapolated from the efficacy of caspofungin (158) (13\% of 109 patients) for the treatment of C/IC and the treatment of baseline fungemia when it was used empirically (349), as well as the merits of the echinocandin class to treat $\mathrm{C} / \mathrm{IC}$ effectively.

The duration of therapy for suspected and proven C/IC in neutropenic patients depends on clearance of the pathogens from the bloodstream, resolution of signs and symptoms of infection for at least $48 \mathrm{~h}$, and the resolution of neutropenia with a rise in ANC to greater than $0.5 \times 10^{9} / \mathrm{L}$ for more than $48 \mathrm{~h}$. This therapy must be continued for at least 14 days beyond the clearance of organisms from the bloodstream (6). Venous access device removal has been associated with more rapid resolution of candidemia and is, therefore, advocated $(4,256,356,357)$. However, there may be occasions when venous access catheter removal is impossible or ill advised (eg, extremely limited access or severe thrombocytopenia). In such situations, administration of the antifungal agent should be alternated among the catheter lumens daily.

In addition, further comments are warranted for the treatment of chronic disseminated hepatosplenic candidiasis, a form of proven $\mathrm{C} / \mathrm{IC}$ infection. Hepatosplenic candidiasis poses a unique problem in neutropenic patients. This infection arises after the dissemination of Candida organisms because of candidemia or by means of translocation from the gastrointestinal tract and transmission to the liver via the portal vein. In the liver, numerous small abscesses are formed, producing necrotizing granulomas. These abscesses with the presence of fever may only become evident with immune reconstitution as neutropenia resolves. The classical finding is multiple target lesions on radiographic imaging of the liver with an elevated alkaline phosphatase level (358-360). The eradication of hepatic lesions is particularly difficult and has been accomplished with fluconazole, other azoles, amphotericin B deoxycholate and lipid formulations of amphotericin B (361-363). Prolonged therapy is suggested until resolution is apparent. When the species of Candida is known to be susceptible, fluconazole is considered to be the treatment of choice (4). Some (364) have advocated the use of adjunctive oral corticosteroids $(0.5 \mathrm{mg} / \mathrm{kg} /$ day to $0.8 \mathrm{mg} /$ $\mathrm{kg} /$ day) for a mean duration of 21 days with slow reduction in dose thereafter for chronic disseminated hepatosplenic candidiasis. This has led to resolution of the hepatic lesions. However, further study is warranted before specific recommendations can be made.

\section{Treatment of $\mathrm{C} / \mathrm{IC}$ in non-neutropenic patients Recommendations (Table 7)}

21. Pre-emptive antifungal therapy in non-neutropenic patients with the presence of colonization is currently not recommended (C-III).

22. Empirical antifungal therapy may be beneficial in critically ill patients who meet specific criteria based on clinical prediction rules for C/IC (B-II). Fluconazole remains efficacious in reducing $\mathrm{C} / \mathrm{IC}$ and is cost effective at a dose of $800 \mathrm{mg}$ loading dose followed by IV $400 \mathrm{mg}$ daily for hemodynamically stable patients (B-II). However, empirical antifungal therapy may not produce resolution of fevers of unknown origin in non-neutropenic ICU patients and is weakly endorsed (C-II). In hemodynamically unstable patients, an echinocandin (anidulafungin $200 \mathrm{mg}$ initially followed by IV $100 \mathrm{mg}$ daily, caspofungin $70 \mathrm{mg}$ initially followed by IV $50 \mathrm{mg}$ daily or IV micafungin $100 \mathrm{mg}$ daily) may be preferred for empirical therapy (C-III).

23. The duration of empirical therapy in non-neutropenic patients should be 14 days (B-II).

24. For microbiologically or histologically documented (proven) C/IC in hemodynamically stable patients with no previous azole exposure in the past 30 days, fluconazole $800 \mathrm{mg}$ initially followed by IV $400 \mathrm{mg}$ daily, or an echinocandin (anidulafungin $200 \mathrm{mg}$ as a loading dose followed by IV $100 \mathrm{mg}$ daily, caspofungin $70 \mathrm{mg}$ as a loading dose followed by IV $50 \mathrm{mg}$ daily, or IV micafungin $100 \mathrm{mg}$ daily) are recommended (A-I).

25. IV amphotericin B deoxycholate at a dose of $0.5 \mathrm{mg} / \mathrm{kg} /$ day to $1 \mathrm{mg} / \mathrm{kg} /$ day (in the absence of risk factors for nephrotoxicity) or lipid formulations of IV amphotericin B at doses $3 \mathrm{mg} / \mathrm{kg} /$ day are alternatives (B-I).

26. For proven $\mathrm{C} / \mathrm{IC}$ caused by $\mathrm{C}$ glabrata in hemodynamically stable patients, in centres where susceptibility testing is available, fluconazole should only be used if the isolate is susceptible. However, if fluconazole is initiated at the outset but susceptibilities are not available and the patient is clinically improved, it may be continued (B-III).

27. For hemodynamically stable or unstable patients with proven C/IC caused by C parapsilosis, fluconazole is preferred (B-II). In hemodynamically unstable patients, lipid formulations of amphotericin B or amphotericin B deoxycholate are alternatives for therapy for $\mathrm{C} / \mathrm{IC}$ (C-II).

28. In hemodynamically unstable patients with proven $\mathrm{C} / \mathrm{IC}$ due to Candida species other than $\mathrm{C}$ parapsilosis with or without azole exposure, an echinocandin (anidulafungin $200 \mathrm{mg}$ followed by IV $100 \mathrm{mg}$ daily, caspofungin $70 \mathrm{mg}$ initially followed by IV $50 \mathrm{mg}$ daily or IV micafungin $100 \mathrm{mg}$ daily) is preferred (B-III).

\section{Summary of evidence}

In non-neutropenic patients, $\mathrm{C} / \mathrm{IC}$ infections occur most frequently in ICU and surgical patients, and those with significant comorbid illness (Table 4). The pre-emptive treatment strategy for non-neutropenic patients has not been investigated adequately. Nonculture-based diagnosis of $\mathrm{C} / \mathrm{IC}$ remains elusive in non-neutropenic patients. Data have been accrued on Candida circulating antigens and antibodies $(365,366),(1,3)$ $\beta$-D-glucan serological testing $(190,367)$ and polymerase chain reaction for Candida DNA (368) in critically ill patients colonized with Candida and possessing risk factors for probable or proven C/IC. Unfortunately, laboratory markers sufficiently predictive for $\mathrm{C} / \mathrm{IC}$ so as to permit the institution of preemptive therapy have not been identified. Piarroux et al (239) attempted to assess the efficacy of pre-emptive antifungal therapy with fluconazole in preventing proven candidiasis in critically ill surgical patients. They evaluated the frequency of proven candidiasis within a specific time frame during which patients with a corrected colonization index of 0.4 or higher 
were treated with fluconazole pre-emptive antifungal therapy. Candida infections occurred more frequently in the control cohort (7\% versus 3.8\%; P=0.03) (239). Proven C/IC decreased from $2.2 \%$ to $0 \%$. However, in light of the absence of a readily available surrogate marker (1,3- $\beta$-D-glucan) in this study, and in Canada presently, and the paucity of efficacy data using this approach, pre-emptive therapy in non-neutropenic patients cannot be advocated at this time.

Empirical antifungal therapy in febrile non-neutropenic critically ill patients who are unresponsive to broad-spectrum antibacterial therapy has been suggested based on the predisposition of such patients to develop C/IC (369). Such an approach may have merit for the treatment of suspected Candida infections producing a fever of unknown origin in an ICU patient with the presence of the previously enumerated risk factors for IC, particularly in light of the poor sensitivity of current diagnostic methods (176,367,369-371). Fluconazole empirical antifungal therapy was predominantly used in the aforementioned studies at a dose of $400 \mathrm{mg} /$ day. Azoulay et al (372) substantiated this approach by demonstrating the impact of colonization with Candida in the ICU populations. In patients with ventilator-associated pneumonia in the ICU, the presence of Candida species in respiratory secretions carried a poor prognosis with a greater risk of death. Moreover, a number of investigators have proposed prediction rules to direct clinicians when empirical antifungal therapy should be contemplated and initiated $(240,242,243)$ (Table 8). In contrast, Schuster et al (373) found in their large, double-blind, placebo-controlled randomized trial for ICU patients with fever (four days or more) despite administration of broad-spectrum antibiotics and a central venous catheter in place for at least $24 \mathrm{~h}$ before study entry, that IV fluconazole $800 \mathrm{mg}$ daily did not produce the desired resolution of fever (failure for fever to resolve in $51 \%$ of the fluconazole patients versus $57 \%$ for the placebo group). Nevertheless, documented C/IC occurred in fewer fluconazole recipients (5\% versus $9 \%$ of the placebo recipients). Therefore, based on these data, it would appear at present that the concept of empirical antifungal therapy remains unsubstantiated in non-neutropenic critically ill patients. It may not resolve fever, but may mildly reduce documented C/IC.

An additional issue for consideration with regard to empirical antifungal therapy is the choice of empirical antifungal treatment for suspected C/IC. This has been assessed in an economic evaluation by Golan et al (176). IV fluconazole $800 \mathrm{mg}$ as a loading dose followed by IV $400 \mathrm{mg}$ daily with the option of oral therapy at a dose of $400 \mathrm{mg}$ daily when the patient is clinically improved and stable appears to be endorsed most consistently (176,369). This approach may be efficacious and cost effective provided that the likelihood of $\mathrm{C} / \mathrm{IC}$ is greater than $25 \%$ and the local fluconazole resistance rate is less than $24 \%$. It should be noted that in Canada, most of the Candida isolates are $\mathrm{C}$ albicans and, therefore, are likely to be fluconazole susceptible (374). In addition, the duration of empirical antifungal therapy in nonneutropenic patients has not been clearly elucidated in clinical trials. Schuster et al (373) used a two-week course in their study. This time course would seem reasonable.

For microbiologically or histologically documented (proven) $\mathrm{C} / \mathrm{IC}$, therapy is predicated on two key principles. First, it is imperative to initiate therapy early. Garey et al (375) have demonstrated that delays in the time to initiation of fluconazole therapy for candidemia resulted in higher mortality rates.
Initiation at day 0 had a mortality rate of $15 \%$, while a delay in therapy initiation of one, two and three or more days resulted in mortality rates of $24 \%, 37 \%$ and $41 \%$, respectively. Morrell et al (376) advanced this concept further by describing how delays in empirical antifungal therapy for candidemia until after blood cultures are positive also increases mortality. Moreover, delays in the initiation of antifungal therapy for Candida sepsis in the ICU are associated with decreased survival (377). The second important principle of therapy is the initiation of appropriate therapy for the pathogens causing candidemia. A multiple logistic regression analysis proved that Candida species infections were most often associated with inadequate therapy (378). Similarly, BSI-related mortality rates were higher for patients receiving inadequate antimicrobial therapy $(57,378)$.

It is, therefore, suggested that non-neutropenic patients be subdivided into those who are hemodynamically stable with no recent azole exposure, thus reducing the risk of azole resistance, and those individuals who are hemodynamically unstable with or without recent azole exposure. For those patients who are hemodynamically stable and have had no antecedent azole exposure within the past 30 days, fluconazole $800 \mathrm{mg}$ as a loading dose followed by IV/oral doses of $400 \mathrm{mg}$ daily or an echinocandin such as IV anidulafungin $200 \mathrm{mg}$ initially followed by IV $100 \mathrm{mg}$ daily, IV caspofungin $70 \mathrm{mg}$ as a loading dose followed by IV $50 \mathrm{mg}$ daily or IV micafungin $100 \mathrm{mg}$ daily are appropriate alternatives. Voriconazole offers no real potency advantage over fluconazole and presents the challenge of interpatient serum concentration variability due to genetic polymorphisms in metabolism while possessing the potential for more toxicities and drug interactions. Transition from an echinocandin to oral fluconazole for fluconazole-susceptible organisms when patients are clinically stable would seem prudent. For C glabrata, an echinocandin is preferred (379). Transition to fluconazole should not be undertaken unless the clinical isolate is fluconazole susceptible. If fluconazole was commenced initially for $\mathrm{C}$ glabrata $\mathrm{C} / \mathrm{IC}$ and the patient has improved, such therapy may be continued. If C parapsilosis has produced proven $\mathrm{C} / \mathrm{IC}$, fluconazole is preferred because of the reduced activity of the echinocandins against $\mathrm{C}$ parapsilosis, although in the micafungin versus caspofungin clinical trial (356), adequate response rates were achieved with micafugin compared with caspofungin. Once again, if the patient has improved on the echinocandin and there is a desire to continue such therapy, it is unnecessary to change it. IV amphotericin B deoxycholate $0.5 \mathrm{mg} / \mathrm{kg} /$ day to $1.0 \mathrm{mg} / \mathrm{kg} /$ day should only be considered an alternative due to its toxicities that may limit its efficacy in the treatment of $\mathrm{C} / \mathrm{IC}$. If there is intolerance or limited availability of other antifungals, amphotericin B deoxycholate and its lipid formulations ( $3 \mathrm{mg} / \mathrm{kg} /$ day IV) would be considered alternatives, but one must be cognizant of the side effect profile and expense of lipid formulations. As mentioned above for empirical therapy, fluconazole is still an efficacious and costeffective agent for the treatment of C/IC. Removal of all intravenous catheters is also recommended, as previously mentioned. The duration of therapy should be two weeks after clearance of organisms from the bloodstream with the resolution of all signs and symptoms of infection. However, for disseminated disease, prolonged therapy beyond two weeks should be undertaken. Such therapy should continue until resolution of all clinical signs and symptoms. 
In contrast, hemodynamically unstable patients with or without recent azole exposure should be treated with a broadspectrum antifungal agent. An echinocandin (anidulafungin, caspofungin or micafungin) is preferred as initial therapy in these patients. Fluconazole, lipid formulations of amphotericin B and amphotericin B deoxycholate would be appropriate alternatives. However, the use of amphotericin B formulations may be limited by their toxicity, particularly in this critically ill population. In hemodynamically unstable patients with proven $\mathrm{C}$ parapsilosis $\mathrm{C} / \mathrm{IC}$, fluconazole, the lipid formulations of amphotericin B or amphotericin B deoxycholate are preferred.

Additional recommendations for the treatment of other clinical infections due to Candida species are provided in Table 7.

\section{FUTURE DIRECTIONS}

The recent addition of new agents to the antifungal armamentarium has provided solutions for circumventing the intrinsic side effects and toxicities associated with older antifungal agents, as well as a broader spectrum of antifungal activity against emerging resistant fungal pathogens. Efficient and appropriate use of antifungal agents will only evolve from future epidemiological observations designed to refine the riskbased preventive and therapeutic use of antifungal agents in patients vulnerable to IFI. Optimal use of combinations of antifungal classes needs to be further explored. Continuous efforts aimed at the development of enhanced, accurate and rapid tests for the diagnosis of IFI will inevitably contribute to the reduction of fungal-related morbidity and mortality.

POTENTIAL CONFLICTS OF INTEREST DECLARED BY WORKING GROUP MEMBERS: Eric Bow has received ongoing paid consultancy, speaker fees and travel assistance from Schering-Plough and Pfizer. Michel Laverdiere has received ongoing paid consultancy from Astellas, Merck Frosst, Pfizer and Schering, and speaker fees from Astellas, Merck Frosst, Pfizer, Schering and Bio-Rad Laboratories. Coleman Rotstein has received ongoing paid consultancy from Astellas, Merck Frosst, Pfizer, Schering and Wyeth, and speaker fees from Astellas, Bayer, Janssen-Ortho, Merck Pfizer, Schering and Wyeth. Jeff Fuller has received speaker fees from Abbott, Bayer, Merck, Schering-Plough and Wyeth, and travel assistance from Bayer, Merck Frosst and Pfizer. In addition, he has received research grants for projects outside the context of this article

\section{REFERENCES}

1. Pappas PG, Kauffman CA, Andes D, et al. Clinical practice guidelines for the management of candidiasis: 2009 update by the Infectious Diseases Society of America. Clin Infect Dis 2009;48:503-35.

2. Girmenia C, Barosi G, Aversa F, et al. Prophylaxis and treatment of invasive fungal diseases in allogeneic stem cell transplantation: Results of a consensus process by Gruppo Italiano Trapianto di Midollo Osseo (GITMO). Clin Infect Dis 2009;49:1226-36.

3. Denning DW, Kibbler CC, Barnes RA. British Society for Medical Mycology proposed standards of care for patients with invasive fungal infections. Lancet Infect Dis 2003;3:230-40.

4. Bohme A, Ruhnke M, Buchheidt D, et al. Treatment of invasive fungal infections in cancer patients - recommendations of the Infectious Diseases Working Party (AGIHO) of the German Society of Hematology and Oncology (DGHO). Ann Hematol 2009;88:97-110.

5. Fluckiger U, Marchetti O, Bille J, et al. Treatment options of invasive fungal infections in adults. Swiss Med Wkly 2006;136:447-63. from Bayer, Merck and Wyeth. Donald C Vinh is supported by a Canadian Institutes of Health Research fellowship and a National Institutes of Health supplemental visiting fellowship award. Peter Phillips has received ongoing paid consultancy and speaker fees from Astellas, Fujisawa, Merck, Pfizer and Schering. Stephen D Shafran has received ongoing paid consultancy from Abbott, Bristol-Myers Squibb, Gilead, Merck Frosst, Pfizer, Schering-Plough and Tibotec, and has been an external safety monitor for Virochem Pharma (now owned by Vertex). He has also received speaker fees from Abbott, Merck, Pfizer, Schering-Plough and Tibotec, and travel assistance from Abbott, Gilead, Merck, Roche and Schering-Plough. In addition, he has received an honorarium from Pfizer for conducting research related to material contained in this article. Don Sheppard has received ongoing paid consultancy and speaker fees from Astellas, Merck Frosst, Pfizer and Schering, and travel assistance from Merck Frosst. Sylvie Carle has received speaker fees from Merck Frosst and has participated in advisory board meetings for Pfizer and Wyeth. Gerald Evans and Robert P Rennie have no conflicts of interest to declare.

FINANCIAL SUPPORT: Financial assistance for the development of these guidelines was provided in the form of arm's-length grants-in-aid from Astellas Pharma Canada Inc, Enzon Pharmaceuticals Inc, Merck Frosst Canada Ltd and Pfizer Canada Inc. Sponsors were not involved in any aspect of the guidelines development, the literature interpretation, the decision to publish or any other aspect of publication of the guidelines. The funds were used for conference calls and for organization of and travel to meetings for the members of the Expert Author Working Group. None of the members of the author group received any financial or in-kind remuneration for their contribution to this work.

NOTE: Core Health Services Inc (Toronto, Ontario) kindly provided organizational and administrative assistance for the preparation of these guidelines, but was not involved in any aspect of the intellectual content or writing of the document. Core Health Services Inc declares no conflicts of interest.

ACKNOWLEDGEMENTS: The authors gratefully acknowledge Dr Annette Reboli, Dr Gary Garber, Dr Ethan Rubinstein and the AMMI Canada Guidelines Committee for their assistance and review of the guideline document.

6. Herbrecht R, Fluckiger U, Gachot B, Ribaud P, Thiebaut A, Cordonnier C. Treatment of invasive Candida and invasive Aspergillus infections in adult haematological patients. Eur J Cancer Suppl 2007;5:49-59.

7. Link $\mathrm{H}$, Bohme A, Cornely OA, et al. Antimicrobial therapy of unexplained fever in neutropenic patients - guidelines of the Infectious Diseases Working Party (AGIHO) of the German Society of Hematology and Oncology (DGHO), Study Group Interventional Therapy of Unexplained Fever, Arbeitsgemeinschaft Supportivmassnahmen in der Onkologie (ASO) of the Deutsche Krebsgesellschaft (DKG-German Cancer Society). Ann Hematol 2003;(82 Suppl 2):S105-S117.

8. Santolaya ME, Rabagliati R, Bidart T, et al. [Consensus: Rational approach towards the patient with cancer, fever and neutropenia.] Rev Chilena Infectol 2005;(22 Suppl 2):S79-S113.

9. Slavin MA, Szer J, Grigg AP, et al. Guidelines for the use of antifungal agents in the treatment of invasive Candida and mould infections. Intern Med J 2004;34:192-200. 
10. Montero JG, Gil CL. Resumen de las recomendaciones terapéuticas para infecciones fúngicas en el paciente crítico no neutropénico: Una visión multidisciplinar. Farmacia Hospitalaria 2005;29:283-9.

11. National Comprehensive Cancer Network. Prevention and treatment of cancer-related infections. National Comprehensive Cancer Network, 2007.

12. Jun HX, Zhixiang S, Chun W, et al. Clinical guidelines for the management of cancer patients with neutropenia and unexplained fever. Int J Antimicrob Agents 2005;(26 Suppl 2):S128-S132.

13. Gavalda J, Ruiz I. [Guidelines for the treatment of infection due to Aspergillus spp.] Enferm Infecc Microbiol Clin 2003;21:571-8.

14. The Canadian Task Force on the Periodic Health Examination. The periodic health examination. Can Med Assoc J 1979;121:1193-254.

15. de Meyrick J. The Delphi method and health research. Health Edu 2003;103:7-16.

16. Zaoutis TE, Greves HM, Lautenbach E, Bilker WB, Coffin SE. Risk factors for disseminated candidiasis in children with candidemia. Pediatr Infect Dis J 2004;23:635-41.

17. Tortorano AM, Kibbler C, Peman J, Bernhardt H, Klingspor L, Grillot R. Candidemia in Europe: Epidemiology and resistance. Int J Antimicrob Agents 2006;27:359-66.

18. Wisplinghoff H, Seifert H, Tallent SM, Bischoff T, Wenzel RP, Edmond MB. Nosocomial bloodstream infections in pediatric patients in United States hospitals: Epidemiology, clinical features and susceptibilities. Pediatr Infect Dis J 2003;22:686-91.

19. Eggimann P, Garbino J, Pittet D. Epidemiology of Candida species infections in critically ill non-immunosuppressed patients. Lancet Infect Dis 2003;3:685-702.

20. Colombo AL, Nucci M, Park BJ, et al. Epidemiology of candidemia in Brazil: A nationwide sentinel surveillance of candidemia in eleven medical centers. J Clin Microbiol 2006;44:2816-23.

21. Laupland KB, Gregson DB, Church DL, Ross T, Elsayed S. Invasive Candida species infections: A 5 year population-based assessment. J Antimicrob Chemother 2005;56:532-7.

22. Almirante B, Rodriguez D, Park BJ, et al. Epidemiology and predictors of mortality in cases of Candida bloodstream infection: Results from population-based surveillance, Barcelona, Spain, from 2002 to 2003. J Clin Microbiol 2005;43:1829-35.

23. Shetty SS, Harrison LH, Hajjeh RA, et al. Determining risk factors for candidemia among newborn infants from population-based surveillance: Baltimore, Maryland, 1998-2000. Pediatr Infect Dis J 2005;24:601-4.

24. Arendrup MC, Fuursted K, Gahrn-Hansen B, et al. Seminational surveillance of fungemia in Denmark: Notably high rates of fungemia and numbers of isolates with reduced azole susceptibility. J Clin Microbiol 2005;43:4434-40.

25. Saiman L, Ludington E, Dawson JD, et al. Risk factors for Candida species colonization of neonatal intensive care unit patients. Pediatr Infect Dis J 2001;20:1119-24.

26. Marchetti O, Bille J, Fluckiger U, et al. Epidemiology of candidemia in Swiss tertiary care hospitals: secular trends, 1991-2000. Clin Infect Dis 2004:38:311-20.

27. Asmundsdottir LR, Erlendsdottir H, Gottfredsson M. Increasing incidence of candidemia: Results from a 20-year nationwide study in Iceland. J Clin Microbiol 2002;40:3489-92.

28. Karlowsky JA, Zhanel GG, Klym KA, Hoban DJ, Kabani AM. candidemia in a Canadian tertiary care hospital from 1976 to 1996. Diagn Microbiol Infect Dis 1997;29:5-9.

29. Wu CJ, Lee HC, Lee NY, et al. Predominance of Gram-negative bacilli and increasing antimicrobial resistance in nosocomial bloodstream infections at a university hospital in southern Taiwan, 1996-2003. J Microbiol Immunol Infect 2006;39:135-43.

30. Edmond MB, Wallace SE, McClish DK, Pfaller MA, Jones RN, Wenzel RP. Nosocomial bloodstream infections in United States hospitals: A three-year analysis. Clin Infect Dis 1999;29:239-44.

31. Pfaller MA, Diekema DJ. Epidemiology of invasive candidiasis: A persistent public health problem. Clin Microbiol Rev 2007;20:133-63.

32. Wisplinghoff H, Bischoff T, Tallent SM, Seifert H, Wenzel RP, Edmond MB. Nosocomial bloodstream infections in US hospitals: Analysis of 24,179 cases from a prospective nationwide surveillance study. Clin Infect Dis 2004;39:309-17.

33. Laupland KB, Kirkpatrick AW, Church DL, Ross T, Gregson DB. Intensive-care-unit-acquired bloodstream infections in a regional critically ill population. J Hosp Infect 2004;58:137-45.
34. Lyytikainen O, Lumio J, Sarkkinen H, Kolho E, Kostiala A, Ruutu P. Nosocomial bloodstream infections in Finnish hospitals during 1999-2000. Clin Infect Dis 2002;35:e14-e19.

35. Service PHL. Nosocomial infection national surveillance service: Surveillance of hospital-acquired bacteremia in English hospitals between 1997-2002. Public Health Laboratory Services, 2002.

36. Diekema DJ, Messer SA, Brueggemann AB, et al. Epidemiology of candidemia: 3-year results from the emerging infections and the epidemiology of Iowa organisms study. J Clin Microbiol 2002;40:1298-302.

37. Poikonen E, Lyytikainen O, Anttila VJ, Ruutu P. Candidemia in Finland, 1995-1999. Emerg Infect Dis 2003;9:985-90.

38. Sandven P, Bevanger L, Digranes A, Haukland HH, Mannsaker T, Gaustad P. 2006. Candidemia in Norway (1991 to 2003): Results from a nationwide study. J Clin Microbiol 44:1977-81.

39. Martin GS, Mannino DM, Eaton S, Moss M. The epidemiology of sepsis in the United States from 1979 through 2000. N Engl J Med 2003;348:1546-54.

40. Martin D, Persat F, Piens MA, Picot S. Candida species distribution in bloodstream cultures in Lyon, France, 1998-2001.

Eur J Clin Microbiol Infect Dis 2005;24:329-33.

41. San Miguel LG, Cobo J, Otheo E, Sanchez-Sousa A, Abraira V, Moreno S. Secular trends of candidemia in a large tertiary-care hospital from 1988 to 2000: Emergence of Candida parapsilosis. Infect Control Hosp Epidemiol 2005;26:548-52.

42. Garbino J, Kolarova L, Rohner P, Lew D, Pichna P, Pittet D. Secular trends of candidemia over 12 years in adult patients at a tertiary care hospital. Medicine (Baltimore) 2002;81:425-33.

43. Trick WE, Fridkin SK, Edwards JR, Hajjeh RA, Gaynes RP. Secular trend of hospital-acquired candidemia among intensive care unit patients in the United States during 1989-1999. Clin Infect Dis 2002;35:627-30.

44. Hachem R, Hanna H, Kontoyiannis D, Jiang Y, Raad I. The changing epidemiology of invasive candidiasis: Candida glabrata and Candida krusei as the leading causes of candidemia in hematologic malignancy. Cancer 2008;112:2493-9.

45. Viscoli C, Girmenia C, Marinus A, et al. Candidemia in cancer patients: A prospective, multicenter surveillance study by the Invasive Fungal Infection Group (IFIG) of the European Organization for Research and Treatment of Cancer (EORTC). Clin Infect Dis 1999;28:1071-9.

46. Rodriguez D, Almirante B, Park BJ, et al. Candidemia in neonatal intensive care units: Barcelona, Spain. Pediatr Infect Dis J 2006;25:224-9

47. Marr KA, Seidel K, White TC, Bowden RA. Candidemia in allogeneic blood and marrow transplant recipients: Evolution of risk factors after the adoption of prophylactic fluconazole. J Infect Dis 2000;181:309-16.

48. Laverdiere M, Rotstein C, Bow EJ, et al. Impact of fluconazole prophylaxis on fungal colonization and infection rates in neutropenic patients. The Canadian Fluconazole Study. J Antimicrob Chemother 2000;46:1001-8.

49. Testore GP, Falco F, Sarrecchia C, Sordillo P, Bontempo G, Andreoni M. Two-year surveillance on fluconazole susceptibility of Candida spp isolates in a general and university hospital in Rome. Diagn Microbiol Infect Dis 2001:41:23-7.

50. Abi-Said D, Anaissie E, Uzun O, Raad I, Pinzcowski H, Vartivarian S. The epidemiology of hematogenous candidiasis caused by different Candida species. Clin Infect Dis 1997;24:1122-8.

51. Chen S, Slavin M, Nguyen Q, et al. Active surveillance for candidemia, Australia. Emerg Infect Dis 2006;12:1508-16.

52. Tortorano AM, Peman J, Bernhardt H, et al. Epidemiology of candidemia in Europe: Results of 28-month European Confederation of Medical Mycology (ECMM) hospital-based surveillance study. Eur J Clin Microbiol Infect Dis 2004;23:317-22.

53. Hajjeh RA, Sofair AN, Harrison LH, et al. Incidence of bloodstream infections due to Candida species and in vitro susceptibilities of isolates collected from 1998 to 2000 in a population-based active surveillance program. J Clin Microbiol 2004;42:1519-27.

54. Sofair AN, Lyon GM, Huie-White S, et al. Epidemiology of community-onset candidemia in Connecticut and Maryland. Clin Infect Dis 2006;43:32-9.

55. Diekema DJ, MA Pfaller. Nosocomial candidemia: An ounce of prevention is better than a pound of cure. Infect Control Hosp Epidemiol 2004;25:624-6. 
56. Gudlaugsson $\mathrm{O}$, Gillespie S, Lee K, et al. Attributable mortality of nosocomial candidemia, revisited. Clin Infect Dis. 2003;37:1172-7.

57. Morgan J, Meltzer MI, Plikaytis BD, et al. Excess mortality, hospital stay, and cost due to candidemia: A case-control study using data from population-based candidemia surveillance. Infect Control Hosp Epidemiol 2005;26:540-7.

58. Rentz AM, Halpern MT, Bowden R. The impact of candidemia on length of hospital stay, outcome, and overall cost of illness. Clin Infect Dis 1998;27:781-8.

59. Zaoutis TE, Coffin SE, Chu JH, et al. Risk factors for mortality in children with candidemia. Pediatr Infect Dis J 2005;24:736-9.

60. Rotstein C, Cragin L, Laverdiere M, et al. Economic evaluation of voriconazole for the treatment of candidemia in Canadian patients. Can J Infect Dis Med Microbiol 2008;19:219-26.

61. Krause W, Matheis H, Wulf K. Fungaemia and funguria after oral administration of Candida albicans. Lancet 1969;1:598-9.

62. Lillegard JB, Sim RB, Thorkildson P, Gates MA, Kozel TR. Recognition of Candida albicans by mannan-binding lectin in vitro and in vivo. J Infect Dis 2006;193:1589-97.

63. Lee SJ, Gonzalez-Aseguinolaza G, Nussenzweig MC. Disseminated candidiasis and hepatic malarial infection in mannose-bindinglectin-A-deficient mice. Mol Cell Biol 2002;22:8199-203.

64. Edwards JE Jr, Gaither TA, O'Shea JJ, et al. Expression of specific binding sites on Candida with functional and antigenic characteristics of human complement receptors. J Immunol 1986;137:3577-83.

65. Kozel TR, Weinhold LC, Lupan DM. Distinct characteristics of initiation of the classical and alternative complement pathways by Candida albicans. Infect Immun 1996;64:3360-8.

66. Gelfand JA, Hurley DL, Fauci AS, Frank MM. Role of complement in host defense against experimental disseminated candidiasis. J Infect Dis 1978;138:9-16.

67. Kozel TR, MacGill RS, Percival A, Zhou Q. Biological activities of naturally occurring antibodies reactive with Candida albicans mannan. Infect Immun 2004;72:209-18.

68. Netea MG, Van der Graaf CA, Vonk AG, Verschueren I, van der Meer JW, Kullberg BJ. The role of toll-like receptor (TLR) 2 and TLR4 in the host defense against disseminated candidiasis. J Infect Dis 2002;185:1483-9.

69. Jouault T, Ibata-Ombetta S, Takeuchi O, et al. Candida albicans phospholipomannan is sensed through toll-like receptors. J Infect Dis 2003;188:165-72.

70. Netea MG, Sutmuller R, Hermann C, et al. Toll-like receptor 2 suppresses immunity against Candida albicans through induction of IL-10 and regulatory T cells. J Immunol 2004;172:3712-8.

71. Spellberg B, Johnston D, Phan QT, et al. Parenchymal organ, and not splenic, immunity correlates with host survival during disseminated candidiasis. Infect Immun 2003;71:5756-64.

72. Brown GD, Gordon S. Immune recognition. A new receptor for beta-glucans. Nature 2001;413:36-7.

73. McGreal EP, Rosas M, Brown GD, et al. The carbohydraterecognition domain of Dectin-2 is a C-type lectin with specificity for high mannose. Glycobiology 2006;16:422-30.

74. Cambi A, Gijzen K, de Vries JM, et al. The C-type lectin DC-SIGN (CD209) is an antigen-uptake receptor for Candida albicans on dendritic cells. Eur J Immunol 2002;33:532-8.

75. Baccarini M, Blasi E, Puccetti P, Bistoni F. Phagocytic killing of Candida albicans by different murine effector cells. Sabouraudia 1983;21:271-86.

76. Cohen MS, Isturiz RE, Malech HL, et al. Fungal infection in chronic granulomatous disease. The importance of the phagocyte in defense against fungi. Am J Med 1981;71:59-66.

77. Winkelstein JA, Marino MC, Johnston RB Jr, et al. Chronic granulomatous disease. Report on a national registry of 368 patients. Medicine (Baltimore) 2000;79:155-69.

78. Kim MH, Rodey GE, Good RA, Chilgren RA, Quie PG. Defective candidacidal capacity of polymorphonuclear leukocytes in chronic granulomatous disease of childhood. J Pediatr 1969;75:300-3.

79. Wysong DR, Christin L, Sugar AM, Robbins PW, Diamond RD. Cloning and sequencing of a Candida albicans catalase gene and effects of disruption of this gene. Infect Immun 1998;66:1953-61.

80. Tosado-Acevedo R, Toranzos GA, Alsina A. Extraction and purification of a catalase from Candida albicans. PR Health Sci J 1992;11:77-80.

81. Lorenz MC, Fink GR. The glyoxylate cycle is required for fungal virulence. Nature 2001;412:83-6.
82. Ibrahim AS, Filler SG, Sanglard D, Edwards JE Jr, Hube B. Secreted aspartyl proteinases and interactions of Candida albicans with human endothelial cells. Infect Immun 1998;66:3003-5.

83. Filler SG, Swerdloff JN, Hobbs C, Luckett PM. Penetration and damage of endothelial cells by Candida albicans. Infect Immun 1995;63:976-83.

84. Mayer CL, Filler SG, Edwards JE Jr. Candida albicans adherence to endothelial cells. Microvasc Res 1992;43:218-26.

85. Filler SG, Pfunder AS, Spellberg BJ, Spellberg JP, Edwards JE Jr. Candida albicans stimulates cytokine production and leukocyte adhesion molecule expression by endothelial cells. Infect Immun 1996;64:2609-17.

86. Cannom RR, French SW, Johnston D, Edwards JE Jr, Filler SG. Candida albicans stimulates local expression of leukocyte adhesion molecules and cytokines in vivo. J Infect Dis 2002;186:389-96.

87. Phan QT, Fratti RA, Prasadarao NV, Edwards JE Jr, Filler SG. $\mathrm{N}$-cadherin mediates endocytosis of Candida albicans by endothelial cells. J Biol Chem 2005;280:10455-61.

88. Ibrahim AS, Mirbod F, Filler S, et al. Evidence implicating phospholipase as a virulence factor of Candida albicans. Infect Immun 1995;63:1993-8.

89. Fu Y, Ibrahim AS, Fonzi W, Zhou X, Ramos CF, Ghannoum MA. Cloning and characterization of a gene (LIP1) which encodes a lipase from the pathogenic yeast Candida albicans. Microbiology 1997;143:331-40.

90. Tumbarello M, Posteraro B, Trecarichi EM, et al. Biofilm production by Candida species and inadequate antifungal therapy as predictors of mortality for patients with candidemia. J Clin Microbiol 2007;45:1843-50.

91. DeKruijff B, Demel RA. Polyene antibiotic-sterol interactions in membranes of Acholeplasma laidlawaii cells and lecithin liposomes. III. Molecular structure of the polyene antibiotic-cholesterol complexes. Biochim Biophys Acta 1974;339:57-70.

92. Holz RW. The effects of the polyene antibiotic nystatin and amphotericin B on thin lipid membranes. Ann NY Acad Sci 1974;235:469-79.

93. Kerridge D. The plasma membrane of Candida albicans and its role in the action of antifungal drugs. In: Gooday GW, Lloyd D, Trinci APJ, eds. The Eukaryotic Microbial Cell. Cambridge: Cambridge University Press, 1980.

94. Kerridge D. The protoplast membrane and antifungal drugs. In: Peberdy JF, Ferenczy I, eds. Fungal Protoplast Applications in Biochemistry and Genetics. New York: Marcel Dekker Inc, 1985.

95. Liao RS, Rennie RP, Talbot JA. Assessment of the effect of amphotericin B on the vitality of Candida albicans. Antimicrob Agents Chemother 1999;43:1034-41.

96. Liao RS, Rennie RP, Talbot JA. Sublethal injury and resuscitation of Candida albicans after amphotericin B treatment. Antimicrob Agents Chemother 2003;47:1200-6.

97. Bowden R, Chandrasekar P, White MH, et al. A double-blind, randomized, controlled trial of amphotericin $\mathrm{B}$ colloidal dispersion versus amphotericin $B$ for treatment of invasive aspergillosis in immunocompromised patients. Clin Infect Dis 2002;35:359-66.

98. Hitchcock CA, Dickinson K, Brown SB, Evans EG, Adams DJ. Interaction of azole antifungal antibiotics with cytochrome P-450-dependent 14 alpha-sterol demethylase purified from Candida albicans. Biochem J 1990;266:475-80.

99. Sanati H, Belanger P, Fratti R, Ghannoum M. A new triazole, voriconazole (UK-109,496), blocks sterol biosynthesis in Candida albicans and Candida krusei. Antimicrob Agents Chemother 1997;41:2492-6

100. Geber A, Hitchcock CA, Swartz JE, et al. Deletion of the Candida glabrata ERG3 and ERG11 genes: Effect on cell viability, cell growth, sterol composition, and antifungal susceptibility. Antimicrob Agents Chemother 1995;39:2708-17.

101. Sheehan DJ, Hitchcock CA, Sibley CM. Current and emerging azole antifungal agents. Clin Microbiol Rev 1999;12:40-79.

102. Beggs WH. Comparison of miconazole- and ketoconazole-induced release of $\mathrm{K}+$ from Candida species. J Antimicrob Chemother 1983;11:381-3.

103. Ghannoum MA, Spellberg BJ, Ibrahim AS, et al. Sterol composition of Cryptococcus neoformans in the presence and absence of fluconazole. Antimicrob Agents Chemother 1994:38:2029-33.

104. Vanden BH, Marichal P, Le JL, Coene MC, Gorrens J, Cools W. Effects of itraconazole on cytochrome P-450-dependent sterol 14 
alpha-demethylation and reduction of 3-ketosteroids in Cryptococcus neoformans. Antimicrob Agents Chemother 1993;37:2101-5.

105. Hoffman HL, Ernst EJ, Klepser ME. Novel triazole antifungal agents. Expert Opin Investig Drugs 2000;9:593-605.

106. Dodds Ashley ES, Alexander BD. Posaconazole. Drugs Today (Barc) 2005;41:393-400

107. Hector RF. Compounds active against cell walls of medically important fungi. Clin Microbiol Rev 1993;6:1-21.

108. Pfaller M, Riley J, Koerner T. Effects of cilofungin (LY121019) on carbohydrate and sterol composition of Candida albicans. Eur J Clin Microbiol Infect Dis 1989;8:1067-70.

109. Cassone A, Mason RE, Kerridge D. Lysis of growing yeast-form cells of Candida albicans by echinocandin: A cytological study. Sabouraudia 1982;19:97-110.

110. Denning DW. Echinocandin antifungal drugs. Lancet 2003;362:1142-51.

111. Polak A, Scholer HJ. Mode of action of 5-fluorocytosine and mechanisms of resistance. Chemotherapy 1975;21:113-30.

112. Diasio R, Bennett J, Myers C. Mode of action of 5-fluorocytosine. Biochim Biophys Acta 1978;27:703-7.

113. Michaelis S, Berkower C. Sequence comparison of yeast ATP-binding cassette proteins. Cold Spring Harb Symp Quant Biol 1995;60:291-307.

114. Dick JD, Merz WG, Saral R. Incidence of polyene-resistant yeasts recovered from clinical specimens. Antimicrob Agents Chemother 1980;18:158-63.

115. Orozco AS, Higginbotham LM, Hitchcock CA, et al. Mechanism of fluconazole resistance in Candida krusei. Antimicrob Agents Chemother 1998;42:2645-9.

116. Vanden BH, Marichal P, Odds FC, Le JL, Coene MC. Characterization of an azole-resistant Candida glabrata isolate. Antimicrob Agents Chemother 1992;36:2602-10.

117. White TC. Increased mRNA levels of ERG16, CDR, and MDR1 correlate with increases in azole resistance in Candida albicans isolates from a patient infected with human immunodeficiency virus. Antimicrob Agents Chemother 1997;41:1482-7.

118. Parkinson T, Falconer DJ, Hitchcock CA. Fluconazole resistance due to energy-dependent drug efflux in Candida glabrata. Antimicrob Agents Chemother 1995;39:1696-9.

119. Clark FS, Parkinson T, Hitchcock CA, Gow NA. Correlation between rhodamine 123 accumulation and azole sensitivity in Candida species: Possible role for drug efflux in drug resistance. Antimicrob Agents Chemother 1996;40:419-25.

120. Sanglard D, Kuchler K, Ischer F, Pagani JL, Monod M, Bille J. Mechanisms of resistance to azole antifungal agents in Candida albicans isolates from AIDS patients involve specific multidrug transporters. Antimicrob Agents Chemother 1995;39:2378-86.

121. Balashov SV, Park S, Perlin DS. Assessing resistance to the echinocandin antifungal drug caspofungin in Candida albicans by profiling mutations in FKS1. Antimicrob Agents Chemother 2006;50:2058-63.

122. Hakki M, Staab JF, Marr KA. Emergence of a Candida krusei isolate with reduced susceptibility to caspofungin during therapy. Antimicrob Agents Chemother 2006;50:2522-4.

123. Daneman N, Chan AK, Poutanen SM, Rennie R, Sand C, Porter S. The emergence of caspofungin resistance during treatment of recurrent Candida glabrata candidaemia. 16th European Congress on Clinical Microbiology and Infectious Diseases (ECCMID), 2006. (Abst)

124. Thompson GR III, Wiederhold NP, Vallor AC, Villareal NC, Lewis JS, Patterson TF. Development of caspofungin resistance following prolonged therapy for invasive candidiasis secondary to Candida glabrata infection. Antimicrob Agents Chemother 2008;52:3783-5.

125. Hernandez S, Lopez-Ribot JL, Najvar JK, McCarthy DI, Bocanegra R, Graybill JR. Caspofungin resistance in Candida albicans: Correlating clinical outcome with laboratory susceptibility testing of three isogenic isolates serially obtained from a patient with progressive Candida esophagitis. Antimicrob Agents Chemother 2004;48:1382-3.

126. Laverdiere M, Lalonde RG, Baril JG, Sheppard DC, Park S, Perlin DS. Progressive loss of echinocandin activity following prolonged use for treatment of Candida albicans oesophagitis. J Antimicrob Chemother 2006;57:705-8.

127. Iwata K. Drug resistance in human pathogenic fungi. Eur J Epidemiol 1992;8:407-21.
128. Whelan WL. The genetic basis of resistance to 5 -fluorocytosine in Candida species and Cryptococcus neoformans. Crit Rev Microbiol $1987 ; 15: 45-56$

129. CLSI. Reference method for broth dilution antifungal susceptibility testing of yeasts; third informational supplement. Wayne: Clinical and Laboratory Standards Institute, 2008.

130. Rex JH, Pfaller MA, Galgiani JN, et al. Development of interpretive breakpoints for antifungal susceptibility testing: Conceptual framework and analysis of in vitro-in vivo correlation data for fluconazole, itraconazole, and Candida infections. Subcommittee on Antifungal Susceptibility Testing of the National Committee for Clinical Laboratory Standards. Clin Infect Dis 1997;24:235-47.

131. Pfaller MA, Diekema DJ, Rex JH, et al. Correlation of MIC with outcome for Candida species tested against voriconazole: Analysis and proposal for interpretive breakpoints. J Clin Microbiol 2006;44:819-26.

132. Pfaller MA, Diekema DJ, Sheehan DJ. Interpretive breakpoints for fluconazole and Candida revisited: A blueprint for the future of antifungal susceptibility testing. Clin Microbiol Rev 2006;19:435-47.

133. Alexander BD, Schell WA, Miller JL, Long GD, Perfect JR. Candida glabrata fungemia in transplant patients receiving voriconazole after fluconazole. Transplantation 2005;80:868-71.

134. Magill SS, Shields C, Sears CL, Choti M, Merz WG. Triazole cross-resistance among Candida spp.: Case report, occurrence among bloodstream isolates, and implications for antifungal therapy. J Clin Microbiol 2006;44:529-35.

135. Panackal AA, Gribskov JL, Staab JF, Kirby KA, Rinaldi M, Marr KA. Clinical significance of azole antifungal drug cross-resistance in Candida glabrata. J Clin Microbiol 2006;44:1740-3.

136. Pfaller MA, Diekema DJ, Messer SA, Boyken L, Hollis RJ. Activities of fluconazole and voriconazole against 1,586 recent clinical isolates of Candida species determined by Broth microdilution, disk diffusion, and Etest methods: Report from the ARTEMIS Global Antifungal Susceptibility Program, 2001. J Clin Microbiol 2003;41:1440-6.

137. Pfaller MA, Messer SA, Boyken L, Huynh H, Hollis RJ, Diekema DJ. In vitro activities of 5 -fluorocytosine against 8,803 clinical isolates of Candida spp.: Global assessment of primary resistance using National Committee for Clinical Laboratory Standards susceptibility testing methods. Antimicrob Agents Chemother 2002;46:3518-21.

138. Ostrosky-Zeichner L, Rex JH, Pappas PG, et al. Antifungal susceptibility survey of 2,000 bloodstream Candida isolates in the United States. Antimicrob Agents Chemother 2003;47:3149-54.

139. Pfaller MA, Diekema DJ. Role of sentinel surveillance of candidemia: Trends in species distribution and antifungal susceptibility. J Clin Microbiol 2002;40:3551-7.

140. Pfaller MA, Diekema DJ. Twelve years of fluconazole in clinical practice: Global trends in species distribution and fluconazole susceptibility of bloodstream isolates of Candida. Clin Microbiol Infect 2004;(10 Suppl 1):11-23.

141. Pfaller MA, Messer SA, Boyken L, et al. In vitro activities of voriconazole, posaconazole, and fluconazole against 4,169 clinical isolates of Candida spp. and Cryptococcus neoformans collected during 2001 and 2002 in the ARTEMIS global antifungal surveillance program. Diagn Microbiol Infect Dis 2004;48:201-5.

142. Pfaller MA, Messer SA, Boyken L, Tendolkar S, Hollis RJ, Diekema DJ. Variation in susceptibility of bloodstream isolates of Candida glabrata to fluconazole according to patient age and geographic location. J Clin Microbiol 2003;41:2176-9.

143. Pfaller MA, Diekema DJ, Gibbs DL, et al. Results from the ARTEMIS DISK Global Antifungal Surveillance study, 1997 to 2005: An 8.5-year analysis of susceptibilities of Candida species and other yeast species to fluconazole and voriconazole determined by CLSI standardized disk diffusion testing. J Clin Microbiol 2007;45:1735-45.

144. Pfaller MA, Boyken L, Hollis RJ, Messer SA, Tendolkar S, Diekema DJ. In vitro susceptibilities of clinical isolates of Candida species, Cryptococcus neoformans, and Aspergillus species to itraconazole: Global survey of 9,359 isolates tested by clinical and laboratory standards institute broth microdilution methods. J Clin Microbiol 2005;43:3807-10.

145. Pfaller MA, Messer SA, Boyken L, et al. Use of fluconazole as a surrogate marker to predict susceptibility and resistance to voriconazole among 13,338 clinical isolates of Candida spp. 
Tested by clinical and laboratory standards institute-recommended broth microdilution methods. J Clin Microbiol 2007;45:70-5.

146. Park BJ, Arthington-Skaggs BA, Hajjeh RA, et al. Evaluation of amphotericin B interpretive breakpoints for Candida bloodstream isolates by correlation with therapeutic outcome. Antimicrob Agents Chemother 2006;50:1287-92.

147. Yang YL, Li SY, Cheng HH, Lo HJ. Susceptibilities to amphotericin B and fluconazole of Candida species in TSARY 2002. Diagn Microbiol Infect Dis 2005;51:179-83.

148. Spellberg BJ, Filler SG, Edwards JE Jr. Current treatment strategies for disseminated candidiasis. Clin Infect Dis 2006;42:244-51.

149. Krogh-Madsen M, Arendrup MC, Heslet L, Knudsen JD. Amphotericin B and caspofungin resistance in Candida glabrata isolates recovered from a critically ill patient. Clin Infect Dis 2006;42:938-44.

150. Pfaller MA, Boyken L, Messer SA, Tendolkar S, Hollis RJ, Diekema DJ. Evaluation of the etest method using Mueller-Hinton agar with glucose and methylene blue for determining amphotericin B MICs for 4,936 clinical isolates of Candida species. J Clin Microbiol 2004:42:4977-9.

151. Pfaller MA, Messer SA, Boyken L, Tendolkar S, Hollis RJ, Diekema DJ. Geographic variation in the susceptibilities of invasive isolates of Candida glabrata to seven systemically active antifungal agents: A global assessment from the ARTEMIS Antifungal Surveillance Program conducted in 2001 and 2002. J Clin Microbiol 2004;42:3142-6.

152. Pappas PG, Rex JH, Sobel JD, et al. Guidelines for treatment of candidiasis. Clin Infect Dis 2004;38:161-89.

153. Pfaller MA, Diekema DJ, Ostrosky-Zeichner L, et al. Correlation of MIC with outcome for Candida species tested against caspofungin, anidulafungin, and micafungin: Analysis and proposal for interpretive MIC breakpoints. J Clin Microbiol 2008;46:2620-9.

154. Kartsonis N, Killar J, Mixson L, et al. Caspofungin susceptibility testing of isolates from patients with esophageal candidiasis or invasive candidiasis: Relationship of MIC to treatment outcome. Antimicrob Agents Chemother 2005;49:3616-23.

155. Pfaller MA, Boyken L, Hollis RJ, Messer SA, Tendolkar S, Diekema DJ. In vitro susceptibilities of Candida spp. to caspofungin: Four years of global surveillance. J Clin Microbiol 2006;44:760-3.

156. Ernst EJ, Klepser ME, Pfaller MA. Postantifungal effects of echinocandin, azole, and polyene antifungal agents against Candida albicans and Cryptococcus neoformans. Antimicrob Agents Chemother 2000;44:1108-11.

157. Pfaller MA, Messer SA, Boyken L, et al. Further standardization of broth microdilution methodology for in vitro susceptibility testing of caspofungin against Candida species by use of an international collection of more than 3,000 clinical isolates. J Clin Microbiol 2004:42:3117-9.

158. Mora-Duarte J, Betts R, Rotstein C, et al. Comparison of caspofungin and amphotericin B for invasive candidiasis. N Engl J Med 2002;347:2020-9.

159. Odds FC, Motyl M, Andrade R, et al. Interlaboratory comparison of results of susceptibility testing with caspofungin against Candida and Aspergillus species. J Clin Microbiol 2004;42:3475-82.

160. Nivoix Y, Leveque D, Herbrecht R, Koffel JC, Beretz L, Ubeaud-Sequier $\mathrm{G}$. The enzymatic basis of drug-drug interactions with systemic triazole antifungals. Clin Pharmacokinet 2008;47:779-92.

161. Dodds Ashley E, Lewis R, Lewis J, Martin C, Andes D. Pharmacology of systemic antifungal agents. Clin Infect Dis 2006;43:S28-S39.

162. Goodwin ML, Drew RH. Antifungal serum concentration monitoring: An update. J Antimicrob Chemother 2008;61:17-25.

163. Smith J. Pharmacokinetics of antifungals: Implications for drug selection (drug overview). Infect Med 2006;23:328-33.

164. Black KE, Baden LR. Fungal infections of the CNS: Treatment strategies for the immunocompromised patient. CNS Drugs 2007;21:293-318

165. Louria DB, Stiff DP, Bennett B. Disseminated moniliasis in the adult. Medicine (Baltimore) 1962;41:307-37.

166. Gaines JD, Remington JS. Disseminated candidiasis in the surgical patient. Surgery 1972;72:730-6.

167. Ascioglu S, Rex JH, De PB, et al. Defining opportunistic invasive fungal infections in immunocompromised patients with cancer and hematopoietic stem cell transplants: An international consensus. Clin Infect Dis 2002;34:7-14.
168. Berenguer J, Buck M, Witebsky F, Stock F, Pizzo PA, Walsh TJ. Lysis-centrifugation blood cultures in the detection of tissue-proven invasive candidiasis. Disseminated versus single-organ infection. Diagn Microbiol Infect Dis 1993;17:103-9.

169. Pfaller MA, Houston A, Coffmann S. Application of CHROMagar Candida for rapid screening of clinical specimens for Candida albicans, Candida tropicalis, Candida krusei, and Candida (Torulopsis) glabrata. J Clin Microbiol 1996;34:58-61.

170. Cardenes CD, Carrillo AJ, Arias A, et al. Comparison of albicans ID2 agar plate with the germ tube for presumptive identification of Candida albicans. Diagn Microbiol Infect Dis 2002;42:181-5.

171. Wilson DA, Joyce MJ, Hall LS, et al. Multicenter evaluation of a Candida albicans peptide nucleic acid fluorescent in situ hybridization probe for characterization of yeast isolates from blood cultures. J Clin Microbiol 43:2909-12.

172. Sheppard DC, Locas MC, Restieri C, Laverdiere M. Utility of the germ tube test for direct identification of Candida albicans from positive blood culture bottles. J Clin Microbiol 2008;46:3508-9.

173. Terlecka JA, du Cros PA, Orla MC, Spelman D. Rapid differentiation of Candida albicans from non-albicans species by germ tube test directly from BacTAlert blood culture bottles. Mycoses 2007;50:48-51.

174. Solomkin JS, Flohr AM, Simmons RL. Indications for therapy for fungemia in postoperative patients. Arch Surg 1982;117:1272-5.

175. Martino P, Girmenia C, Micozzi A, et al. Fungemia in patients with leukemia. Am J Med Sci 1993;306:225-32.

176. Golan Y, Wolf MP, Pauker SG, Wong JB, Hadley S. Empirical anti-Candida therapy among selected patients in the intensive care unit: A cost-effectiveness analysis. Ann Intern Med 2005;143:857-69.

177. Pittet D, Garbino J. Fungal infections in the critically ill. Curr Opin Crit Care 1995;1:369-80.

178. Kontoyiannis DP, Luna MA, Samuels BI, Bodey GP. Hepatosplenic candidiasis. A manifestation of chronic disseminated candidiasis. Infect Dis Clin North Am 2000;14:721-39.

179. Masood A, Sallah S. Chronic disseminated candidiasis in patients with acute leukemia: Emphasis on diagnostic definition and treatment. Leuk Res 2005;29:493-501.

180. Yeo SF, Wong B. Current status of nonculture methods for diagnosis of invasive fungal infections. Clin Microbiol Rev 2002;15:465-84.

181. Phillips P, Dowd A, Jewesson P, et al. Nonvalue of antigen detection immunoassays for diagnosis of candidemia. J Clin Microbiol 1990;28:2320-6.

182. Bougnoux ME, Hill C, Moissenet D, et al. Comparison of antibody, antigen, and metabolite assays for hospitalized patients with disseminated or peripheral candidiasis. J Clin Microbiol 1990;28:905-9.

183. Morace G, Pagano L, Sanguinetti M, et al. PCR-restriction enzyme analysis for detection of Candida DNA in blood from febrile patients with hematological malignancies. J Clin Microbiol 1999;37:1871-5.

184. Alexander BD. Diagnosis of fungal infection: New technologies for the mycology laboratory. Transpl Infect Dis 2002;(4 Suppl 3):32-7.

185. Walsh TJ, Hathorn JW, Sobel JD, et al. Detection of circulating Candida enolase by immunoassay in patients with cancer and invasive candidiasis. N Engl J Med 1991;324:1026-31.

186. Mitsutake K, Miyazaki T, Tashiro T, et al. Enolase antigen, mannan antigen, Cand-Tec antigen, and beta-glucan in patients with candidemia. J Clin Microbiol 1996;34:1918-21.

187. Sendid B, Caillot D, Baccouch-Humbert B, et al. Contribution of the Platelia Candida-specific antibody and antigen tests to early diagnosis of systemic Candida tropicalis infection in neutropenic adults. J Clin Microbiol 2003;41:4551-8.

188. Senn L, Robinson JO, Schmidt S, et al. 1,3-Beta-D-glucan antigenemia for early diagnosis of invasive fungal infections in neutropenic patients with acute leukemia. Clin Infect Dis 2008;46:878-85.

189. Odabasi Z, Mattiuzzi G, Estey E, et al. Beta-D-glucan as a diagnostic adjunct for invasive fungal infections: Validation, cutoff development, and performance in patients with acute myelogenous leukemia and myelodysplastic syndrome. Clin Infect Dis 2004:39:199-205.

190. Ostrosky-Zeichner L, Alexander BD, Kett DH, et al. Multicenter clinical evaluation of the (1-->3) beta-D-glucan assay as an aid to 
diagnosis of fungal infections in humans. Clin Infect Dis 2005;41:654-9.

191. Pickering JW, Sant HW, Bowles CA, Roberts WL, Woods GL. Evaluation of a (1->3)-beta-D-glucan assay for diagnosis of invasive fungal infections. J Clin Microbiol 2005;43:5957-62.

192. Fridkin SK. Candidemia is costly - plain and simple. Clin Infect Dis 2005;41:1240-1.

193. Voss A, Hollis RJ, Pfaller MA, Wenzel RP, Doebbeling BN. Investigation of the sequence of colonization and candidemia in nonneutropenic patients. J Clin Microbiol 1994;32:975-80.

194. Nucci M, Anaissie E. Revisiting the source of candidemia: Skin or gut? Clin Infect Dis 2001;33:1959-67.

195. Cole GT, Halawa AA, Anaissie EJ. The role of the gastrointestinal tract in hematogenous candidiasis: From the laboratory to the bedside. Clin Infect Dis 1996;(22 Suppl 2):S73-S88.

196. Martino P, Girmenia C, Micozzi A, De BF, Boccanera M, Cassone A. Prospective study of Candida colonization, use of empiric amphotericin B and development of invasive mycosis in neutropenic patients. Eur J Clin Microbiol Infect Dis 1994;13:797-804.

197. Martino P, Girmenia C, Venditti M, et al. Candida colonization and systemic infection in neutropenic patients. A retrospective study. Cancer 1989;64:2030-4.

198. Lass-Florl C, Gunsilius E, Gastl G, et al. Fungal colonization in neutropenic patients: A randomized study comparing itraconazole solution and amphotericin B solution. Ann Hematol 2003;82:565-9.

199. Pittet D, Monod M, Suter PM, Frenk E, Auckenthaler R. Candida colonization and subsequent infections in critically ill surgical patients. Ann Surg 1994;220:751-8.

200. Reagan DR, Pfaller MA, Hollis RJ, Wenzel RP. Characterization of the sequence of colonization and nosocomial candidemia using DNA fingerprinting and a DNA probe. J Clin Microbiol 1990;28:2733-8.

201. Chen YC, Chang SC, Tai HM, Hsueh PR, Luh KT. Molecular epidemiology of Candida colonizing critically ill patients in intensive care units. J Formos Med Assoc 2001;100:791-7.

202. Pittet D, Monod M, Filthuth I, Frenk E, Suter PM, Auckenthaler R. Contour-clamped homogeneous electric field gel electrophoresis as a powerful epidemiologic tool in yeast infections. Am J Med 1991;91:256S-263S.

203. Cerikcioglu N, Ilki A, Bilgen H, Ozek E, Metin F, Kalaca S. The relationships between candidemia and candidal colonization and virulence factors of the colonizing strains in preterm infants. Turk J Pediatr 2004;46:245-50.

204. Fanello S, Bouchara JP, Jousset N, Delbos V, LeFlohic AM. Nosocomial Candida albicans acquisition in a geriatric unit: Epidemiology and evidence for person-to-person transmission. J Hosp Infect 2001;47:46-52.

205. Betremieux P, Chevrier S, Quindos G, Sullivan D, Polonelli L, Guiguen C. Use of DNA fingerprinting and biotyping methods to study a Candida albicans outbreak in a neonatal intensive care unit. Pediatr Infect Dis J 1994;13:899-905.

206. Huang YC, Lin TY, Leu HS, Peng HL, Wu JH, Chang HY. Outbreak of Candida parapsilosis fungemia in neonatal intensive care units: Clinical implications and genotyping analysis. Infection 1999;27:97-102.

207. Huang YC, Lin TY, Peng HL, Wu JH, Chang HY, Leu HS, Outbreak of Candida albicans fungaemia in a neonatal intensive care unit. Scand J Infect Dis 1998;30:137-42.

208. Barchiesi F, Caggiano G, Falconi Di Francesco L, Montagna MT, Barbuti S, Scalise G. Outbreak of fungemia due to Candida parapsilosis in a pediatric oncology unit. Diagn Microbiol Infect Dis 2004:49:269-71.

209. Posteraro B, Bruno S, Boccia S, et al. Candida parapsilosis bloodstream infection in pediatric oncology patients: Results of an epidemiologic investigation. Infect Control Hosp Epidemiol 2004;25:641-5.

210. Diekema DJ, Messer SA, Hollis RJ, Wenzel RP, Pfaller MA. An outbreak of Candida parapsilosis prosthetic valve endocarditis. Diagn Microbiol Infect Dis 1997;29:147-53.

211. Lupetti A, Tavanti A, Davini P, et al. Horizontal transmission of Candida parapsilosis candidemia in a neonatal intensive care unit. J Clin Microbiol 2002;40:2363.

212. Clark TA, Slavinski SA, Morgan J, et al. Epidemiologic and molecular characterization of an outbreak of Candida parapsilosis bloodstream infections in a community hospital. J Clin Microbiol 2004:42:4468-72.
213. Pertowski CA, Baron RC, Lasker BA, Werner SB, Jarvis WR. Nosocomial outbreak of Candida albicans sternal wound infections following cardiac surgery traced to a scrub nurse. J Infect Dis 1995;172:817-22.

214. Strausbaugh LJ, Sewell DL, Ward TT, Pfaller MA, Heitzman T, Tjoelker R. High frequency of yeast carriage on hands of hospital personnel. J Clin Microbiol 1994;32:2299-300.

215. Huang YC, Lin TY, Leu HS, Wu JL, Wu JH. Yeast carriage on hands of hospital personnel working in intensive care units. J Hosp Infect 1998;39:47-51.

216. Trick WE, Vernon MO, Hayes RA, et al. Impact of ring wearing on hand contamination and comparison of hand hygiene agents in a hospital. Clin Infect Dis 2003;36:1383-90.

217. Traore O, Springthorpe VS, Sattar SA. A quantitative study of the survival of two species of Candida on porous and non-porous environmental surfaces and hands. J Appl Microbiol 2002;92:549-55.

218. Bart-Delabesse E, van Deventer H, Goessens W, et al. Contribution of molecular typing methods and antifungal susceptibility testing to the study of a candidemia cluster in a burn care unit. J Clin Microbiol 1995;33:3278-83.

219. Sherertz RJ, Gledhill KS, Hampton KD, et al. Outbreak of Candida bloodstream infections associated with retrograde medication administration in a neonatal intensive care unit. J Pediatr 1992;120:455-61.

220. Zancope-Oliveira RM, James MJ, Derossi AP, et al. Strain characterization of Candida parapsilosis fungemia by molecular typing methods. Eur J Clin Microbiol Infect Dis 2000;19:514-20.

221. Yagupsky P, Dagan R, Chipman M, Goldschmied-Reouven A, Zmora E, Karplus M. Pseudooutbreak of Candida guilliermondii fungemia in a neonatal intensive care unit. Pediatr Infect Dis J 1991;10:928-32.

222. Welbel SF, McNeil MM, Kuykendall RJ, et al. Candida parapsilosis bloodstream infections in neonatal intensive care unit patients: Epidemiologic and laboratory confirmation of a common source outbreak. Pediatr Infect Dis J 1996;15:998-1002.

223. Sanchez V, Vazquez JA, Barth-Jones D, Dembry L, Sobel JD, Zervos MJ. Nosocomial acquisition of Candida parapsilosis: An epidemiologic study. Am J Med 1993;94:577-82.

224. Vazquez JA, Dembry LM, Sanchez V, et al. Nosocomial Candida glabrata colonization: An epidemiologic study. J Clin Microbiol 1998;36:421-6.

225. Vazquez JA, Sanchez V, Dmuchowski C, Dembry LM, Sobel JD, Zervos MJ. Nosocomial acquisition of Candida albicans: An epidemiologic study. J Infect Dis 1993;168:195-201.

226. Chowdhary A, Becker K, Fegeler W, et al. An outbreak of candidemia due to Candida tropicalis in a neonatal intensive care unit. Mycoses 2003;46:287-92.

227. Doi M, Homma M, Iwaguchi S, Horibe K, Tanaka K. Strain relatedness of Candida albicans strains isolated from children with leukemia and their bedside parents. J Clin Microbiol 1994;32:2253-9.

228. Marco F, Lockhart SR, Pfaller MA, et al. Elucidating the origins of nosocomial infections with Candida albicans by DNA fingerprinting with the complex probe Ca3. J Clin Microbiol 1999;37:2817-28.

229. Verduyn Lunel FM, Meis JF, Voss A. Nosocomial fungal infections: Candidemia. Diagn Microbiol Infect Dis 1999;34:213-20.

230. Hedderwick SA, Lyons MJ, Liu M, Vazquez JA, Kauffman CA. Epidemiology of yeast colonization in the intensive care unit. Eur J Clin Microbiol Infect Dis 2000;19:663-70.

231. Barchiesi F, Hollis RJ, Del PM, et al. Transmission of fluconazole-resistant Candida albicans between patients with AIDS and oropharyngeal candidiasis documented by pulsed-field gel electrophoresis. Clin Infect Dis 1995;21:561-4.

232. Berger C, Frei R, Gratwohl A, Scheidegger C. Bottled lemon juice a cryptic source of invasive Candida infections in the immunocompromised host. J Infect Dis 1988;158:654-5.

233. Charles PE, Dalle F, Aube H, et al. Candida spp. colonization significance in critically ill medical patients: A prospective study. Intensive Care Med 2005;31:393-400.

234. Garcia-San ML, Cobo J, Martos I, et al. Risk factors for candidemia in pediatric patients with congenital heart disease. Infect Control Hosp Epidemiol 2006;27:576-80.

235. Nucci M, Colombo AL. Risk factors for breakthrough candidemia. Eur J Clin Microbiol Infect Dis 2002;21:209-11. 
236. Wey SB, Mori M, Pfaller MA, Woolson RF, Wenzel RP. Risk factors for hospital-acquired candidemia. A matched case-control study. Arch Intern Med 1989;149:2349-53.

237. Wenzel RP. Nosocomial candidemia: Risk factors and attributable mortality. Clin Infect Dis 1995;20:1531-4.

238. Kollef MH. Is antibiotic cycling the answer to preventing the emergence of bacterial resistance in the intensive care unit? Clin Infect Dis 2006;(43 Suppl 2):S82-S88.

239. Piarroux R, Grenouillet F, Balvay P, et al. Assessment of preemptive treatment to prevent severe candidiasis in critically ill surgical patients. Crit Care Med 2004;32:2443-9.

240. Leon C, Ruiz-Santana S, Saavedra P, et al. A bedside scoring system ("Candida score") for early antifungal treatment in nonneutropenic critically ill patients with Candida colonization. Crit Care Med 2006;34:730-7.

241. Paphitou NI, Ostrosky-Zeichner L, Rex JH. Rules for identifying patients at increased risk for candidal infections in the surgical intensive care unit: Approach to developing practical criteria for systematic use in antifungal prophylaxis trials. Med Mycol 2005;43:235-43.

242. Dupont H, Bourichon A, Paugam-Burtz C, Mantz J, Desmonts JM. Can yeast isolation in peritoneal fluid be predicted in intensive care unit patients with peritonitis? Crit Care Med 2003;31:752-7.

243. Ostrosky-Zeichner L, Sable C, Sobel J, et al. Multicenter retrospective development and validation of a clinical prediction rule for nosocomial invasive candidiasis in the intensive care setting. Eur J Clin Microbiol Infect Dis 2007;26:271-6.

244. Rho J, Shin JH, Song JW, et al. Molecular investigation of two consecutive nosocomial clusters of Candida tropicalis candiduria using pulsed-field gel electrophoresis. J Microbiol 2004;42:80-6.

245. Jang SJ, Han HL, Lee SH, et al. PFGE-based epidemiological study of an outbreak of Candida tropicalis candiduria: The importance of medical waste as a reservoir of nosocomial infection. Jpn J Infect Dis 2005;58:263-7.

246. Pittet D, Allegranzi B, Boyce J. The World Health Organization guidelines on hand hygiene in health care and their consensus recommendations. Infect Control Hosp Epidemiol 2009;30:611-22.

247. McGinley KJ, Larson EL, Leyden JJ. Composition and density of microflora in the subungual space of the hand. J Clin Microbiol 1988;26:950-3.

248. Hedderwick SA, McNeil SA, Lyons MJ, Kauffman CA. Pathogenic organisms associated with artificial fingernails worn by healthcare workers. Infect Control Hosp Epidemiol 2000;21:505-9.

249. McNeil SA, Foster CL, Hedderwick SA, Kauffman CA. Effect of hand cleansing with antimicrobial soap or alcohol-based gel on microbial colonization of artificial fingernails worn by health care workers. Clin Infect Dis 2001;32:367-72.

250. Ostrosky-Zeichner L. Prophylaxis or preemptive therapy of invasive candidiasis in the intensive care unit? Crit Care Med 2004:32:2552-3.

251. Vos MC, Endtz HP, Horst-Kreft D, et al. Candida krusei transmission among hematology patients resolved by adapted antifungal prophylaxis and infection control measures. J Clin Microbiol 2006;44:1111-4.

252. Kojic EM, Darouiche RO. Candida infections of medical devices. Clin Microbiol Rev 2004;17:255-67.

253. McGee DC, Gould MK. Preventing complications of central venous catheterization. N Engl J Med 2003;348:1123-33.

254. O'Grady NP, Alexander M, Dellinger EP, et al. Guidelines for the prevention of intravascular catheter-related infections. Centers for Disease Control and Prevention. MMWR Recomm Rep 2002;51:1-29.

255. Mermel LA, Farr BM, Sherertz RJ, et al. Guidelines for the management of intravascular catheter-related infections. Infect Control Hosp Epidemiol 2001;22:222-42.

256. Wolf HH, Leithauser M, Maschmeyer G, et al. Central venous catheter-related infections in hematology and oncology: Guidelines of the Infectious Diseases Working Party (AGIHO) of the German Society of Hematology and Oncology (DGHO). Ann Hematol 2008;87:863-76.

257. Yamamura DL, Rotstein C, Nicolle LE, Ioannou S. Candidemia at selected Canadian sites: Results from the Fungal Disease Registry, 1992-1994. Fungal Disease Registry of the Canadian Infectious Disease Society. CMAJ 1999;160:493-9.
258. Pizzo PA, Robichaud KJ, Gill FA, Witebsky FG. Empiric antibiotic and antifungal therapy for cancer patients with prolonged fever and granulocytopenia. Am J Med 1982;72:101-11.

259. EORTC International Antimicrobial Therapy Cooperative Group. Empiric antifungal therapy in febrile granulocytopenic patients. Am J Med 1989;86:668-72.

260. Baden LR. Prophylactic antimicrobial agents and the importance of fitness. N Engl J Med 2005;353:1052-4

261. Blijlevens NM, Donnelly JP, de Pauw BE. Impaired gut function as risk factor for invasive candidiasis in neutropenic patients. $\mathrm{Br} \mathrm{J}$ Haematol 2002;117:259-64.

262. Donnelly JP, Blijlevens NM, Verhagen CA. Can anything be done about oral mucositis? Ann Oncol 2003;14:505-7.

263. Trifilio S, Verma A, Mehta J. Antimicrobial prophylaxis in hematopoietic stem cell transplant recipients: Heterogeneity of current clinical practice. Bone Marrow Transpl 2004;33:735-9.

264. Imataki O, Kami M, Kim SW, et al. A nationwide survey of deep fungal infections and fungal prophylaxis after hematopoietic stem cell transplantation in Japan. Bone Marrow Transpl 2004:33:1173-9.

265. Maertens J. Evaluating prophylaxis of invasive fungal infections in patients with haematologic malignancies. Eur J Haematol 2007;78:275-82.

266. Maertens JA, Frere P, Lass-Florl C, Heinz W, Cornely OA. Primary antifungal prophylaxis in leukaemia patients. Eur J Cancer Suppl 2007;5:43-8.

267. Bow EJ, Laverdiere M, Lussier N, Rotstein C, Cheang MS, Ioannou S. Antifungal prophylaxis for severely neutropenic chemotherapy recipients: A meta analysis of randomized-controlled clinical trials. Cancer 2002;94:3230-46.

268. Glasmacher A, Prentice A, Gorschluter M, et al. Itraconazole prevents invasive fungal infections in neutropenic patients treated for hematologic malignancies: Evidence from a meta-analysis of 3,597 patients. J Clin Oncol 2003;21:4615-26.

269. Wingard JR, Carter CL, Walsh TJ, et al. Results of a randomized, double-blind trial of fluconazole (FLU) vs. voriconazole (VORI) for the prevention of invasive fungal infections (IFI) in 600 allogeneic blood and marrow transplant (BMT) patients. Blood 2007;110:55a. (Abst)

270. Vehreschild JJ, Bohme A, Buchheidt D, et al. A double-blind trial on prophylactic voriconazole (VRC) or placebo during induction chemotherapy for acute myelogenous leukaemia (AML). J Infect 2007;55:445-9.

271. Cornely OA, Maertens J, Winston DJ, et al. Posaconazole vs. fluconazole or itraconazole prophylaxis in patients with neutropenia. N Engl J Med 2007;356:348-59.

272. Ullmann AJ, Lipton JH, Vesole DH, et al. Posaconazole or fluconazole for prophylaxis in severe graft-versus-host disease. N Engl J Med 2007;356:335-47.

273. van Burik JA, Ratanatharathorn V, Stepan DE, et al. Micafungin versus fluconazole for prophylaxis against invasive fungal infections during neutropenia in patients undergoing hematopoietic stem cell transplantation. Clin Infect Dis 2004:39:1407-16.

274. Mattiuzzi GN, Alvarado G, Giles FJ, et al. Open-label, randomized comparison of itraconazole versus caspofungin for prophylaxis in patients with hematologic malignancies. Antimicrob Agents Chemother 2006:50:143-7.

275. Marr KA, Crippa F, Leisenring W, et al. Itraconazole versus fluconazole for prevention of fungal infections in patients receiving allogeneic stem cell transplants. Blood 2004;103:1527-33.

276. Rotstein C, Bow EJ, Laverdiere M, Ioannou S, Carr D, Moghaddam N. Randomized placebo-controlled trial of fluconazole prophylaxis for neutropenic cancer patients: Benefit based on purpose and intensity of cytotoxic therapy. The Canadian Fluconazole Prophylaxis Study Group. Clin Infect Dis 1999;28:331-40.

277. Yoshida M, Ohno R. Antimicrobial prophylaxis in febrile neutropenia. Clin Infect Dis 2004;(39 Suppl 1):S65-S67.

278. Winston DJ, Maziarz RT, Chandrasekar PH, et al. Intravenous and oral itraconazole versus intravenous and oral fluconazole for longterm antifungal prophylaxis in allogeneic hematopoietic stem-cell transplant recipients. A multicenter, randomized trial. Ann Intern Med 2003;138:705-13.

279. Marr KA, Seidel K, Slavin MA, et al. Prolonged fluconazole prophylaxis is associated with persistent protection against 
candidiasis-related death in allogeneic marrow transplant recipients: Long-term follow-up of a randomized, placebo-controlled trial. Blood 2000;96:2055-61.

280. Kanda Y, Yamamoto R, Chizuka A, et al. Prophylactic action of oral fluconazole against infection in neutropenic patients a meta-analysis of 16 randomized, controlled trials. Cancer 2000;89:1611-25.

281. Cornely OA, Ullmann AJ, Karthaus M. Evidence-based assessment of primary antifungal prophylaxis in patients with hematologic malignancies. Blood 2003;101:3365-72.

282. Glasmacher A, Prentice AG. Evidence-based review of antifungal prophylaxis in neutropenic patients with haematological malignancies. J Antimicrob Chemother 2005;(56 Suppl 1):i23-i32.

283. Vardakas KZ, Michalopoulos A, Falagas ME. Fluconazole versus itraconazole for antifungal prophylaxis in neutropenic patients with haematological malignancies: A meta-analysis of randomised-controlled trials. Br J Haematol 2005;131:22-8.

284. Robenshtok E, Gafter-Gvili A, Goldberg E, et al. Antifungal prophylaxis in cancer patients after chemotherapy or hematopoietic stem-cell transplantation: Systematic review and meta-analysis. J Clin Oncol 2007;25:5471-89.

285. Slavin MA, Osborne B, Adams R, et al. Efficacy and safety of fluconazole prophylaxis for fungal infections after marrow transplantation - a prospective, randomized, double-blind study. J Infect Dis 1995;171:1545-52.

286. Goodman JL, Winston DJ, Greenfield RA, et al. A controlled trial of fluconazole to prevent fungal infections in patients undergoing bone marrow transplantation. N Engl J Med 1992;326:845-51.

287. Rubin RH. Overview: Pathogenesis of fungal infections in the organ transplant recipient. Transpl.Infect Dis 2002;(4 Suppl 3):12-7.

288. American Society of Transplantation. Fungal infections. Am J Transplant 2004;(4 Suppl 10):110-34.

289. Silveira FP, Husain S. Fungal infections in solid organ transplantation. Med Mycol 2007:45:305-20.

290. Cruciani M, Mengoli C, Malena M, Bosco O, Serpelloni G, Grossi P. Antifungal prophylaxis in liver transplant patients: A systematic review and meta-analysis. Liver Transpl 2006;12:850-8.

291. Playford EG, Webster AC, Sorrell TC, Craig JC. Systematic review and meta-analysis of antifungal agents for preventing fungal infections in liver transplant recipients. Eur J Clin Microbiol Infect Dis 2006;25:549-61.

292. Cornely OA, Ullmann AJ. Numbers needed to treat with posaconazole prophylaxis to prevent invasive fungal infection and death. Clin Infect Dis 2008;46:1626-7.

293. Fortun J, Martin-Davila P, Montejo M, et al. Prophylaxis with caspofungin for invasive fungal infections in high-risk liver transplant recipients. Transplantation 2009;87:424-35.

294. Garbino J, Lorenzi P, Morel P, Romand JA. Kidney and pancreas transplantation: Postoperative infectious complications. Clin Microbiol Infect 1999;5:48-51.

295. Benedetti E, Gruessner AC, Troppmann C, et al. Intra-abdominal fungal infections after pancreatic transplantation: Incidence, treatment, and outcome. J Am Coll Surg 1996;183:307-16.

296. Singh N. Antifungal prophylaxis in solid-organ transplant recipients: Considerations for clinical trial design. Clin Infect Dis 2004;(39 Suppl 4):S200-S206.

297. Woeste G, Wullstein C, Vogt J, Zapletal C, Bechstein WO. Value of donor swabs for intra-abdominal infection in simultaneous pancreas-kidney transplantation. Transplantation 2003;76:1073-8.

298. Steurer W, Bonatti H, Obrist P, et al. Incidence of intraabdominal infection in a consecutive series of 40 enteric-drained pancreas transplants with FK506 and MMF immunosuppression. Transpl Int 2000;(13 Suppl 1):S195-S198.

299. Humar A, Kandaswamy R, Granger D, Gruessner RW, Gruessner AC, Sutherland DE. Decreased surgical risks of pancreas transplantation in the modern era. Ann Surg 2000;231:269-75.

300. Stratta RJ. Ganciclovir/acyclovir and fluconazole prophylaxis after simultaneous kidney-pancreas transplantation. Transplant Proc 1998;30:262.

301. Smets YF, van der Pijl JW, van Dissel JT, Ringers J, de Fijter JW, Lemkes HH. Infectious disease complications of simultaneous pancreas kidney transplantation. Nephrol Dial Transplant 1997;12:764-71.
302. Berger N, Guggenbichler S, Steurer W, et al. Bloodstream infection following 217 consecutive systemic-enteric drained pancreas transplants. BMC Infect Dis 2006;6:127.

303. Strahilevitz J, Sugar AM, Engelhard D. Fluconazole in transplant recipients: Options and limitations. Transpl Infect Dis 2000;2:62-71

304. Abbott KC, Hypolite I, Poropatich RK, et al. Hospitalizations for fungal infections after renal transplantation in the United States. Transpl Infect Dis 2001;3:203-11.

305. Martinez-Marcos F, Cisneros J, Gentil M, et al. Prospective study of renal transplant infections in 50 consecutive patients. Eur J Clin Microbiol Infect Dis 1994;13:1023-8.

306. Nampoory MR, Khan ZU, Johny KV, et al. Invasive fungal infections in renal transplant recipients. J Infect 1996;33:95-101.

307. Alangaden GJ, Thyagarajan R, Gruber SA, et al. Infectious complications after kidney transplantation: Current epidemiology and associated risk factors. Clin Transplant 2006;20:401-9.

308. Grossi P, Farina C, Fiocchi R, Dalla GD. Prevalence and outcome of invasive fungal infections in 1,963 thoracic organ transplant recipients: A multicenter retrospective study. Italian Study Group of Fungal Infections in Thoracic Organ Transplant Recipients. Transplantation 2000;70:112-6.

309. Kubak BM. Fungal infection in lung transplantation. Transpl Infect Dis 2002;(4 Suppl 3):24-31.

310. Dummer JS, Lazariashvilli N, Barnes J, Ninan M, Milstone AP. A survey of anti-fungal management in lung transplantation. J Heart Lung Transplant 2004;23:1376-81.

311. Kanj SS, Welty-Wolf K, Madden J, et al. Fungal infections in lung and heart-lung transplant recipients. Report of 9 cases and review of the literature. Medicine (Baltimore) 1996;75:142-56.

312. Rex JH, Sobel JD. Prophylactic antifungal therapy in the intensive care unit. Clin Infect Dis 2001;32:1191-200.

313. Lipsett PA. Surgical critical care: Fungal infections in surgical patients. Crit Care Med 2006;34:S215-S224.

314. Blumberg HM, Jarvis WR, Soucie JM, et al. Risk factors for candidal bloodstream infections in surgical intensive care unit patients: The NEMIS prospective multicenter study. The National Epidemiology of Mycosis Survey. Clin Infect Dis 2001;33:177-86.

315. Beck-Sague C, Jarvis WR. Secular trends in the epidemiology of nosocomial fungal infections in the United States, 1980-1990. National Nosocomial Infections Surveillance System. J Infect Dis 1993;167:1247-51.

316. Wey SB, Mori M, Pfaller MA, Woolson RF, Wenzel RP. Hospital-acquired candidemia. The attributable mortality and excess length of stay. Arch Intern Med 1988;148:2642-5.

317. Charles PE, Doise JM, Quenot JP, et al. Candidemia in critically ill patients: Difference of outcome between medical and surgical patients. Intensive Care Med 2003;29:2162-9.

318. Garey KW, Neuhauser MM, Bearden DT, et al. Evaluation of antifungals in the surgical intensive care unit: A multi-institutional study. Mycoses 2006;49:226-31.

319. Savino JA, Agarwal N, Wry P, Policastro A, Cerabona T, Austria L. Routine prophylactic antifungal agents (clotrimazole, ketoconazole, and nystatin) in nontransplant/nonburned critically ill surgical and trauma patients. J Trauma 1994;36:20-5.

320. Ables A, Blumer N, Valainis G, Godenick M, Kajdasz D, Palesch Y. Fluconazole prophylaxis of severe Candida infection in trauma and postsurgical patients: A prospective, double-blind, randomized, placebo-controlled trial. Infect Dis Clin Pract 2000;9:169-75.

321. Playford EG, Webster AC, Sorrell TC, Craig JC. Antifungal agents for preventing fungal infections in non-neutropenic critically ill and surgical patients: Systematic review and meta-analysis of randomized clinical trials. J Antimicrob Chemother 2006;57:628-38.

322. Playford EG, Webster AC, Sorrell TC, Craig JC. Antifungal agents for preventing fungal infections in non-neutropenic critically ill patients. Cochrane Database Syst Rev 2006;CD004920.

323. Villatoro E, Bassi C, Larvin M. Antibiotic therapy for prophylaxis against infection of pancreatic necrosis in acute pancreatitis. Cochrane Database Syst Rev 2006;CD002941.

324. UK Working Party on Acute Pancreatitis. UK guidelines for the management of acute pancreatitis. Gut 2005;(54 Suppl 3):iii1-iii9.

325. Uhl W, Warshaw A, Imrie C, et al. IAP Guidelines for the surgical management of acute pancreatitis. Pancreatology 2002;2:565-73 
326. Nathens AB, Curtis JR, Beale RJ, et al. Management of the critically ill patient with severe acute pancreatitis. Crit Care Med 2004:32:2524-36.

327. Isenmann R, Schwarz M, Rau B, Trautmann M, Schober W, Beger HG. Characteristics of infection with Candida species in patients with necrotizing pancreatitis. World J Surg 2002;26:372-6.

328. Gloor B, Muller CA, Worni M, et al. Pancreatic infection in severe pancreatitis: The role of fungus and multiresistant organisms. Arch Surg 2001;136:592-6.

329. Isaji S, Takada T, Kawarada Y, et al. JPN Guidelines for the management of acute pancreatitis: Surgical management. J Hepatobiliary Pancreat Surg 2006;13:48-55.

330. Pfaller MA, Pappas PG, Wingard JR. Invasive fungal pathogens: Current epidemiological trends. Clin Infect Dis 2006;43:S3-S14.

331. Hoerauf A, Hammer S, Muller-Myhsok B, Rupprecht H. Intra-abdominal Candida infection during acute necrotizing pancreatitis has a high prevalence and is associated with increased mortality. Crit Care Med 1998;26:2010-5.

332. Gotzinger P, Wamser P, Barlan M, Sautner T, Jakesz R, Fugger R. Candida infection of local necrosis in severe acute pancreatitis is associated with increased mortality. Shock 2000;14:320-3.

333. Grewe M, Tsiotos GG, Luque de-Leon E, Sarr MG. Fungal infection in acute necrotizing pancreatitis. J Am Coll Surg 1999;188:408-14.

334. Connor S, Alexakis N, Neal T, et al. Fungal infection but not type of bacterial infection is associated with a high mortality in primary and secondary infected pancreatic necrosis. Dig Surg 2004;21:297-304.

335. Aloia T, Solomkin J, Fink AS, et al. Candida in pancreatic infection: A clinical experience. Am Surg 1994;60:793-6.

336. De Waele JJ, Vogelaers D, Blot S, Colardyn F. Fungal infections in patients with severe acute pancreatitis and the use of prophylactic therapy. Clin Infect Dis 2003;37:208-13.

337. He YM, Lv XS, Ai ZL, et al. Prevention and therapy of fungal infection in severe acute pancreatitis: A prospective clinical study. World J Gastroenterol 2003;9:2619-21.

338. Chamilos G, Luna MA, Lewis RE. Invasive fungal infections in patients with hematologic malignancies in a tertiary care cancer center; an autopsy study over a 15-year period (1980-2003). Haematologica 2006;91:986-9.

339. Maertens J, Theunissen K, Verhoef G, et al. Galactomannan and computed tomography-based preemptive antifungal therapy in neutropenic patients at high risk for invasive fungal infection: A prospective feasibility study. Clin Infect Dis 2005;41:1242-50.

340. Cordonnier C, Pautas C, Maury S, et al. Empirical versus preemptive antifungal therapy for high-risk, febrile, neutropenic patients: A randomized, controlled trial. Clin Infect Dis 2009;48:1042-51.

341. Marchetti O, Cordonnier C, Calandra T. Empirical antifungal therapy in neutropaenic cancer patients with persistent fever. Eur J Cancer Suppl 2007;5:32-42.

342. Wingard JR, White MH, Anaissie E, Raffalli J, Goodman J, Arrieta A. A randomized, double-blind comparative trial evaluating the safety of liposomal amphotericin B versus amphotericin B lipid complex in the empirical treatment of febrile neutropenia. L Amph/ABLC Collaborative Study Group. Clin Infect Dis 2000;31:1155-63.

343. Goldberg E, Gafter-Gvili A, Robenshtok E, Leibovici L, Paul M. Empirical antifungal therapy for patients with neutropenia and persistent fever: Systematic review and meta-analysis. Eur J Cancer 2008;44:2192-203.

344. Hughes WT, Armstrong D, Bodey GP, et al. 2002 guidelines for the use of antimicrobial agents in neutropenic patients with cancer. Clin Infect Dis 2002;34:730-51.

345. Walsh TJ, Finberg RW, Arndt C, et al. Liposomal amphotericin B for empirical therapy in patients with persistent fever and neutropenia. National Institute of Allergy and Infectious Diseases Mycoses Study Group. N Engl J Med 1999;340:764-71.

346. Viscoli C, Castagnola E, Van Lint MT, et al. Fluconazole versus amphotericin $\mathrm{B}$ as empirical antifungal therapy of unexplained fever in granulocytopenic cancer patients: A pragmatic, multicentre, prospective and randomised clinical trial. Eur J Cancer 1996;32A:814-20.

347. Winston DJ, Hathorn JW, Schuster MG, Schiller GJ, Territo MC. A multicenter, randomized trial of fluconazole versus amphotericin B for empiric antifungal therapy of febrile neutropenic patients with cancer. Am J Med 2000;108:282-9.
348. Boogaerts M, Winston DJ, Bow EJ, et al. Intravenous and oral itraconazole versus intravenous amphotericin $\mathrm{B}$ deoxycholate as empirical antifungal therapy for persistent fever in neutropenic patients with cancer who are receiving broad-spectrum antibacterial therapy. A randomized, controlled trial. Ann Intern Med 2001;135:412-22.

349. Walsh TJ, Teppler H, Donowitz GR, et al. Caspofungin versus liposomal amphotericin B for empirical antifungal therapy in patients with persistent fever and neutropenia. N Engl J Med 2004:351:1391-402.

350. Jorgensen KJ, Johansen HK, Gotzsche PC. Flaws in design, analysis and interpretation of Pfizer's antifungal trials of voriconazole and uncritical subsequent quotations. Trials 2006;7:3.

351. Walsh TJ, Pappas P, Winston DJ, et al. Voriconazole compared with liposomal amphotericin B for empirical antifungal therapy in patients with neutropenia and persistent fever. N Engl J Med 2002;346:225-34.

352. Bow EJ. Considerations in the approach to invasive fungal infection in patients with haematological malignancies. $\mathrm{Br} J$ Haematol 2008;140:133-52.

353. Betts R, Glasmacher A, Maertens J, et al. Efficacy of caspofungin against invasive Candida or invasive Aspergillus infections in neutropenic patients. Cancer 2006;106:466-73.

354. Anaissie EJ, Vartivarian SE, bi-Said D, et al. Fluconazole versus amphotericin B in the treatment of hematogenous candidiasis: A matched cohort study. Am J Med 1996;101:170-6.

355. Reboli AC, Rotstein C, Pappas PG, et al. Anidulafungin versus fluconazole for invasive candidiasis. N Engl J Med 2007;356:2472-82.

356. Pappas PG, Rotstein CM, Betts RF, et al. Micafungin versus caspofungin for treatment of candidemia and other forms of invasive candidiasis. Clin Infect Dis 2007:45:883-93.

357. Rex JH, Bennett JE, Sugar AM, et al. Intravascular catheter exchange and duration of candidemia. NIAID Mycoses Study Group and the Candidemia Study Group. Clin Infect Dis 1995;21:994-6.

358. Thaler M, Pastakia B, Shawker TH, O'Leary T, Pizzo PA. Hepatic candidiasis in cancer patients: The evolving picture of the syndrome. Ann Intern Med 1988;108:88-100.

359. Flynn PM, Shenep JL, Crawford R, Hughes WT. Use of abdominal computed tomography for identifying disseminated fungal infection in pediatric cancer patients. Clin Infect Dis 1995;20:964-70.

360. Talbot GH, Provencher M, Cassileth PA. Persistent fever after recovery from granulocytopenia in acute leukemia. Arch Intern Med 1988;148:129-35.

361. Kauffman CA, Bradley SF, Ross SC, Weber DR. Hepatosplenic candidiasis: Successful treatment with fluconazole. Am J Med 1991;91:137-41.

362. Anaissie E, Bodey GP, Kantarjian H, et al. Fluconazole therapy for chronic disseminated candidiasis in patients with leukemia and prior amphotericin B therapy. Am J Med 1991;91:142-50.

363. Walsh TJ, Whitcomb P, Piscitelli S, et al. Safety, tolerance, and pharmacokinetics of amphotericin B lipid complex in children with hepatosplenic candidiasis. Antimicrob Agents Chemother 1997;41:1944-8.

364. Legrand F, Lecuit M, Dupont B, et al. Adjuvant corticosteroid therapy for chronic disseminated candidiasis. Clin Infect Dis 2008;46:696-702.

365. Sendid B, Poirot JL, Tabouret M, et al. Combined detection of mannanaemia and antimannan antibodies as a strategy for the diagnosis of systemic infection caused by pathogenic Candida species. J Med Microbiol 2002;51:433-42.

366. Philip A, Odabasi Z, Matiuzzi G, et al. Syscan3, a kit for detection of anti-Candida antibodies for diagnosis of invasive candidiasis. J Clin Microbiol 2005;43:4834-5.

367. Takesue Y, Kakehashi M, Ohge H, et al. Combined assessment of beta-D-glucan and degree of Candida colonization before starting empiric therapy for candidiasis in surgical patients. World J Surg 2004;28:625-30.

368. McMullan R, Metwally L, Coyle PV, et al. A prospective clinical trial of a real-time polymerase chain reaction assay for the diagnosis of candidemia in nonneutropenic, critically ill adults. Clin Infect Dis 2008;46:890-6.

369. Edwards JE Jr, Bodey GP, Bowden RA, et al. International conference for the development of a consensus on the management and prevention of severe candidal infections. Clin Infect Dis $1997 ; 25: 43-59$ 
370. Shan YS, Sy ED, Wang ST, Lee JC, Lin PW. Early presumptive therapy with fluconazole for occult Candida infection after gastrointestinal surgery. World J Surg 2006;30:119-26.

371. Chen H, Suda KJ, Turpin RS, Pai MP, Bearden DT, Garey KW. High-versus low-dose fluconazole therapy for empiric treatment of suspected invasive candidiasis among high-risk patients in the intensive care unit: A cost-effectiveness analysis. Curr Med Res Opin 2007;23:1057-65.

372. Azoulay E, Timsit JF, Tafflet M, et al. Candida colonization of the respiratory tract and subsequent pseudomonas ventilator-associated pneumonia. Chest 2006;129:110-7.

373. Schuster MG, Edwards JE Jr, Sobel JD, et al. Empirical fluconazole versus placebo for intensive care unit patients: A randomized trial. Ann Intern Med 2008;149:83-90.

374. St-Germain G, Laverdiere M, Pelletier R, et al. Epidemiology and antifungal susceptibility of bloodstream Candida isolates in Quebec: Report on 453 cases between 2003 and 2005. Can J Infect Dis Med Microbiol 2008;19:55-62.

375. Garey KW, Rege M, Pai MP, et al. Time to initiation of fluconazole therapy impacts mortality in patients with candidemia: A multi-institutional study. Clin Infect Dis 2006;43:25-31.

376. Morrell M, Fraser VJ, Kollef MH. Delaying the empiric treatment of Candida bloodstream infection until positive blood culture results are obtained: A potential risk factor for hospital mortality. Antimicrob Agents Chemother 2005;49:3640-5.

377. Kumar A, Roberts D, Wood KE, et al. Duration of hypotension before initiation of effective antimicrobial therapy is the critical determinant of survival in human septic shock. Crit Care Med 2006;34:1589-96.

378. Ibrahim EH, Sherman G, Ward S, Fraser VJ, Kollef MH. The influence of inadequate antimicrobial treatment of bloodstream infections on patient outcomes in the ICU setting. Chest 2000;118:146-55.

379. Gafter-Gvili A, Vidal L, Goldberg E, Leibovici L, Paul M. Treatment of invasive candidal infections: Systematic review and meta-analysis. Mayo Clin Proc 2008;83:1011-21.

380. Pappas PG, Rex JH, Lee J, et al. A prospective observational study of candidemia: Epidemiology, therapy, and influences on mortality in hospitalized adult and pediatric patients. Clin Infect Dis 2003;37:634-43.

381. Pfaller MA, Diekema DJ, Jones RN, et al. International surveillance of bloodstream infections due to Candida species: Frequency of occurrence and in vitro susceptibilities to fluconazole, ravuconazole, and voriconazole of isolates collected from 1997 through 1999 in the SENTRY antimicrobial surveillance program. J Clin Microbiol 2001;39:3254-9.

382. Cuenca-Estrella M, Rodriguez D, Almirante B, et al. In vitro susceptibilities of bloodstream isolates of Candida species to six antifungal agents: Results from a population-based active surveillance programme, Barcelona, Spain, 2002-2003. J Antimicrob Chemother 2005;55:194-9.

383. Messer SA, Jones RN, Fritsche TR. International surveillance of Candida spp. and Aspergillus spp.: Report from the SENTRY Antimicrobial Surveillance Program (2003). J Clin Microbiol 2006;44:1782-7.

384. Macphail GL, Taylor GD, Buchanan-Chell M, Ross C, Wilson S, Kureishi A. Epidemiology, treatment and outcome of candidemia: A five-year review at three Canadian hospitals. Mycoses 2002:45:141-5.

385. St-Germain G, Laverdiere M, Pelletier R, et al. Prevalence and antifungal susceptibility of 442 Candida isolates from blood and other normally sterile sites: Results of a 2-year (1996 to 1998) multicenter surveillance study in Quebec, Canada. J Clin Microbiol 2001;39:949-53.

386. Rabinovici R, Szewczyk D, Ovadia P, Greenspan JR, Sivalingam JJ. Candida pericarditis: Clinical profile and treatment. Ann Thorac Surg 1997;63:1200-4

387. Nicolle LE, Rotstein C, Bourgault AM, St-Germain G, Garber G. Invasive fungal infections in Canada 1992-1994. Can J Infect Dis 1998;9:347-52

388. Bille J, Edson RS, Roberts GD. Clinical evaluation of the lysis-centrifugation blood culture system for the detection of fungemia and comparison with a conventional biphasic broth blood culture system. J Clin Microbiol 1984;19:126-8.
389. Franklin WG, Simon AB, Sodeman TM. Candida myocarditis without valvulitis. Am J Cardiol 1976;38:924-8.

390. Lipton SA, Hickey VF, Morris JH. Candidal infection in the central nervous system. Am J Med 1984;76:101-8.

391. Zaoutis TE, Argon J, Chu J, Berlin JA, Walsh TJ, Feudtner C. The epidemiology and attributable outcomes of candidemia in adults and children hospitalized in the United States: A propensity analysis. Clin Infect Dis 2005;41:1232-9.

392. Becker WK, Cioffi WG Jr, McManus AT, et al. Fungal burn wound infection. A 10-year experience. Arch Surg 1991;126:44-8.

393. Launay O, Lortholary O, Bouges-Michel C, Jarrousse B, Bentata M, Guillevin L. Candidemia: A nosocomial complication in adults with late-stage AIDS. Clin Infect Dis 1998;26:1134-41.

394. Tumbarello M, Tacconelli E, de Gaetano DK, Morace G, Fadda G, Cauda R. Candidemia in HIV-infected subjects. Eur J Clin Microbiol Infect Dis 1999;18:478-83.

395. Pittet D, Wenzel RP. Nosocomial bloodstream infections. Secular trends in rates, mortality, and contribution to total hospital deaths. Arch Intern Med 1995;155:1177-84.

396. Sobel JD. The emergence of non-albicans Candida species as causes of invasive candidiasis and candidemia. Curr Infect Dis Rep 2006;8:427-33.

397. Lupetti A, Tavanti A, Davini P, et al. Horizontal transmission of Candida parapsilosis candidemia in a neonatal intensive care unit. J Clin Microbiol 2002;40:2363-9.

398. Opilla M. Epidemiology of bloodstream infection associated with parenteral nutrition. Am J Infect Control 2008;36:S173-S178.

399. Pyrgos V, Ratanavanich K, Donegan N, Veis J, Walsh TJ, Shoham S. Candida bloodstream infections in hemodialysis recipients. Med Mycol 2008:1-5.

400. Kauffman CA, Vazquez JA, Sobel JD, et al. Prospective multicenter surveillance study of funguria in hospitalized patients. The National Institute for Allergy and Infectious Diseases (NIAID) Mycoses Study Group. Clin Infect Dis 2000;30:14-8.

401. Jacobs LG, Skidmore EA, Cardoso LA, Ziv F. Bladder irrigation with amphotericin B for treatment of fungal urinary tract infections. Clin Infect Dis 1994;18:313-8.

402. Sanchez-Portocarrero J, Perez-Cecilia E, Corral O, Romero-Vivas J, Picazo JJ. The central nervous system and infection by Candida species. Diagn Microbiol Infect Dis 2000;37:169-79.

403. Scarcella A, Pasquariello MB, Giugliano B, Vendemmia M, De LA Liposomal amphotericin B treatment for neonatal fungal infections. Pediatr Infect Dis J 1998;17:146-8.

404. Prabhu RM, Orenstein R. Failure of caspofungin to treat brain abscesses secondary to Candida albicans prosthetic valve endocarditis. Clin Infect Dis 2004;39:1253-4.

405. Edwards JE Jr, Foos RY, Montgomerie JZ, Guze LB. Ocular manifestations of Candida septicemia: Review of seventy-six cases of hematogenous Candida endophthalmitis. Medicine (Baltimore) 1974;53:47-75

406. Akler ME, Vellend H, McNeely DM, Walmsley SL, Gold WL. Use of fluconazole in the treatment of candidal endophthalmitis. Clin Infect Dis 1995;20:657-64.

407. Sim JP, Kho BC, Liu HS, Yung R, Chan JC. Candida tropicalis arthritis of the knee in a patient with acute lymphoblastic leukaemia: Successful treatment with caspofungin. Hong Kong Med J 2005;11:120-3.

408. Tunkel AR, Thomas CY, Wispelwey B. Candida prosthetic arthritis: Report of a case treated with fluconazole and review of the literature. Am J Med 1993;94:100-3.

409. Miller DJ, Mejicano GC. Vertebral osteomyelitis due to Candida species: Case report and literature review. Clin Infect Dis 2001;33:523-30.

410. Steinbach WJ, Perfect JR, Cabell CH, et al. A meta-analysis of medical versus surgical therapy for Candida endocarditis. J Infect 2005;51:230-47.

411. Benoit D, Decruyenaere J, Vandewoude K, et al. Management of candidal thrombophlebitis of the central veins: Case report and review. Clin Infect Dis 1998;26:393-7.

412. Leon C, Ruiz-Santana S, Saavedra P, et al. Usefulness of the "Candida score" for discriminating between Candida colonization and invasive candidiasis in non-neutropenic critically ill patients: A prospective multicenter study. Crit Care Med 2009;37:1624-33. 


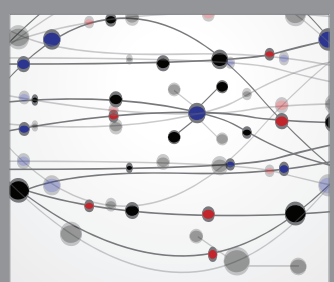

The Scientific World Journal
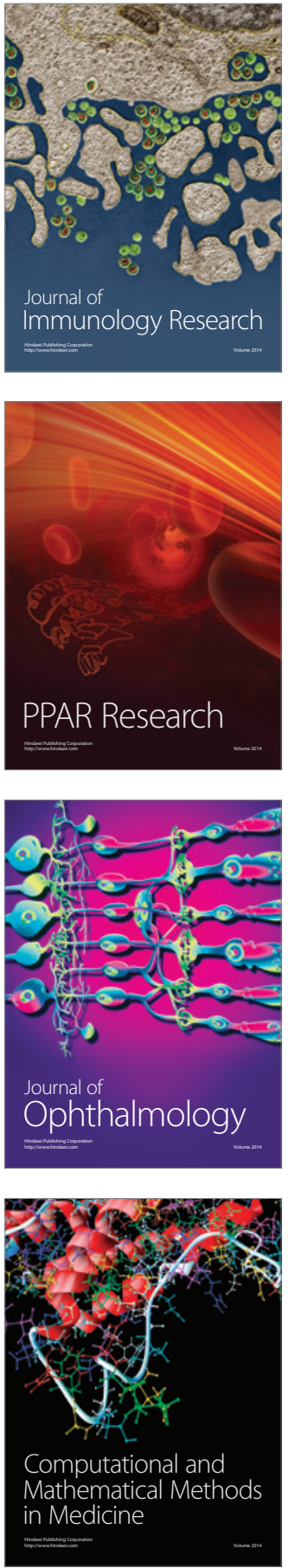

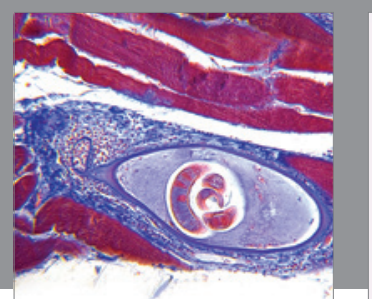

Gastroenterology Research and Practice

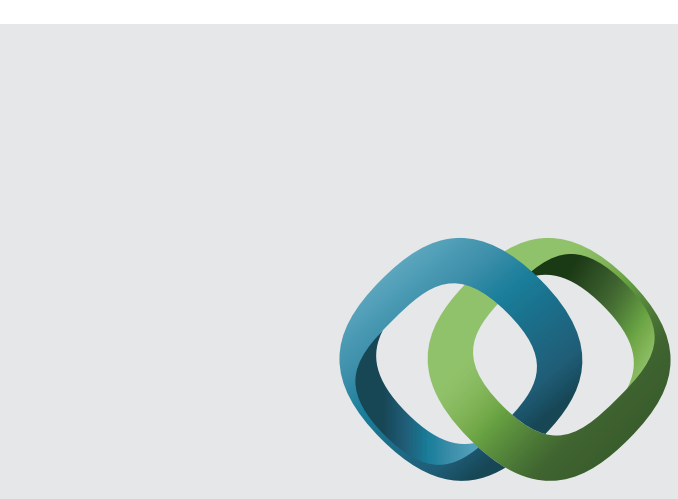

\section{Hindawi}

Submit your manuscripts at

http://www.hindawi.com
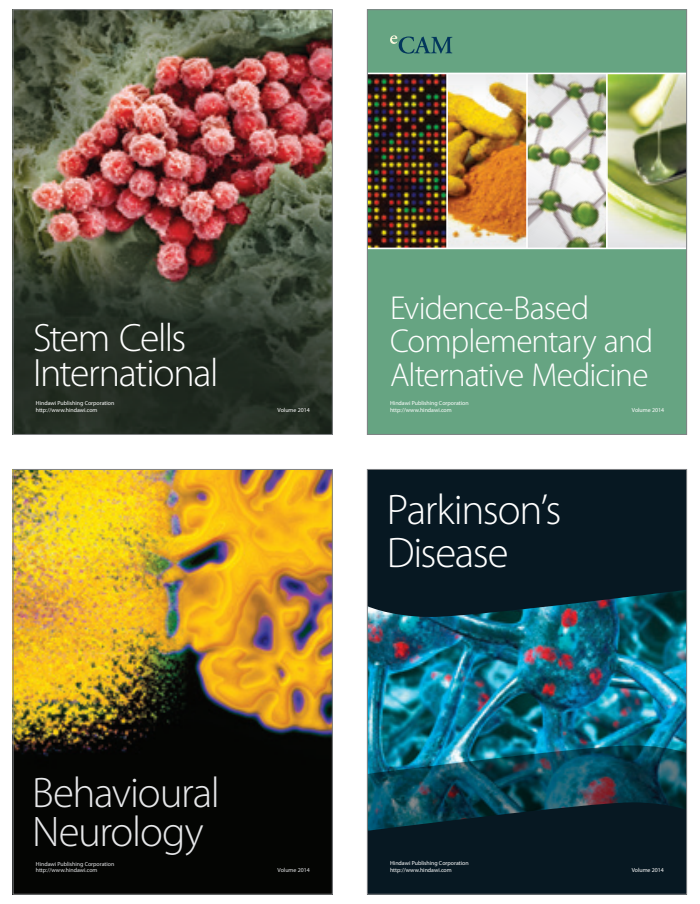
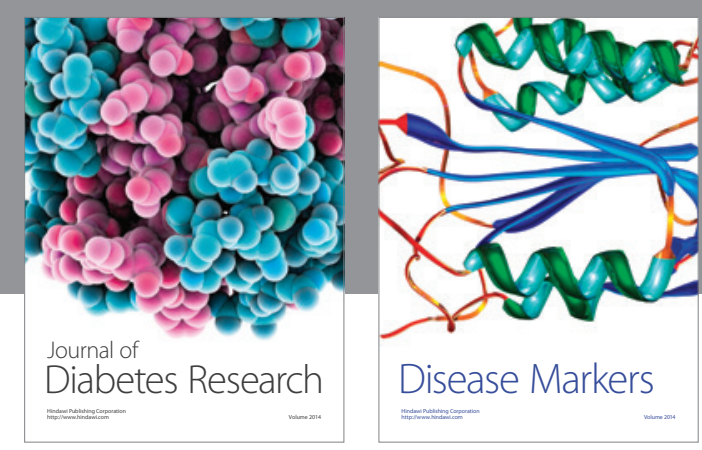

Disease Markers
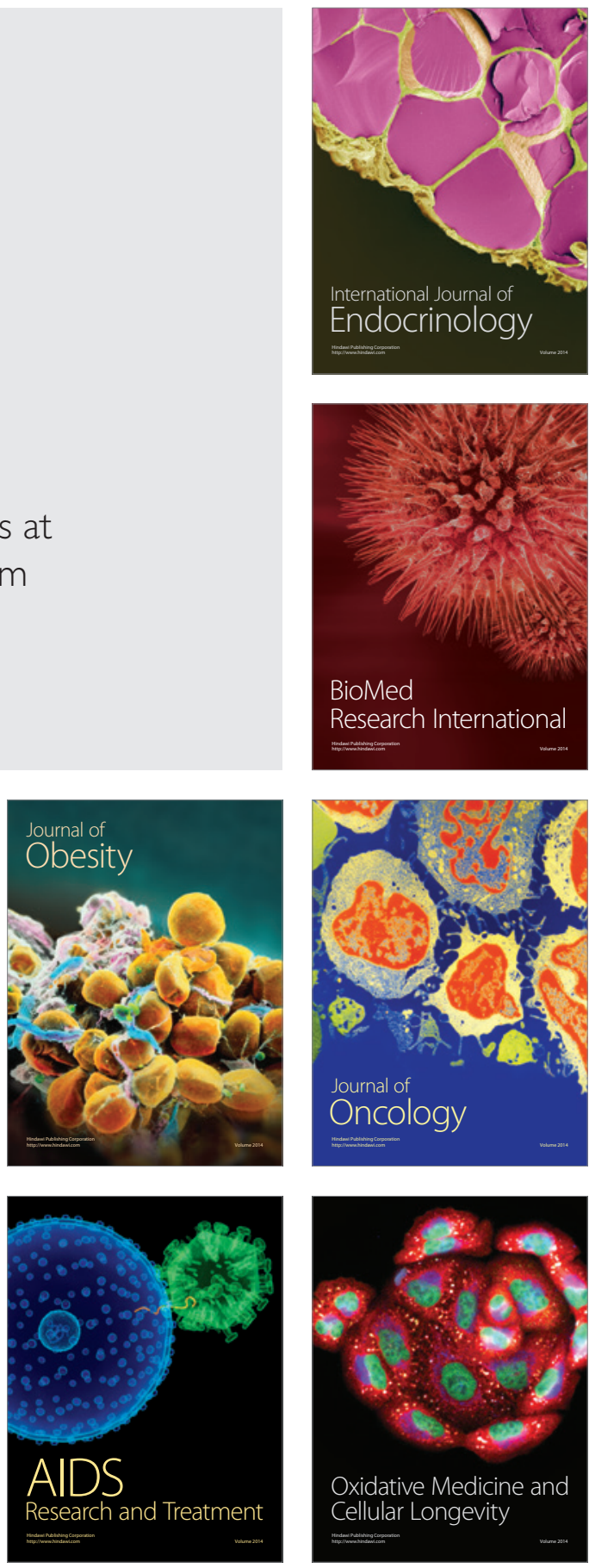